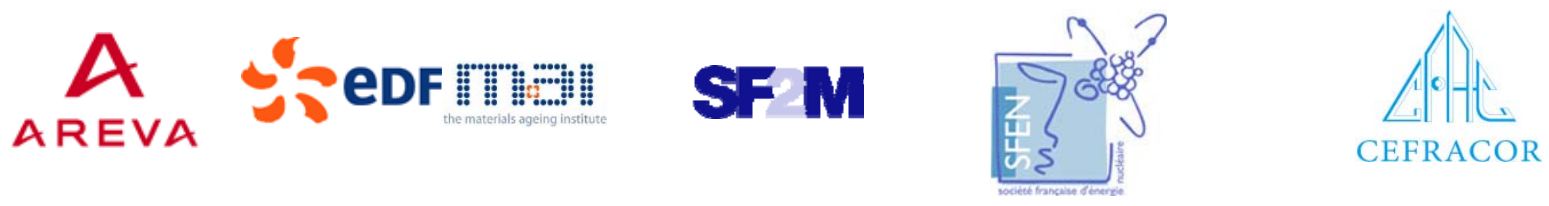

\section{MIN口S}

Centre of Excellence for Nuclear Materials

\section{Workshop}

Materials Innovation for Nuclear Optimized Systems
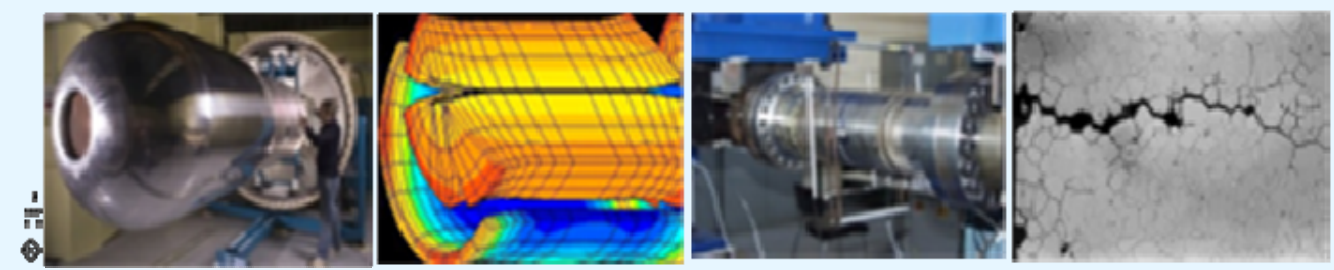

December 5-7, 2012, CEA - INSTN Saclay, France

\section{Tetsuo SHOJI}

University of Tohoku (Japan)

Materials Ageing Degradation Programme in Japan and Proactive Ageing Management in NPP

Workshop organized by:

Christophe GALLÉ, CEA/MINOS, Saclay - christophe.galle@cea.fr Constantin MEIS, CEA/INSTN, Saclay - constantin.meis@cea.fr 


\title{
Materials Ageing Degradation Programme in Japan and Proactive Ageing Management in NPP
}

\author{
Tetsuo SHOJI \\ ${ }^{1}$ Tohoku University, New Industry Creation Hatchery center, LMRR unit (Sendai, Japan)
}

Predictive and preventive maintenance technologies are increasingly of importance for the long term operation (LTO) of Light Water Reactor (LWR) plants. In order for the realization LTO to be successful, it is essential that aging degradation phenomena should be properly managed by using adequate maintenance programs based on foreseeing the aging phenomena and evaluating their rates of development, where Nuclear Power Plants can be continued to operate beyond the original design life depending upon the regulatory authority rules. In combination with Periodic Safety Review (PSR) and adequate maitenance program, a plant life can be extended to 60 years or more. Plant Life Management (PLiM) is based upon various maintenance program as well as systematic safety review updated based upon the state of the art of science and technology. One of the potential life time limiting issue would be materials ageing degradation and therefore an extensive efforts have been paid worldwidely. In 2007, NISA launched a national program on Enhanced Ageing Management Program and 4 nationwide clusters were formed to carry out the national program where materials ageing degradation was one of the major topics. In addition to these degradation modes, one important activities in this program is proactive materials degradation management directed by the autor which is a kind of the extension program of NRC PMDA program based upon more fundamental approach by a systematic elicitation by the experts nominated from all over the world. NISA program can be devived into two phases, one is from fiscal years (FY) $2006-2010$ and the other FY 2011. Later phase is focusing more on System Safety due to Fukushima NPP accident.

The main objectives of the Phase I is to evaluate potential and complex degradation phenomena and their mechanisms in order to identify future risks of component aging in nuclear power plants. The following items are of particular concern in this phase: (a) investigation of potential materials ageing phenomena and corresponding plant issues, and (b) investigation of the effectiveness of evaluation techniques, concerning potential aging phenomena. In NISA PMDM Phase I, three approaches are considered to be essential for proactive aging management. First one is a deductive science- based approach, second one is an intuitive based approach based upon a careful analysis of operating experiences and third one is systematic elucidation. In particularly, the deductive method based on a fundamental scientific understanding of material degradation is highlight for the management of possible latent or cascade materials degradation processes which have not yet become obvious in operating plants. Proactive management issues associated with materials aging in LWRs were discussed in terms of suggested research topics that should be undertaken in either the short or long-term. Based on these discussions prioritized lists of medium and long term research projects were established for both PWRs and BWRs. In this paper, the research subjects to be considered for the aging degradation phenomena in PWR structural materials, which were discussed at the Proactive Aging Management Experts' Panel Meeting of the NISA Project, are introduced as follows.

\section{Pressurized Water Reactor (PWR)}

1.1 Research subjects for shorter term projects to be completed in $\sim 5$ years

1) SCC initiation phenomena, including the effects of surface stress/strain, residual stress, microstructure and strain localization,

2) Development of qualified mechanisms-based lifetime models for PWSCC propagation in nickel base alloys,

3) Characterization of weld metals, dilution at interfaces and heat affected zones, 
4) Strain localization, strain history and relationship to cold work, microstructure and compositional banding,

5) Effect of environment on fatigue and fracture resistance in PWRs,

6) Flow-accelerated corrosion in PWRs.

1.2 Research subjects for longer term projects to be completed in $\sim 5$ to 10 years.

1) Effects of irradiation flux and fluence on stainless steels and nickel base alloys and the effect on SCC,

2) Modeling and validation of residual stress/strain profiles in complex welded geometries and how these may change with neutron fluence,

3) Initiation of SCC in structural alloys, modeling stochastic features, heat to heat variability, effects of long exposure periods,

4) Quantification of potential synergistic effects between competing degradation modes for PWRs,

5) Quantitative modeling of oxidation and EAC based on fundamental physical principles for PWRs.

In particular, oxidation localization and acceleration is a key process of these environmentally assisted cracking and we proposed a novel approach to characterize this oxidation localization behavior based upon the profile analysis of metal/oxide interface. Oxidation localization dynamics can be quantitatively evaluated by the parameter, depth of localized oxidation penetration. Analyzed results can be summarized as Fig. 1.

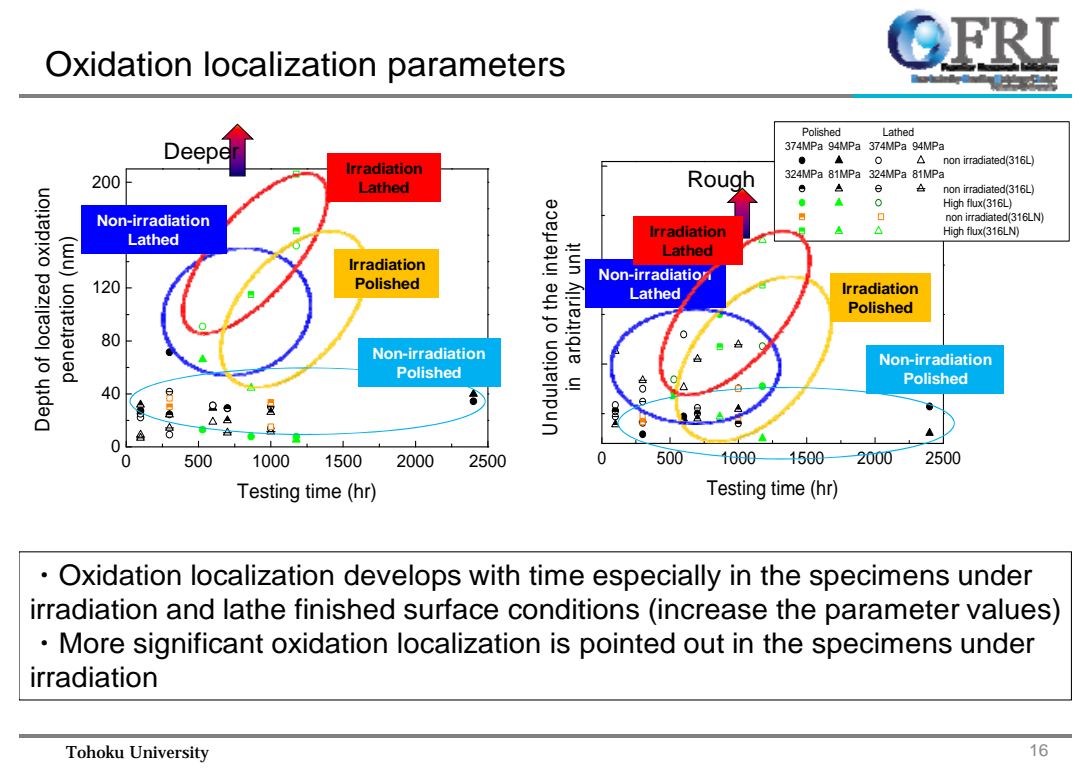

Fig. 1: Oxidation localization behavior and influence of surface finish (polished and lathed) and neutron irradiation on $316 \mathrm{~L}$ stainless steel in oxygenated water.

\section{References}

[1] J. Muscara, Expert Panel Report on Proactive Materials Degradation Assessment. USNRC NUREG Report, CR-6923, February 2007.

[2] T. Shoji et al., Proactive Material Degradation Research Subjects for Light Water Reactors. E-Journal of Advanced Maintenance Vol. 4, No. 2 (2012) pp. 36 - 56, Japan Society of Maintenology.

\section{Acknowledgements}

This work has been performed as part of the Program of Enhancement of Ageing Management and Maintenance of Nuclear Power Plants organized by the Nuclear and Industrial Safety Agency, NISA, in the Ministry of Economy, Trade and Industry, METI, of Japan. The authors would like to thank the Experts' Panel members for their contributions without which no success of the program would never be made. 


\section{Materials ageing degradation program in Japan and proactive ageing management in NPP}

Dec. 6, 2012

Tetsuo Shoji

Frontier Research Initiative, FRI

Long-term Materials Reliability Research unit

New Industry Creation Hatchery Center

TOHOKU University

Sendai, Japan

tshoji@fri.niche.tohoku.ac.jp 


\section{Content}

- Introduction and background

- Technical Evaluation of Aging Management

- Degradation, Materials, Systems, PDCA

- Proactive Materials Aging Degradation Management

- Annual Experts' Panel Meeting

- Proactive Issues raised and summarized by the Experts' Panel

- Proactive Issues raised by FRI from the outcomes of NISA, NRA projects

- Fukushima Daiichi Accident

- Sequence, Actions taken or being taken for future and lesson learn

- Long-and Mid term road map for decommissioning

- Summary 


\section{Nuclear Power Plants in Japan}

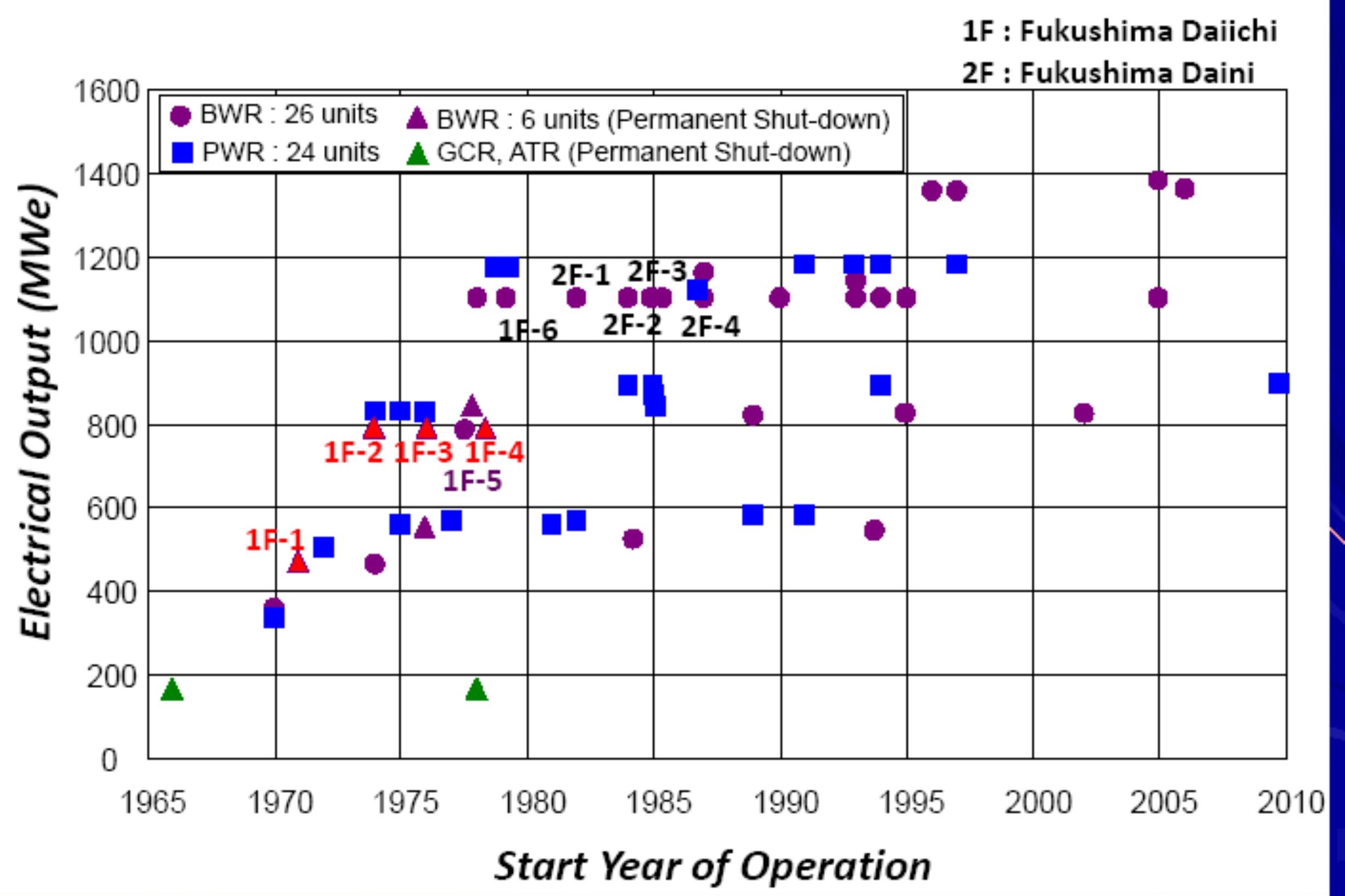




\section{Introduction and Background}

Aging Management is a mandatory action for safety and reliable NPP operation and also as a consequence, it can improve the plant availability and economy. Also, it is important to consider Aging Management before plant constructions to design the systems, structures and components for better maintainability for Aging Management.

Understanding of Aging Mechanism is fundamental for above and continuous concerns and check and review about potential aging degradation is required for Preventive and Predictive aging management, PROACTIVELY

LTO beyond original design life to 60 years/80 years or more Global standard and common understanding based upon scientific/technical basis 


\section{Content}

- Introduction and background

- Technical Evaluation of Aging Management

- Degradation, Materials, Systems, PDCA

- Proactive Materials Aging Degradation Management

- Annual Experts' Panel Meeting

- Proactive Issues raised and summarized by the Experts' Panel

- Proactive Issues raised by FRI from the outcomes of NISA, NRA projects

- Fukushima Daiichi Accident

- Sequence, Actions taken or being taken for future and lesson learn

- Long-and Mid term road map for decommissioning

- Summary 


\section{Current Periodic Inspection, Periodic Safety Review and Ageing Management Technical Evaluation in Japan}

\section{Start of Commercial Operation}

\section{Periodic Inspection (every 13 24 Months)}

Periodic inspection is an inspection for important components conducted in required period.

Government official inspector stands aside the licensee's Periodic Check and confirm licensee's check record : Periodic Safety Review (PSR) (every 10 Years)

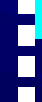
10 Years 10 Years
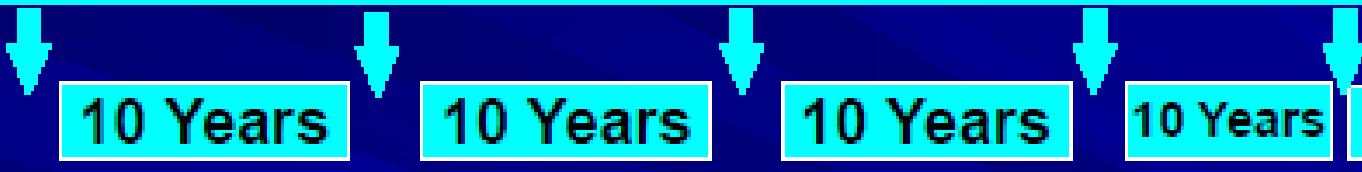

August 2008, NISA established PSR Implementing Guideline. As evaluation objects, implementing status of operational - safety activities, feedback status of latest technical knowledge to licensees' operational safety activities and PSA are provided, however, it is desirable to implement PSA in voluntary manner.

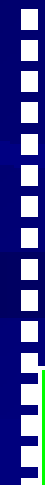

Ageing Management Technical Evaluation (AMTE) for SALTO before the end of 30 years of Operation

30 Years

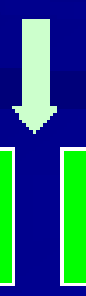

Reevaluation Every 10 Years

10 Years

10 Years

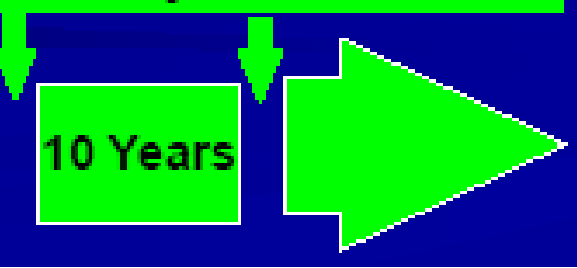




\section{Nuclear Power Plants in Japan}

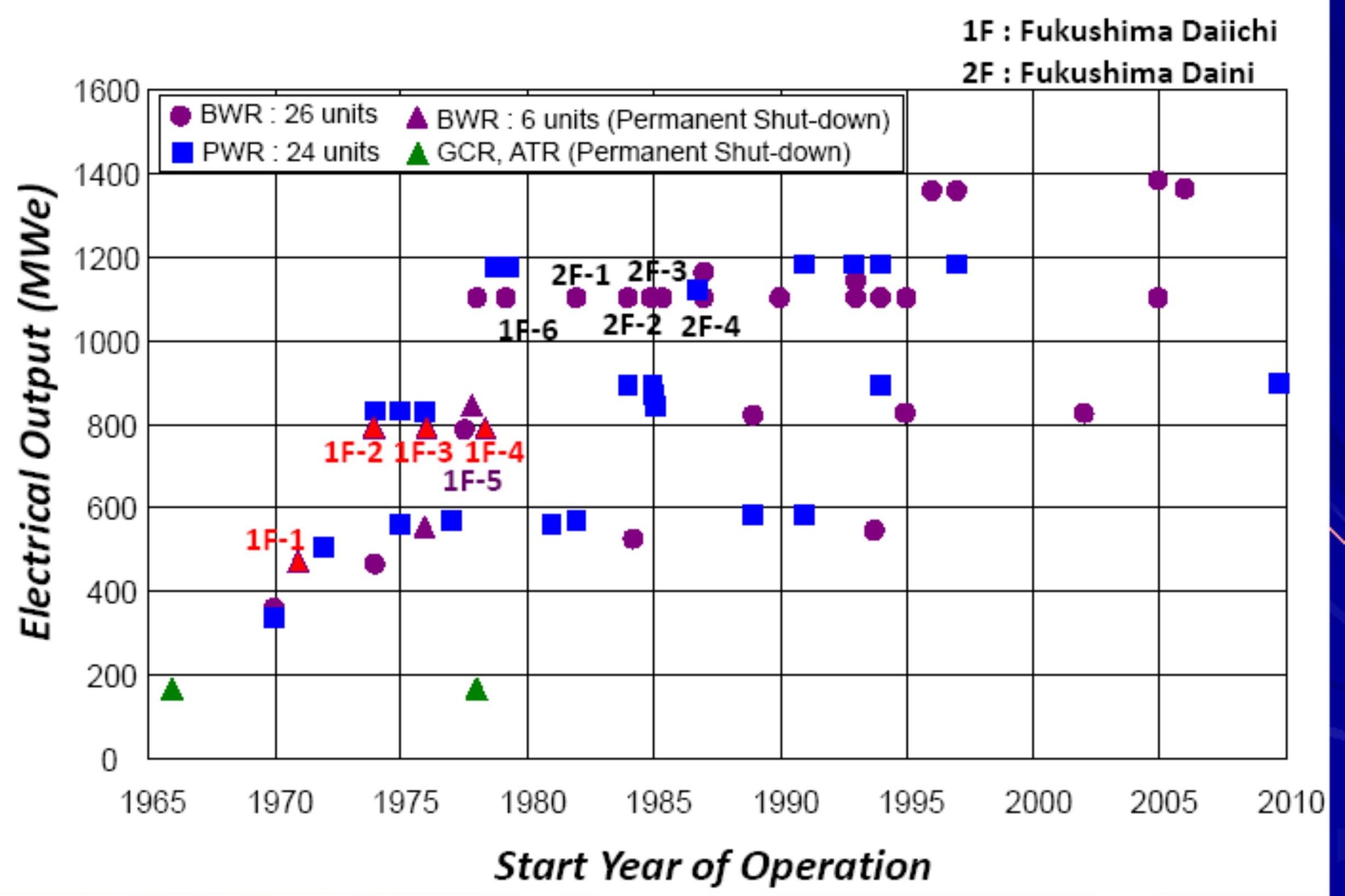




\section{mis}

Three-Stage Approach of Roadmaps for AM Set up Before Fukushima Nuclear Power Station Accident in Japan

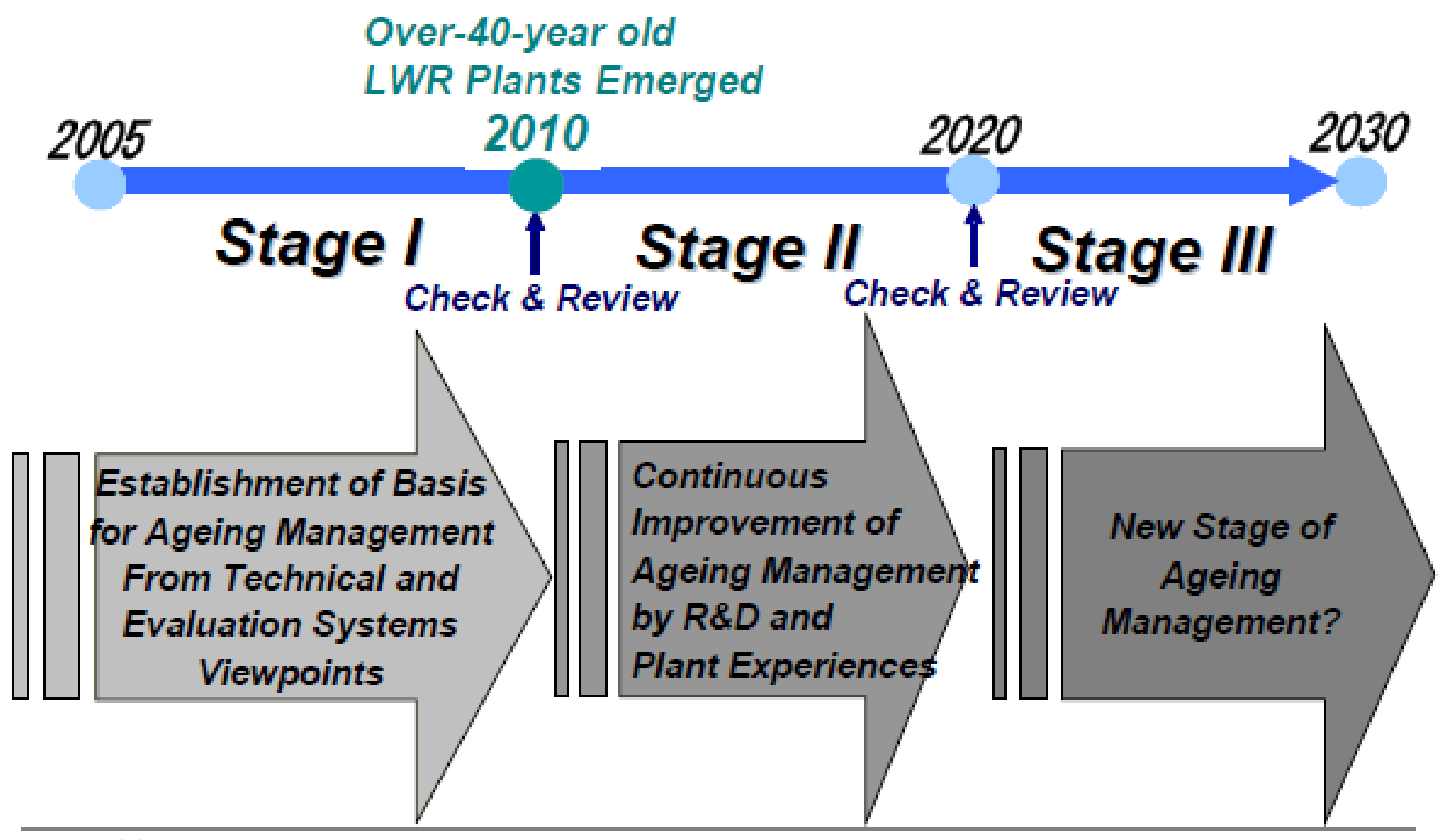




\section{Ageing Management Improvement Activities After Fukushima NPS Accident in Japan}

Fukushima NPS

Accident Occurred

2005

2011

Establishment of Basis

For AM

Development of AMP with relationship among Government, Industry and Academia

1st Stage NISA Project for $A M(2006-2010)$
Safety Regulation Restructure (2012- )
Reform of

Regulatory Organization (2012)
Political Argument about Nuclear Power

Dependency in Japan

(Maybe Fluid)
Technical Basis including AMP should be kept 2nd Stage NISA Project for AMP on System Safety (2011-2015) 


\section{New Plants/Plant Life Extension}

- Limited construction sites

- Long lead time for a new plant

- Flexibility in LTO

- Possible Up-rating and longer fuel cycle

- Advanced Aging Management Technology

- Definition of Plant Life

- Design life, Engineering life, Economical life, Physical life,

- No fixed life by Aging Management including replacements

- Technology transfer through new construction 


\section{Content}

- Introduction and background

- Technical Evaluation of Aging Management

- Degradation, Materials, Systems, PDCA

- Proactive Materials Aging Degradation Management

- Annual Experts' Panel Meeting

- Proactive Issues raised and summarized by the Experts' Panel

- Proactive Issues raised by FRI from the outcomes of NISA, NRA projects

- Issues concerns : Oxidation under irradiation, Charge transfer of hydrogen in metals, Superabundant Vacancies

- Fukushima Daiichi Accident

- Sequence, Actions taken or being taken for future and lesson learn

- Long-and Mid term road map for decommissioning

- Summary 


\section{Proactive Materials Aging Degradation Management}

\section{Concerns related to NP plant ageing}

Apprehensions for the possibility of newly occurrence of potential and latent material aging degradation phenomena (Risk management)

$\hookrightarrow$

the degradation phenomena in components that have not yet experienced $\{\cdot$ Unknown phenomena

$\{\cdot$ Combination of known phenomena Synergy / Cascade

The past and present :Beautiful explanation of the scenario after happening of events

Proactive methodology against ageing degradation phenomena
Known phenomena

become more complex

Systematic reorganization and verification of knowledge acquired on various subjects

The future : Prediction of potential and latent materials ageing degradation phenomena 


\section{Annual Experts' Panel Meeting}

\section{Necessity of proactive action against ageing degradation phenomena and system safety}

More Academic/Fundamental approach for true proactive aging management with better predictive and preventive capability for latent/potential aging degradation, synergistic aging degradation and cascade aging degradation

Plant Ageing Phenomena

Engineering

Basic Science
Plant Ageing Degradation

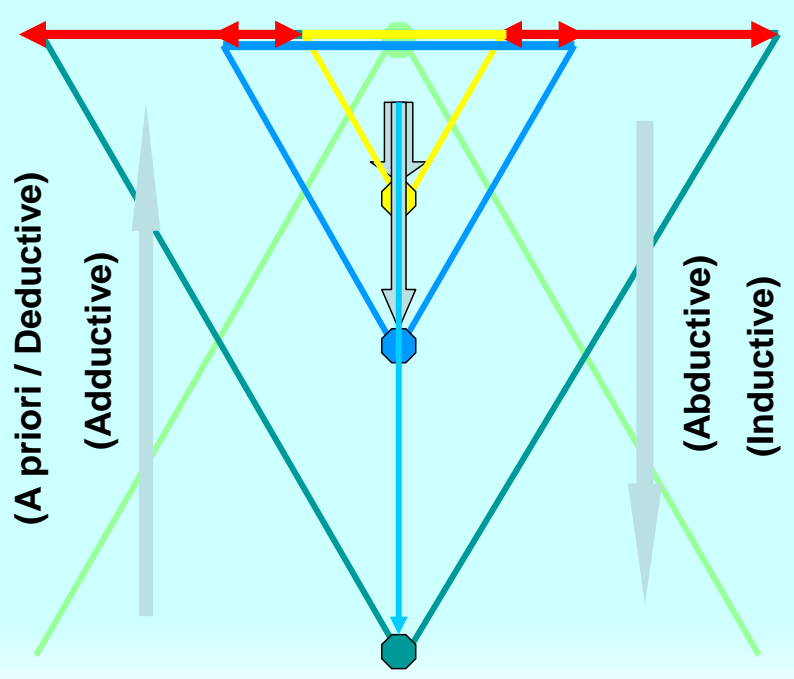

Knowledge Field
Inductive proactive methodology based on the root cause analysis of the events which have occurred in the past.

Deductive proactive methodology based on fundamental understanding of scientific degradation mechanisms and their integration

Systematic elicitation

(To clarify the potential and latent aging degradation phenomena and mechanism by imagination)

An illustration of a formalized relationship between "analytical" and "a priori"

approaches to life prediction based on expert iterations between the two approaches. 


\section{Annual Experts' Panel Meeting}

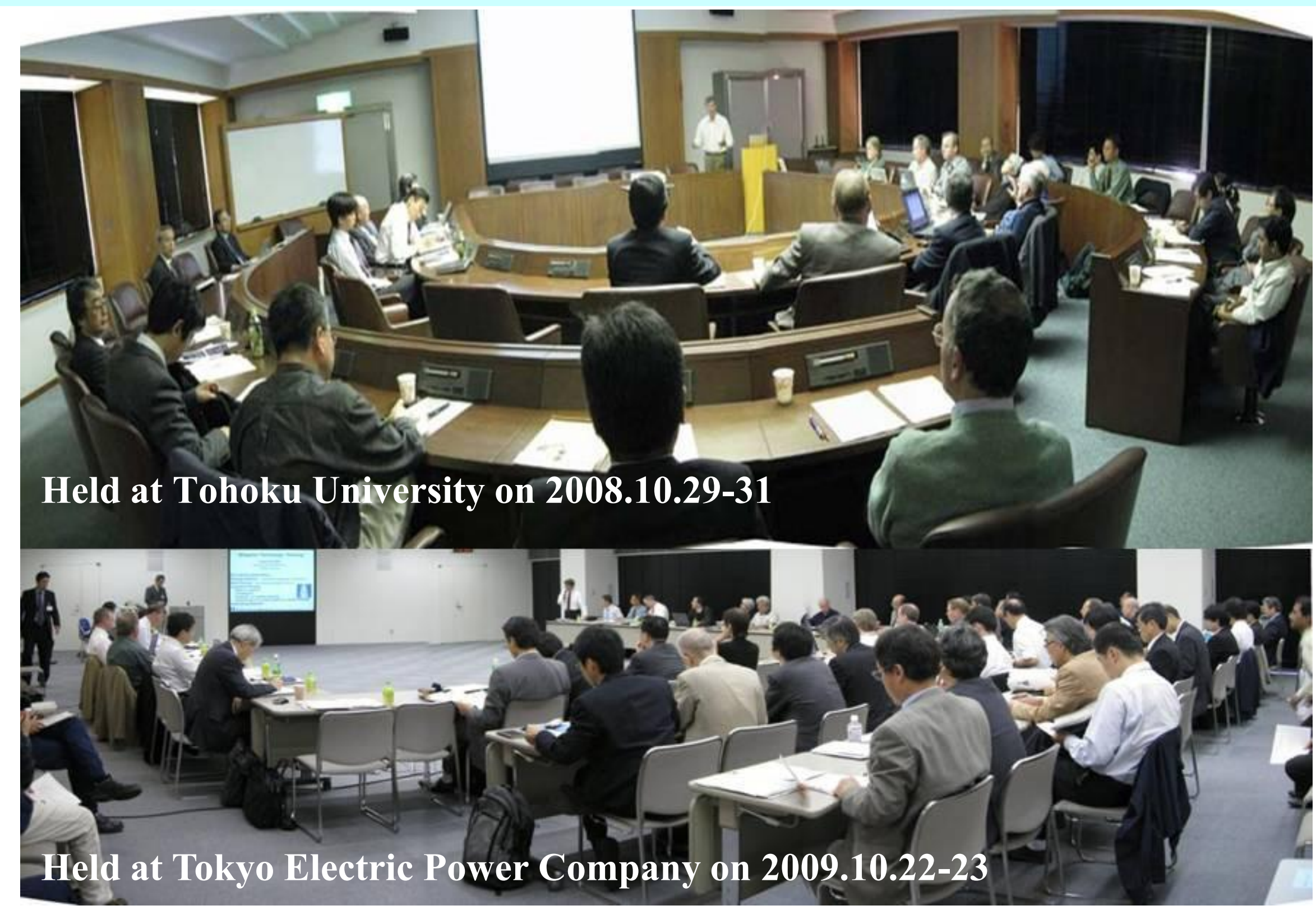




\section{Annual Experts' Panel Meeting}
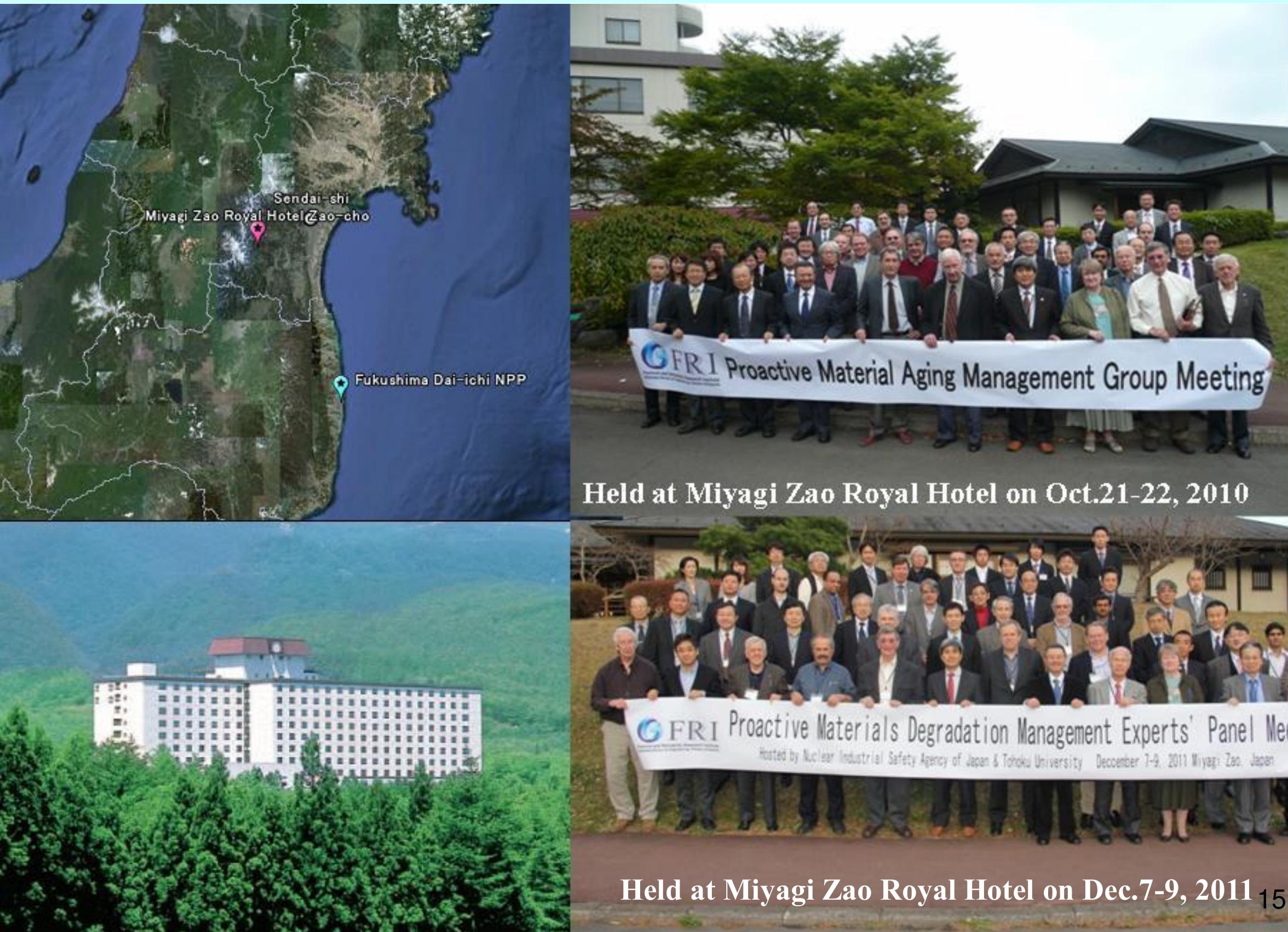

Held at Miyagi Zao Royal Hotel on Oct.21-22, 2010

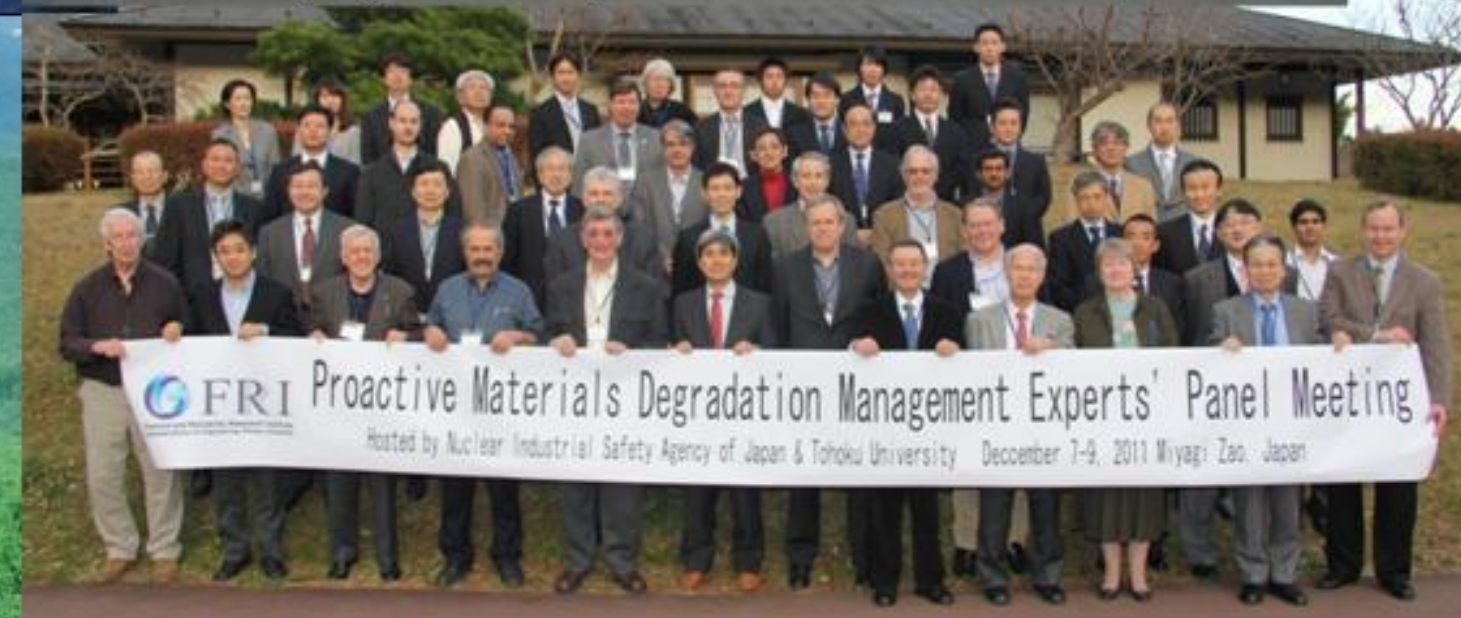

Held at Miyagi Zao Royal Hotel on Dec.7-9, $2011_{15}$ 


\section{PMDM Experts' Panel Meeting Member}

- Dr. Peter Ford (Consultant)

- Dr. Roger Staehle (Consultant)

- Dr. Karen Gott (Consultant)

- Dr. Tiangan Lian (EPRI)

- Dr. Claude Amzallag (ONET - Technologies)

- Dr. Jean-Paul Massoud (EdF SEPTEN)

- Dr. Peter Scott (Consultant)

- Dr. Peter Andresen (GE CRD)

- Prof. Hannu Hanninen (Aalto University)

- Dr. Armin Roth (AREVA)

- Prof. Roger Newman (U. Toronto)

- Prof. Il-Soon Hwang (SNU)

- Prof. En-Hou Han (IMR)

- Dr. Dolores G. Briceno (CIEMAT)

- Dr. Stephen Bruemmer (PNNL)

- Dr. C.E. (Gene) Carpenter (NRC)

- Dr. Alan Turmbull (NPL)

- Prof. Robert Cottis (U. Manchester)

- Prof. Philippe Marcus (ENSCP)

- Dr. Thierry Couvant (EdF)

- Dr. Torill M. Karlsen (OECD Halden)

- Prof. Jean-Y. Cavaille (INSA-Lyon)

- Prof. Yves Brechet (INPG)

- Dr. Pierre Combrade (Consultant)

- Dr. Hans-Peter Seifert (PSI)

- Prof. Tim Burnstein (U. Cambridge)

- Dr. Damien Feron (CEA)

- Dr. Ren Ai (SNPI)

- Prof. Z. P. Lu (Shanghai U)
- Mr. Katsunobu Aoyama (NISA)

- Prof. Naoto Sekimura (U.Tokyo)

- Dr. Shunichi Suzuki (TEPCO)

- Mr. Hideo Tanaka (KEPCO)

- Mr. Hiroyoshi Murakami (JAPCO)

- Mr. Kunihiro Kobayashi (Tohoku-epco)

- Mr. Takaaki Kobayashi (MHI)

- Dr. Haruo Fujimori (Hitachi-GE)

- Dr. Koji Arioka (INSS)

- Dr. Masatsune Akashi (Consultant)

- Associate Prof. Toshiaki Horiuchi (Hokkaido Institute T.)

- Mr. Masanori Kanno(JNES)

- Mr. Kazunobu Sakamoto (JNES)

- Dr. Koji Fukuya (INSS)

- Mr. Mikiro Ito (Toshiba)

- Dr. Fumio Inada, Dr. Taku Arai (CREPRI)

- Prof. Yoshimichi Ohki (Waseda U.)

- Prof. Yoshinori Kitsutaka (Tokyo Metroporitan U.)

- Prof. Hirozo Mihashi (Tohoku Institute of Technology)

- Dr. Kunio Onizawa (JAEA)

- Mr. Takashi Hirano (IHI)

- Mr. Masayuki Takizawa (MRI)

- Prof. Tetsuo Shoji (Tohoku U)

- Prof. Tatsuo Kondo (Emeritus, Tohoku U)

- Prof. Yutaka Watanabe (Tohoku U)

- Associate Prof. Makoto Takahashi (Tohoku U)

- Assistant Prof. Yoichi Takeda (Tohoku U)

- Visiting Prof. Jun Kameda (Tohoku U)

- Visiting Prof. Jiro Kuniya (Tohoku U) 


\section{-SUSCEPTIBILITY Factor}

$0=$ not considered to be an issue

1 = conceptual basis for concern from data, or potential occurrences under unusual operating conditions, etc.

$2=$ strong basis for concern or known but limited plant occurrence

$3=$ demonstrated, compelling evidence for occurrence, or multiple plant observations

\section{- KNOWLEDGE Factor}

1 = poor understanding, little and/or low-confidence data;

$2.5=$ some reasonable basis to know dependencies qualitatively or semi-quantitatively from data or extrapolation in similar "systems";

3 = extensive, consistent data covering all dependencies relevant to the component, perhaps with models; should provide clear insights into mitigation or management of problem hopefully based on its mechanistic understandings.

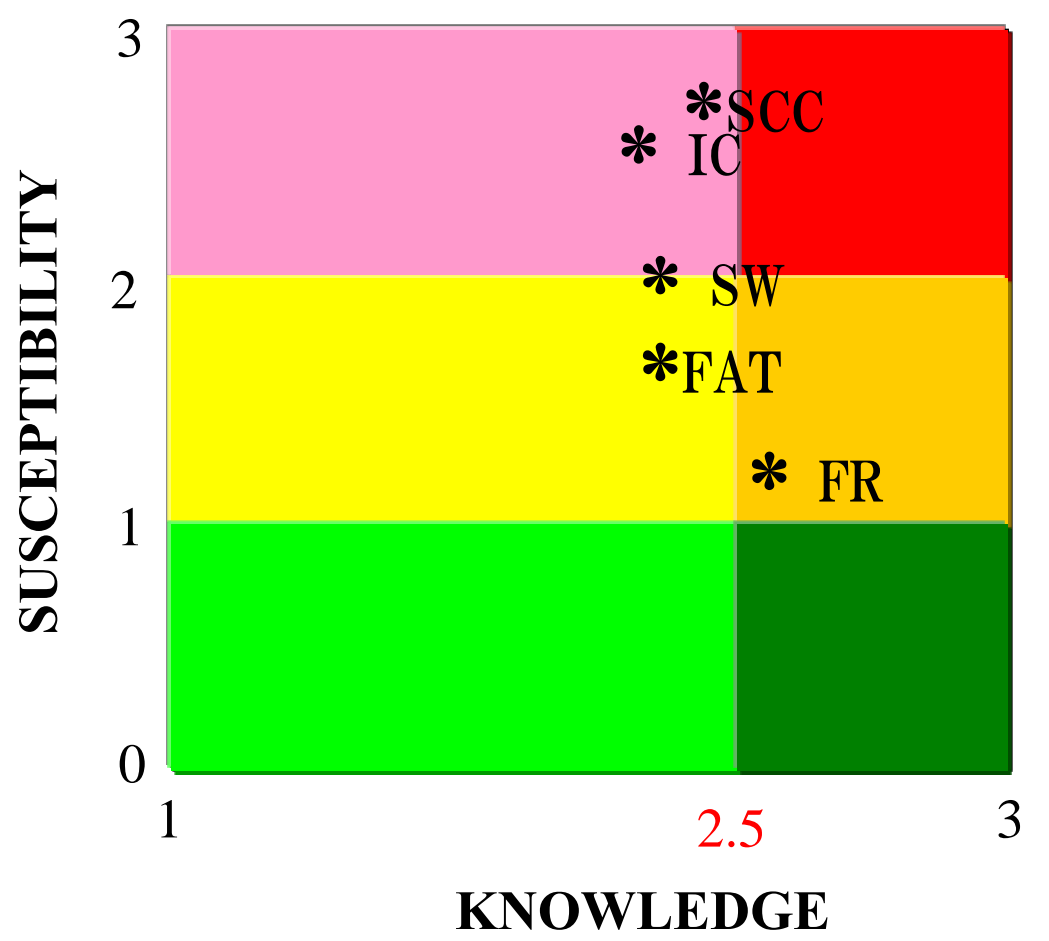

Example of score for several phenomena 


\section{Issues proposed associated with materials aging}

\section{Specific subjects proposed in $\mathbf{2 0 0 8}$}

\section{Potential degradation predicted by laboratory experiments or field incidences}

(1) Cracking of PWR steam generator nozzle dissimilar welds and adjacent austenitic stainless steels $\mathrm{HAZ}$

(2) Corrosion of backside surface of spent fuel pool structure

(3) Any potential risk of degradation such as corrosion in pipe penetration to the concrete confinement due to neutralization

(4) Condition monitoring as an on-line maintenance and/or a backup technique to ensure the degradation monitoring and/or mitigation confirmation

(5) Effects of temperature and ECP transients on environmentally assisted cracking from a point of view of oxide film transient in plants

\section{Any latent phenomena and potential degradation} which we may focus for aged plants in future

(6) Any possible mechanism to form a condition of a localized highly oxidizing area at particular parts in NPP components

(7) Possible role of hydrogen as an oxidant is recently reported and what would be a potential degradation mode to be induced or to be accelerated with oxidant hydrogen

(8) Effect of small ripple stress and/or higher harmonic wave on environmentally assisted cracking
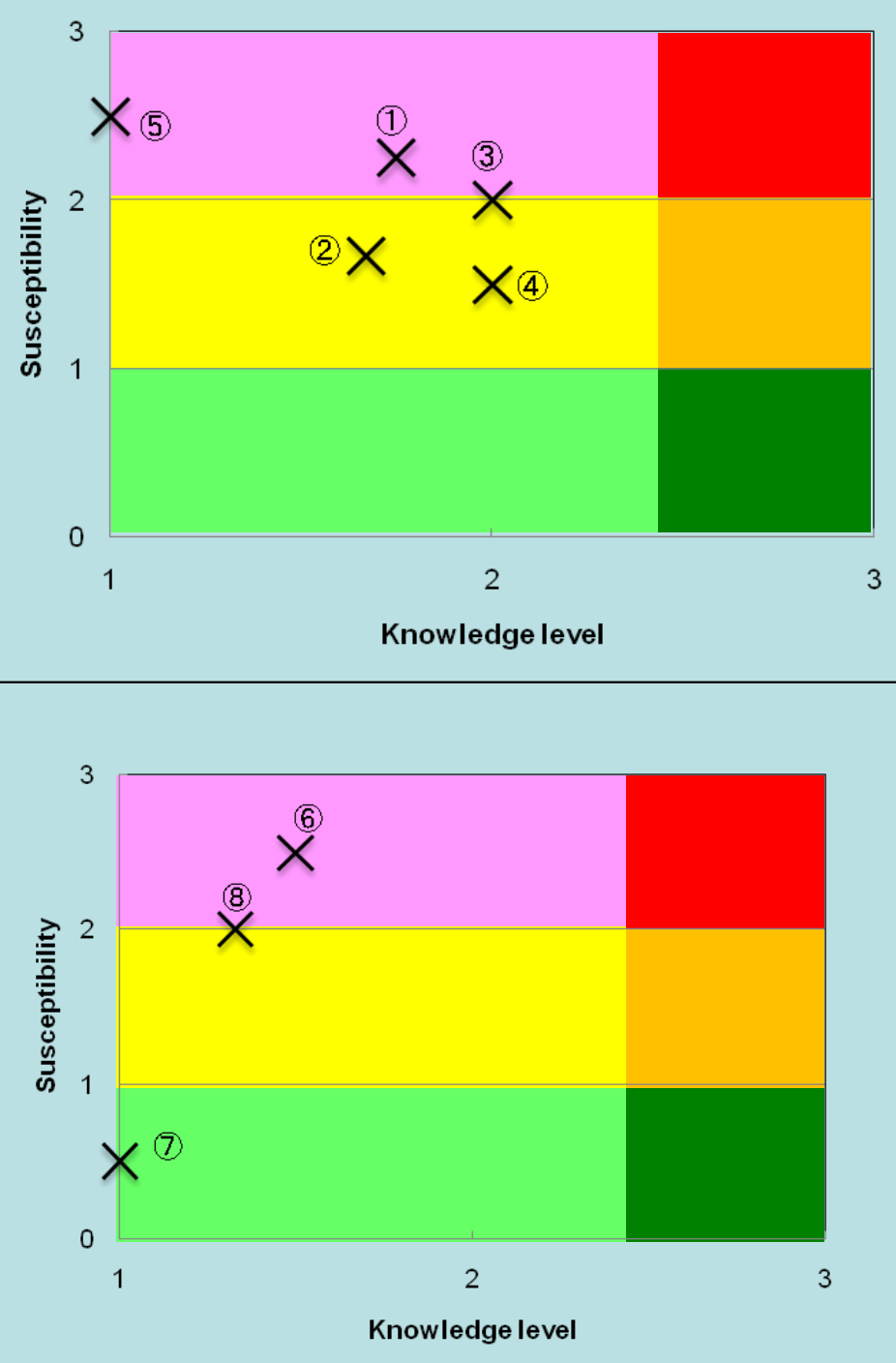

Scoring Results 


\section{PWR Proactive Issues raised and summarized by the Experts' Panel}


1. Research subjects for shorter term projects to be completed in $\sim 5$ years

- 1) SCC initiation phenomena, including the effects of surface stress/strain, residual stress, microstructure and strain localization,

- 2) Development of qualified mechanisms-based lifetime models for PWSCC propagation in nickel base alloys,

- 3) Characterization of weld metals, dilution at interfaces and heat affected zones,

- 4) Strain localization and strain history and relationship to cold work, microstructure and compositional banding,

- 5) Effect of environment on fatigue and fracture resistance in PWRs,

- 6) Flow-accelerated corrosion in PWRs. 


\section{Research subjects for longer term projects to be completed in $\sim 5$ to 10 years}

- 1) Effects of irradiation flux and fluence on stainless steels and nickel base alloys and the effect on SCC,

- 2) Modeling and validation of residual stress/strain profiles in complex welded geometries and how these may change with neutron fluence,

- 3) Initiation of SCC in structural alloys, modeling stochastic features, heat to heat variability, effects of long exposure periods,

- 4) Quantification of potential synergistic effects between competing degradation modes for PWRs,

- 5) Quantitative modeling of oxidation and EAC based on fundamental physical principles for PWRs. 


\section{Typical score distribution of Proactive Issues and those raised by FRI from the outcomes of NISA, NRA projects}

Presented and summarized based upon the PMDM Experts' Panel Meeting of NRA aging management program held on Oct. 24 - 26, 2012, Sendai Japan 
7.3 Acceleration of SCC due to cold work

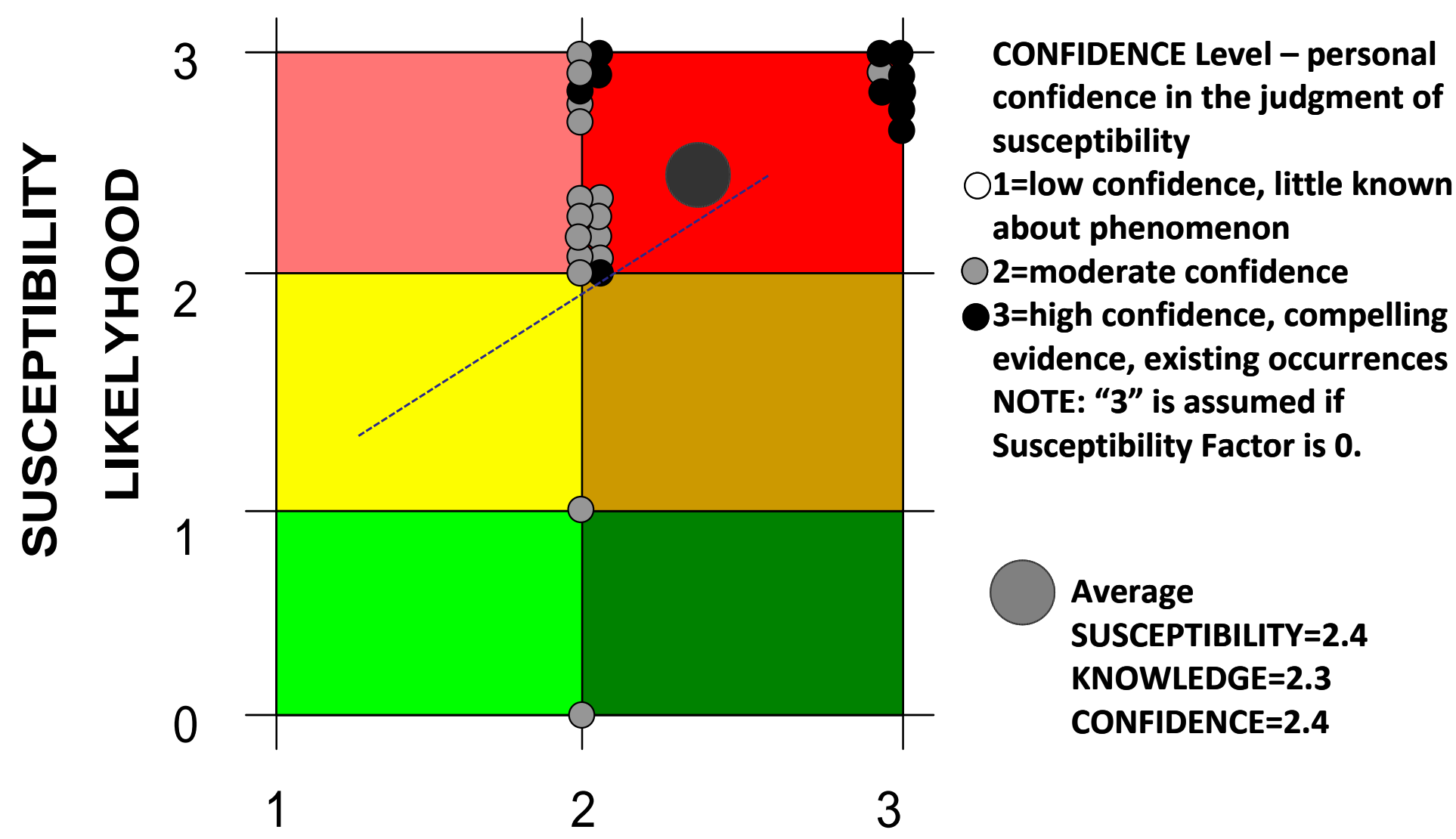

KNOWLEDGE 
7.2 SCC growth characteristics at dissimilar metal welds

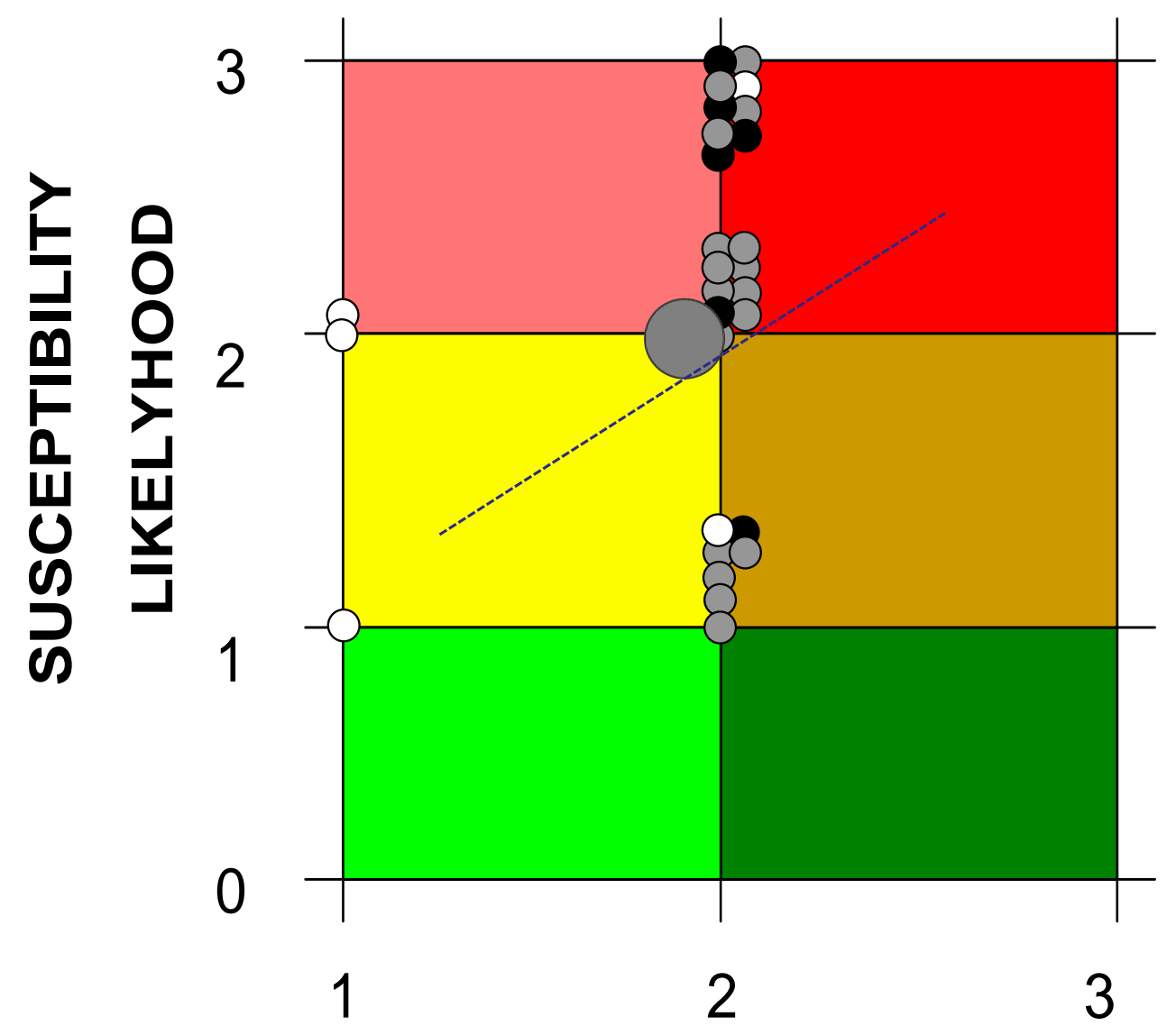

CONFIDENCE Level - personal confidence in the judgment of susceptibility

$\bigcirc 1=$ low confidence, little known about phenomenon

$\bigcirc 2=$ moderate confidence

3=high confidence, compelling evidence, existing occurrences NOTE: " 3 " is assumed if Susceptibility Factor is $\mathbf{0 .}$

\section{Average} SUSCEPTIBILITY=2.0 KNOWLEDGE $=1.9$ CONFIDENCE $=\mathbf{2 . 0}$

KNOWLEDGE 
7.6 Acceleration of SCC and corrosion due to hydrogen accelerated oxidation

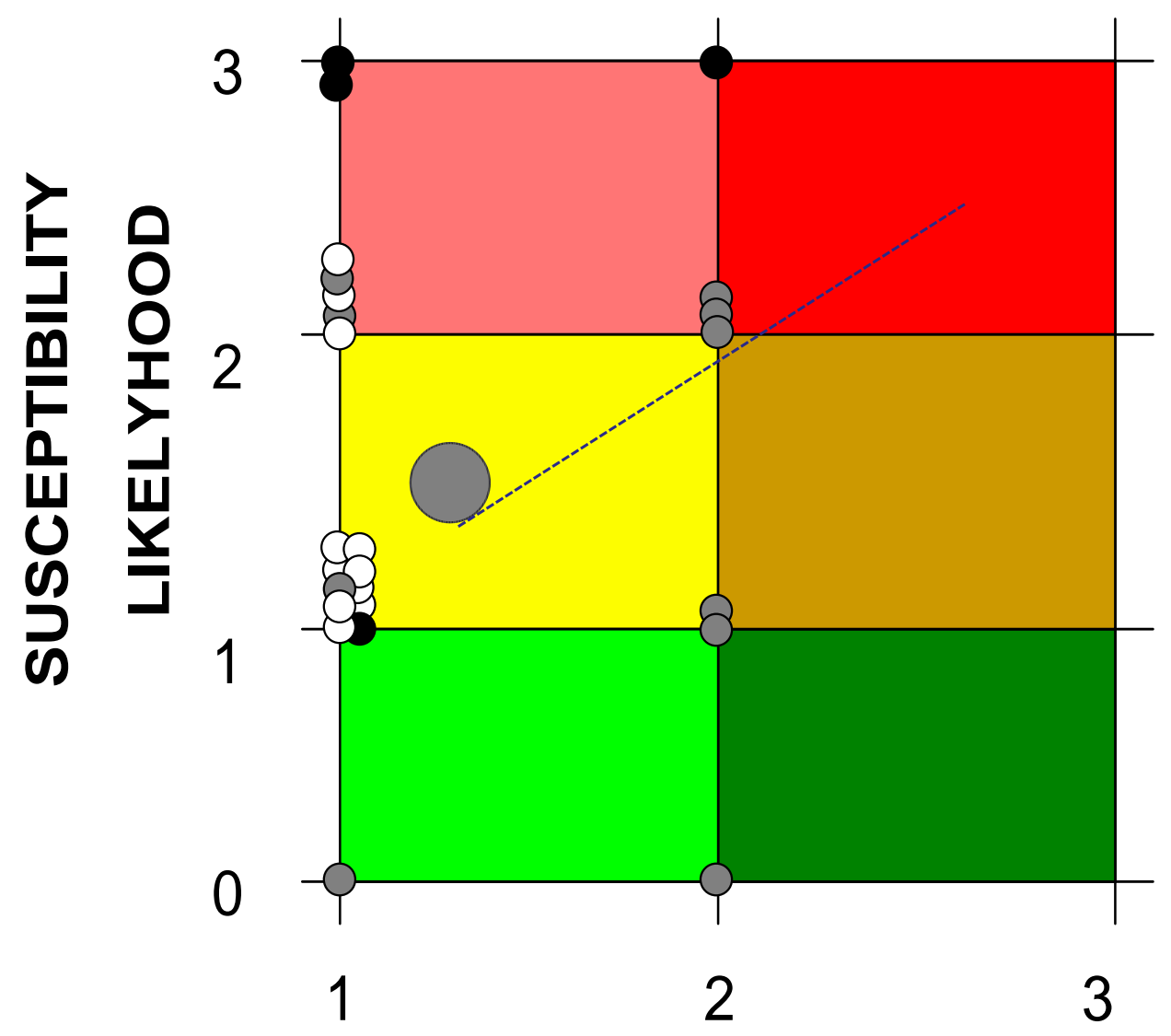

CONFIDENCE Level - personal confidence in the judgment of susceptibility

$\bigcirc 1=$ low confidence, little known about phenomenon

$\bigcirc 2=$ moderate confidence

3=high confidence, compelling evidence, existing occurrences NOTE: " 3 " is assumed if Susceptibility Factor is $\mathbf{0}$.

\section{Average}

SUSCEPTIBILITY=1.4

KNOWLEDGE $=1.3$

CONFIDENCE $=1.7$

\section{KNOWLEDGE}


6.1 Acceleration of irradiation induced sensitization due to carbon formation by nuclear transformation of nitrogen

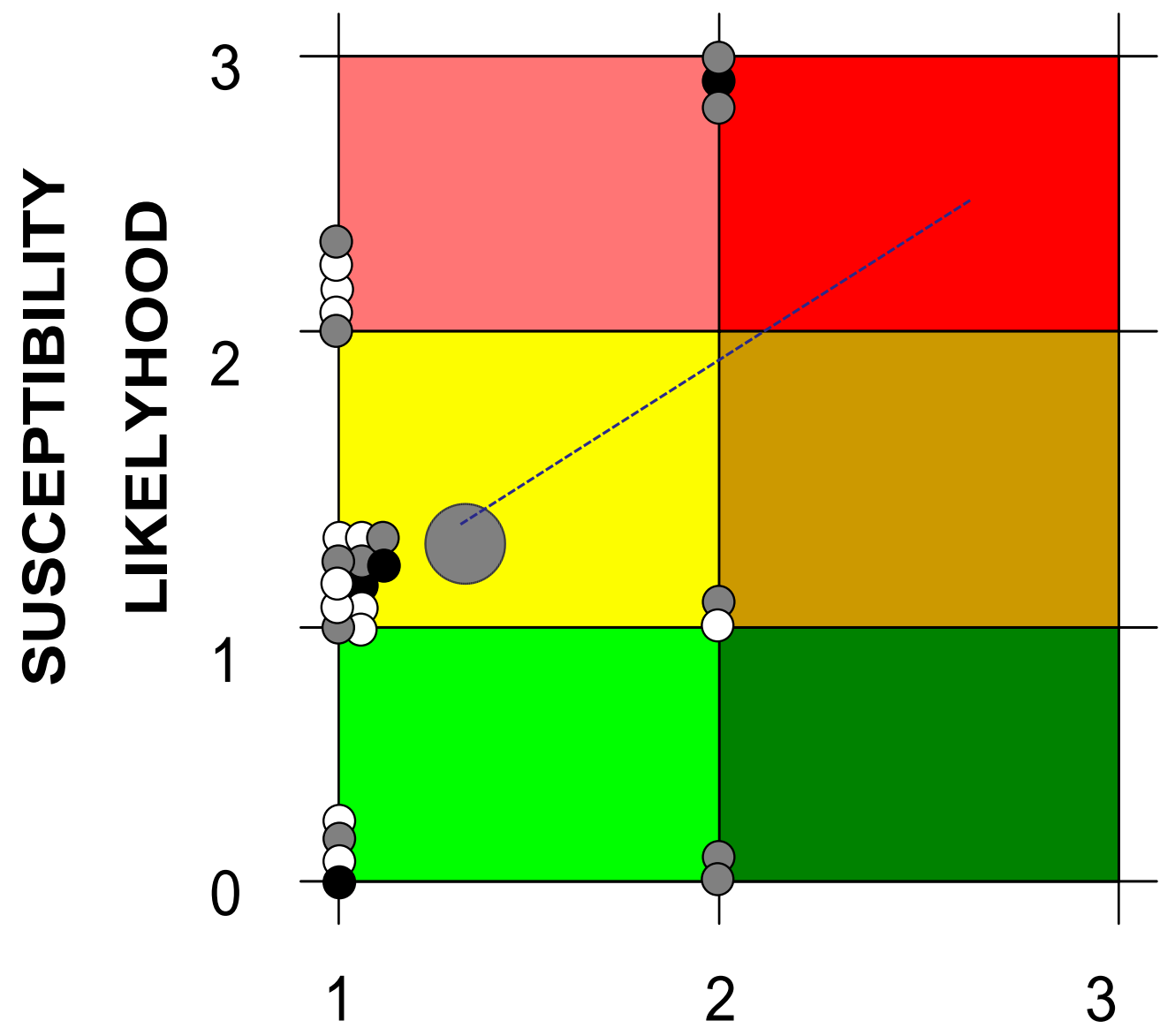

CONFIDENCE Level - personal confidence in the judgment of susceptibility

$\bigcirc 1=$ low confidence, little known about phenomenon

$\bigcirc 2=$ moderate confidence

3=high confidence, compelling evidence, existing occurrences NOTE: " 3 " is assumed if Susceptibility Factor is $\mathbf{0}$.

Average SUSCEPTIBILITY=1.2 KNOWLEDGE $=1.3$ CONFIDENCE $=1.7$

KNOWLEDGE 
6.2 Acceleration of corrosion and stress corrosion cracking due to hydrogen formation by nuclear transformation of nitrogen

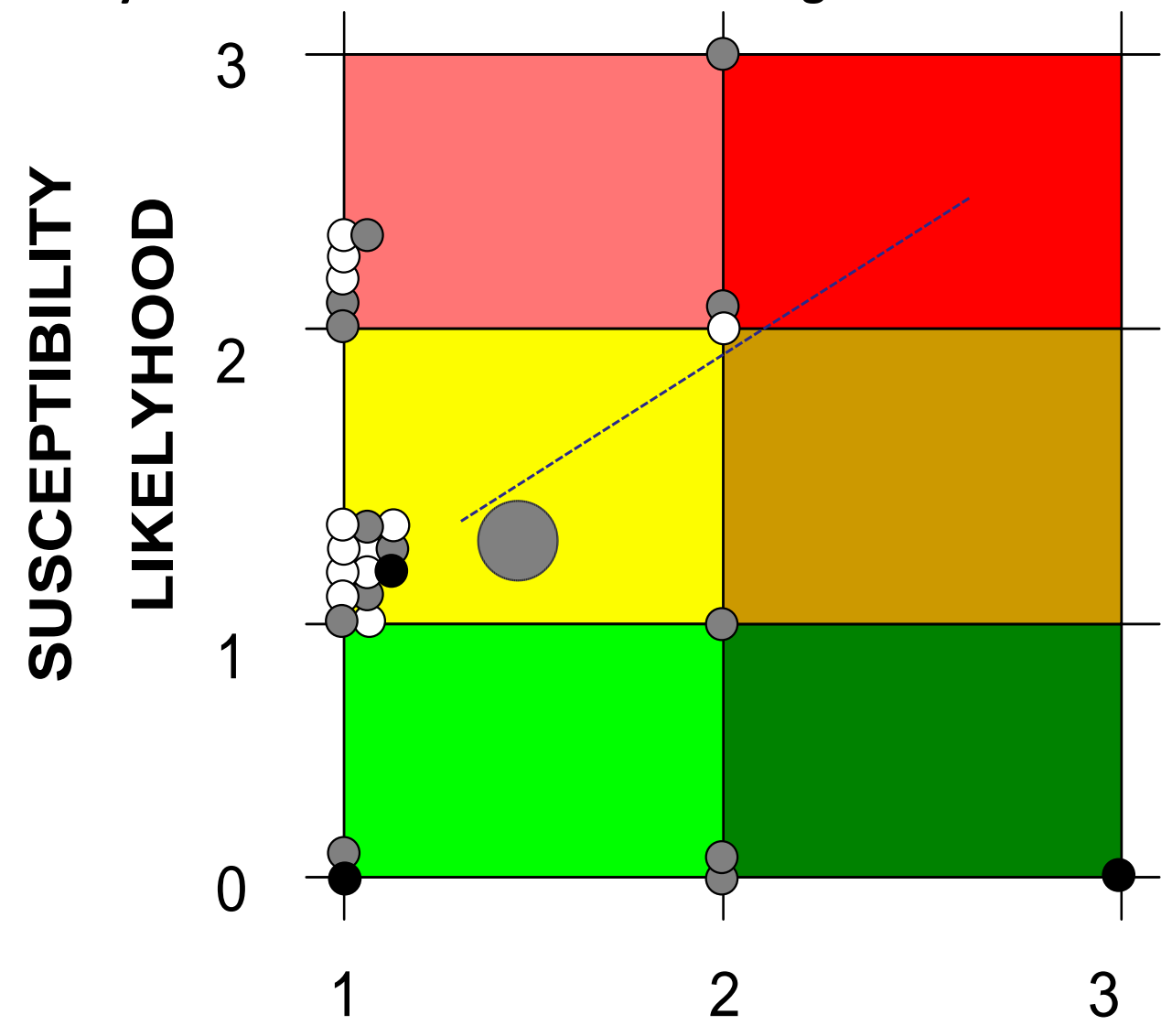

CONFIDENCE Level - personal confidence in the judgment of susceptibility

O1=low confidence, little known about phenomenon

$\bigcirc 2=$ moderate confidence

3=high confidence, compelling evidence, existing occurrences NOTE: " 3 " is assumed if Susceptibility Factor is $\mathbf{0}$.

Average SUSCEPTIBILITY $=1.2$ KNOWLEDGE $=1.3$ CONFIDENCE $=1.7$

\section{KNOWLEDGE}


1.3 Aging damage due to acceleration of material diffusion and microstructure change by interaction of super abundunt vacancy and hydrogen

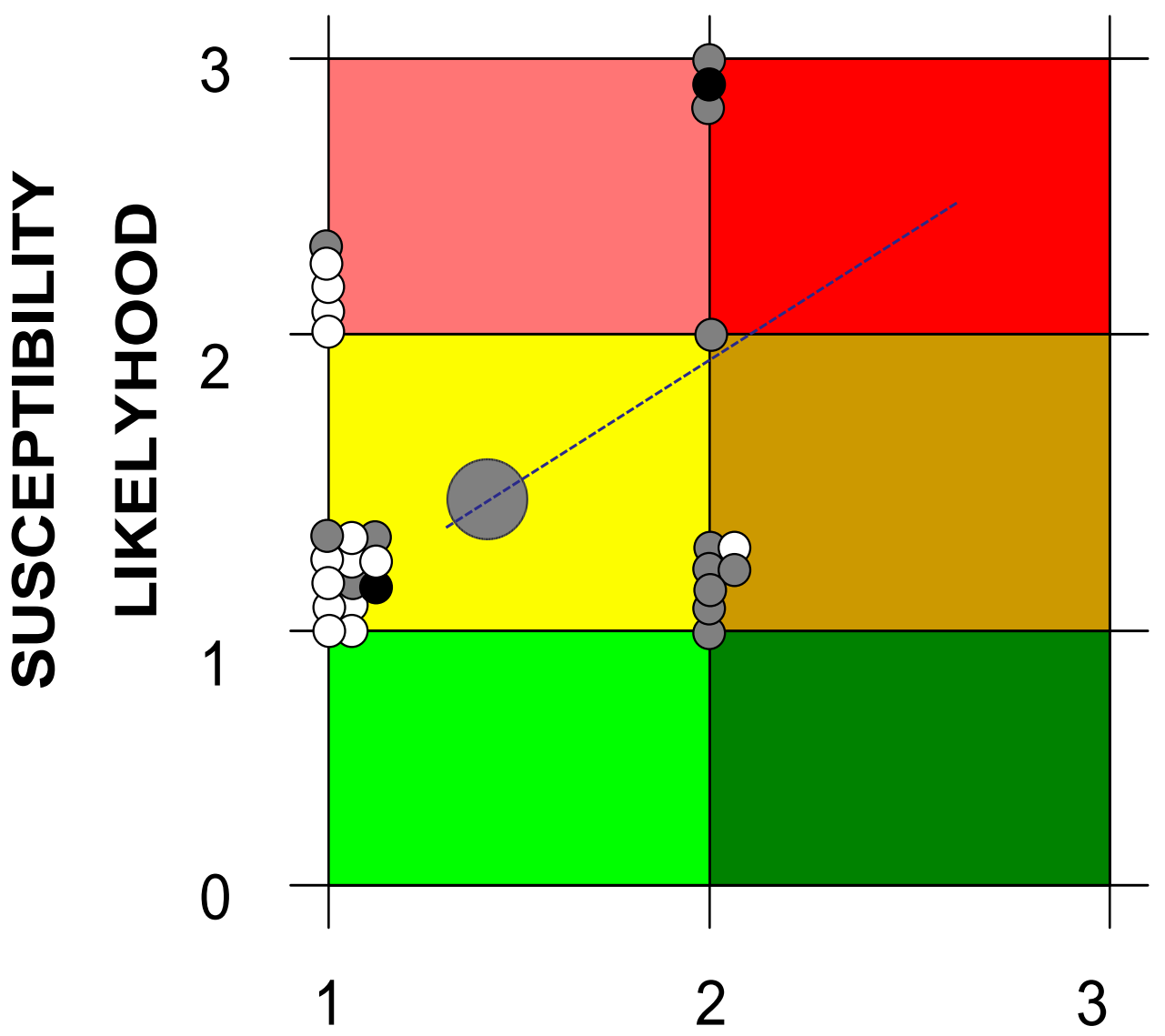

CONFIDENCE Level - personal confidence in the judgment of susceptibility

1=low confidence, little known about phenomenon

2=moderate confidence

3=high confidence, compelling evidence, existing occurrences NOTE: " 3 " is assumed if Susceptibility Factor is $\mathbf{0}$.

Average SUSCEPTIBILITY $=1.4$ KNOWLEDGE $=1.4$ CONFIDENCE $=1.6$

KNOWLEDGE 
Oxidation Dynamics at Oxide/Metal Interface and Oxidation Localization and SCC initiation in High Temperature Water under irradiation

Prepared by Yo-ichi Takeda and T. Shoji 


\section{Outline}

- Oxidation test in Halden reactor using 316L and 316 NG stainless steels

- Comparison of oxidation behaviors in laboratory specimens (non irradiation) and irradiation specimens

- Characterization of oxidation localization on Constant loading specimens

- Weight gain / loss and oxide film thickness on plate type specimens

- Possible hydrogen effect in $316 \mathrm{NG}$ stainless steel in simulated PWR environment 


\section{Materials and test environments}

\section{Materials}

- 316L stainless steel

- 316LN stainless steel

\begin{tabular}{|l|c|c|}
\hline \multicolumn{3}{|l|}{ Stress conditions } \\
\hline \hline \multirow{2}{*}{ Load } & \multicolumn{2}{|c|}{ Average stress in the cross section } \\
\cline { 2 - 3 } & Notch root & Flat \\
\hline $255 \mathrm{~N}$ & $324 \mathrm{MPa}$ & $81 \mathrm{MPa}$ \\
\hline
\end{tabular}

For a part of the nonirradiated specimens,

$374 \mathrm{MPa}$ and $94 \mathrm{MPa}$ were used.

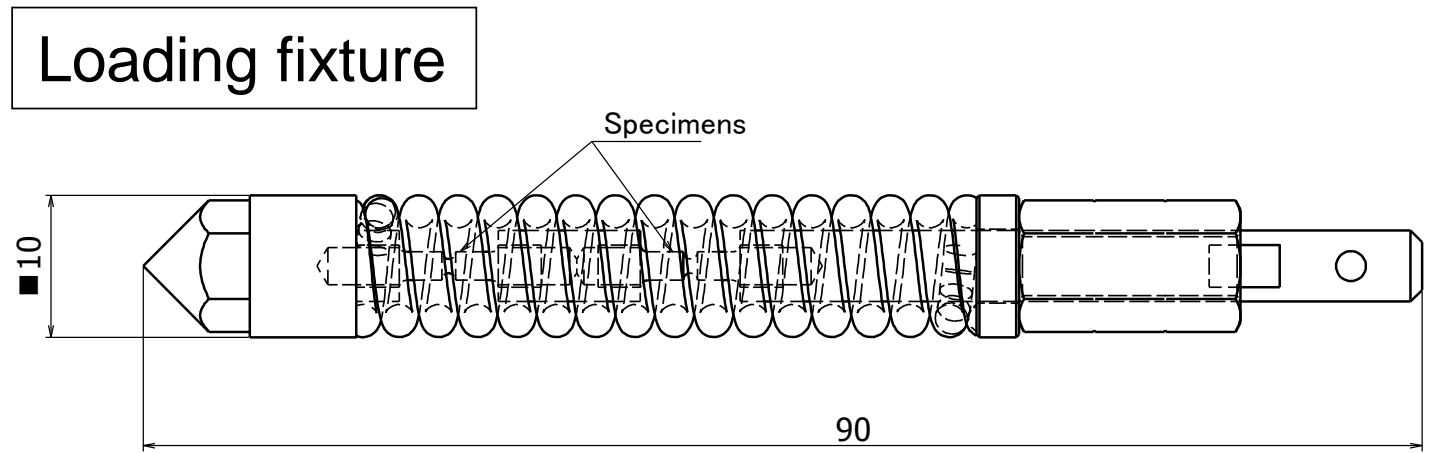

Chemical compositions (wt\%)

\begin{tabular}{|c|c|c|c|c|c|c|c|c|}
\hline & $\mathrm{C}$ & $\mathrm{Si}$ & $\mathrm{Mn}$ & $\mathrm{P}$ & $\mathrm{Ni}$ & $\mathrm{Cr}$ & $\mathrm{Mo}$ & $\mathrm{N}$ \\
\hline $316 \mathrm{~L}$ & 0.018 & 0.47 & 0.82 & 0.028 & 12.06 & 17.68 & 2.17 & 0.039 \\
\hline 316LN & 0.020 & 0.50 & 0.81 & 0.025 & 12.89 & 16.59 & 2.39 & 0.094 \\
\hline
\end{tabular}

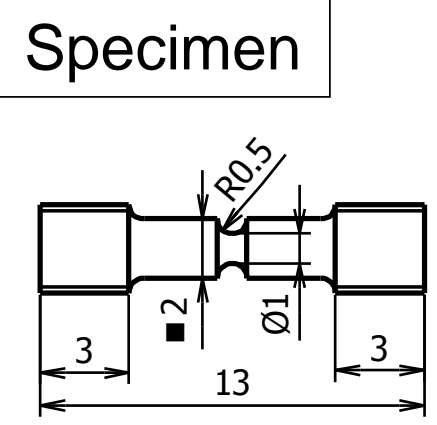

\begin{tabular}{|c|c|}
\hline $\begin{array}{l}\text { Temperature } \\
\left({ }^{\circ} \mathrm{C}\right)\end{array}$ & 288 \\
\hline Pressure (MPa) & $8.1-9.0$ \\
\hline $\begin{array}{l}\text { Dissolved } \\
\text { oxygen (ppm) }\end{array}$ & 2.0 \\
\hline $\begin{array}{l}\text { Conductivity } \\
(\mu \mathrm{S} / \mathrm{cm})\end{array}$ & $<0.2$ (outlet) \\
\hline
\end{tabular}

Irradiation tests were performed in Halden reactor. 


\section{Test conditions for irradiation specimens}

- Halden reactor (OECD-NEA)

- 4 different oxidation time duration

\begin{tabular}{|c|c|c|}
\hline & Geometry & Materials \\
\hline Coupon specimen & $10 \times 10 \mathrm{~mm} \mathrm{t}=1 \mathrm{~mm}$ & $316 \mathrm{~L}, 316 \mathrm{LN}$ \\
\hline Tensile specimen & $\begin{array}{l}\text { Circumferential notched } \\
\text { bar: } \Phi 1 \mathrm{~mm} \text { (at notch root) }\end{array}$ & $316 \mathrm{~L}, 316 \mathrm{LN}$ \\
\hline
\end{tabular}

\begin{tabular}{|l|c|c|c|c|}
\hline $\begin{array}{l}\text { Full power hours } \\
(\mathrm{hr})\end{array}$ & $528 \mathrm{~h}$ & $863 \mathrm{~h}$ & $1176 \mathrm{~h}$ & $2568 \mathrm{~h}$ \\
\hline $\begin{array}{l}\text { Thermal neutron flux } \\
\left(\mathrm{n} / \mathrm{cm}^{2} \mathrm{~s}\right)\end{array}$ & $4.7 \times 10^{13}$ & $4.4 \times 10^{13}$ & $4.7 \times 10^{13}$ & $4.0 \times 10^{13}$ \\
\hline \begin{tabular}{l} 
Gamma heat $(\mathrm{W} / \mathrm{g})$ \\
\hline $\begin{array}{l}\text { Fast neutron flux } \\
\left(\mathrm{n} / \mathrm{cm}^{2} \mathrm{~s}\right)\end{array}$
\end{tabular} & 1.2 & 1.1 & 1.2 & 1.2 \\
\hline $\begin{array}{l}\text { Fast neutron fluence } \\
\left(\mathrm{n} / \mathrm{cm}^{2}\right)\end{array}$ & $0.53 \times 10^{20}$ & $0.78 \times 10^{20}$ & $1.2 \times 10^{20}$ & $3.0 \times 10^{20}$ \\
\hline $\begin{array}{l}\text { Displacement } \\
\text { damage }^{*} \text { (dpa) }\end{array}$ & 0.076 & 0.11 & 0.17 & 0.42 \\
\hline
\end{tabular}


Obtained results

- Oxidation tests under constant load using circumferential notched specimen

- Surface morphology

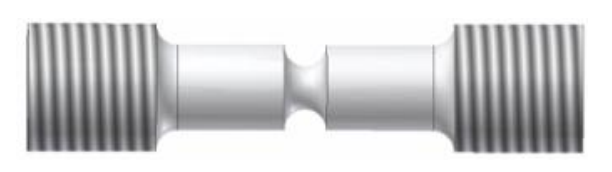

- Cross sectional image and characterization of oxidation localization behavior irradiation / stress / surface work hardened layer

- Weight gain/loss using plate specimen

- weight gain/loss and oxide film thickness

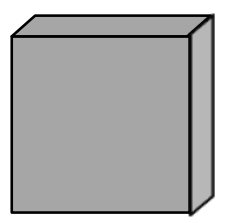




\section{Oxide / steel interface profile}

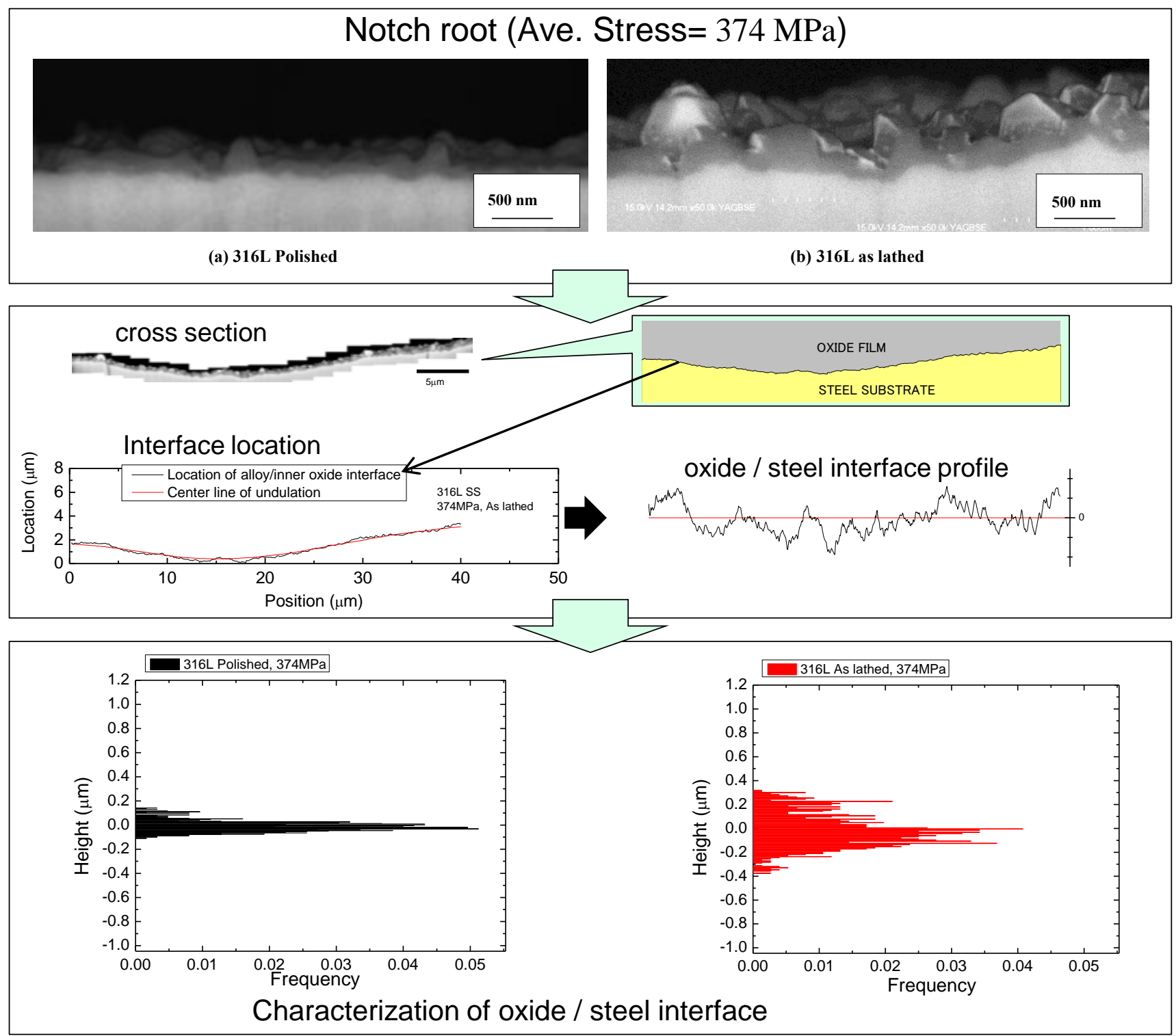




\section{Oxidation localization parameters}
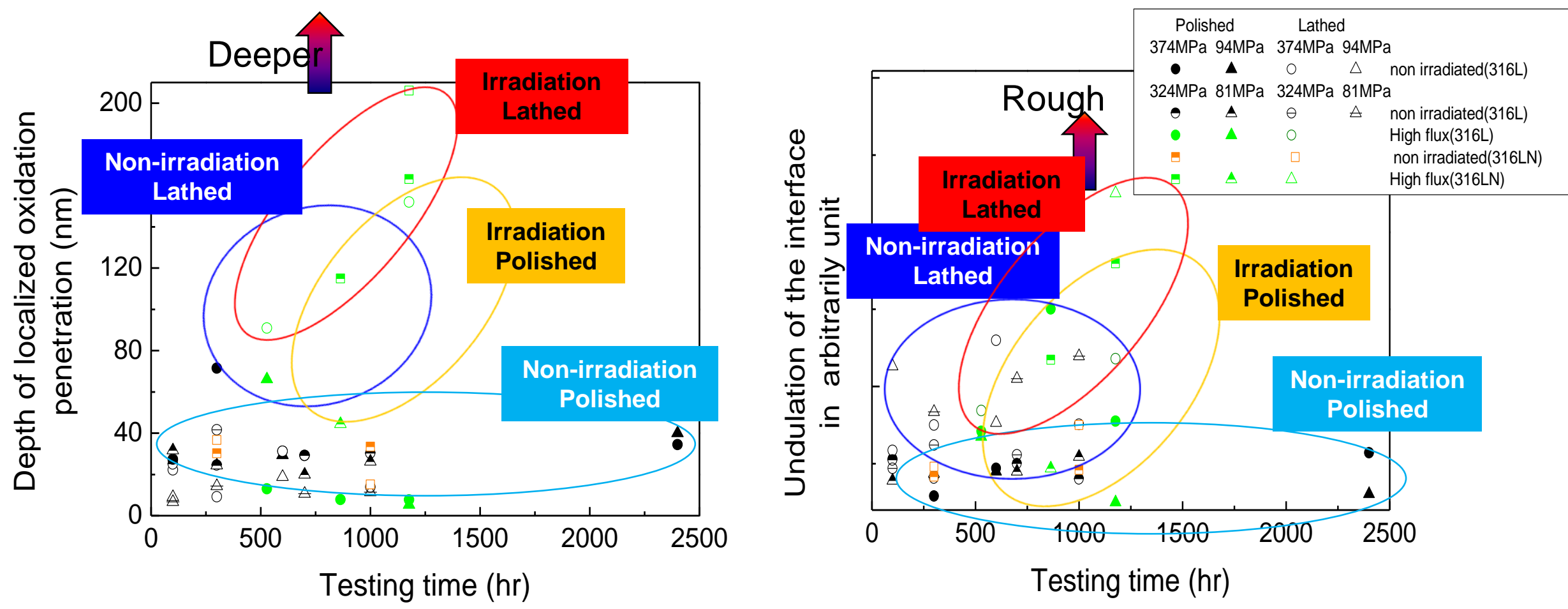

- Oxidation localization develops with time especially in the specimens under irradiation and lathe finished surface conditions (increase the parameter values)

- More significant oxidation localization is pointed out in the specimens under irradiation 


\section{Weight gain / loss and oxide film thickness}

\section{(irradiation)}

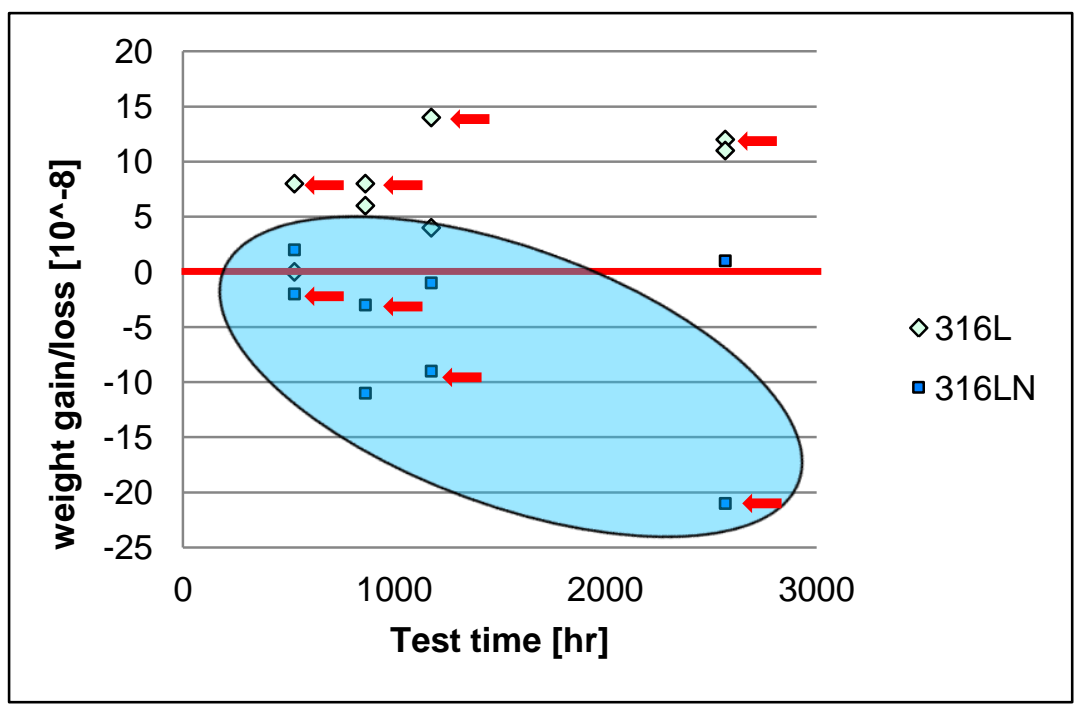

$\Leftarrow$ specimens in which oxide film thickness was examined

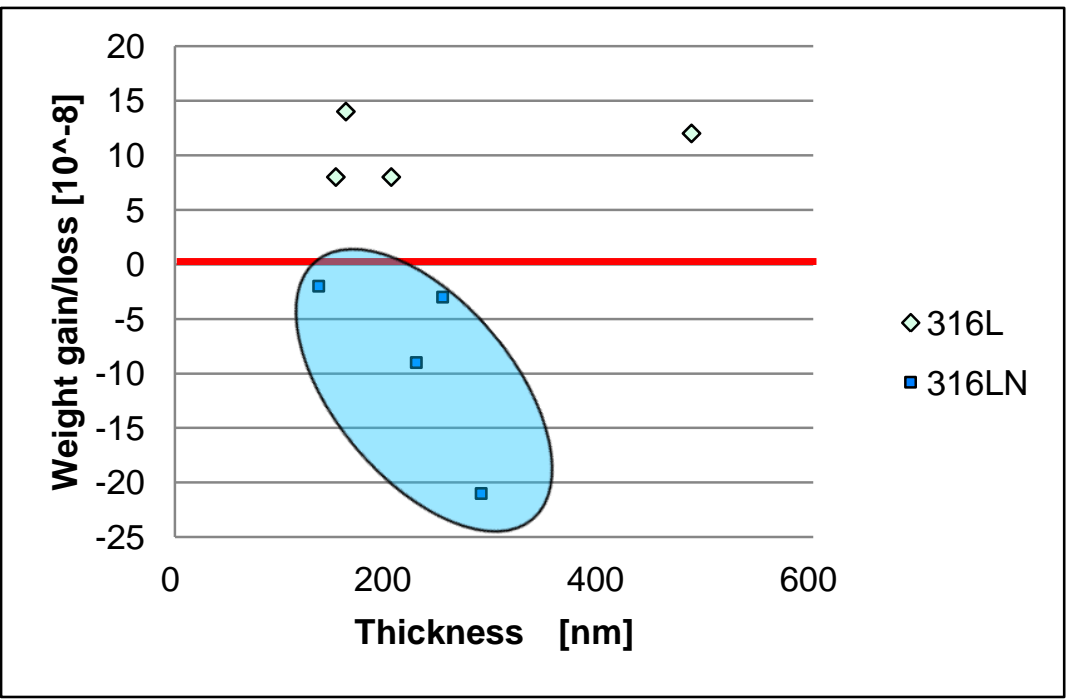

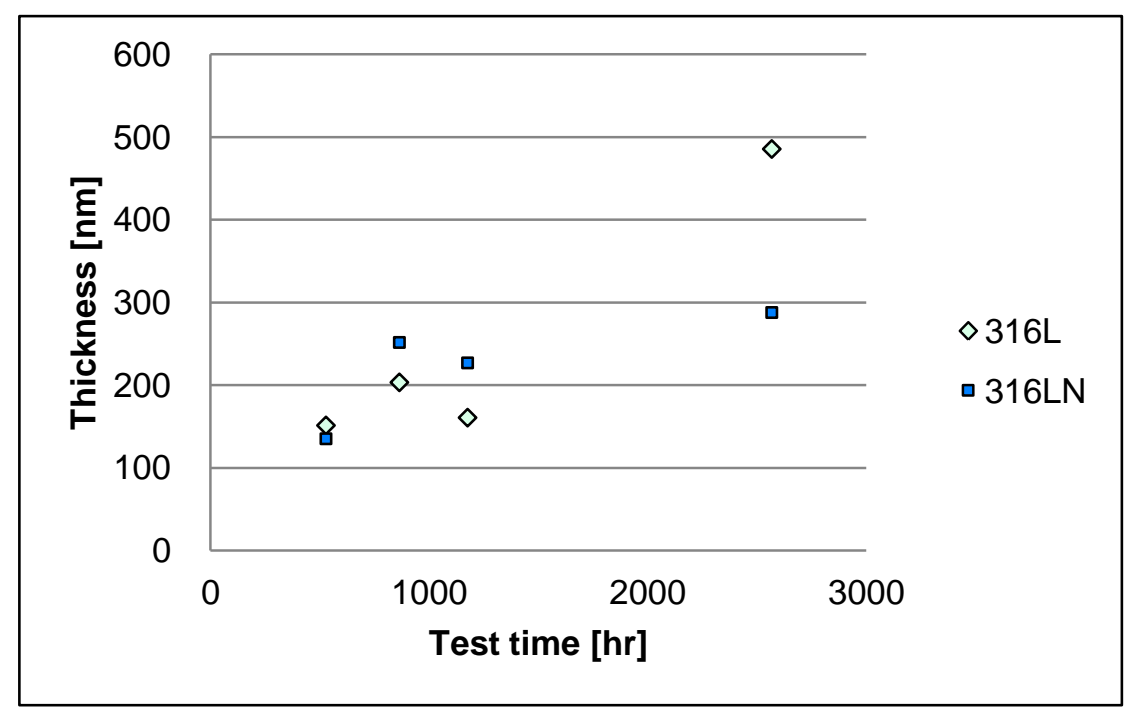

-Thickness of the oxide film monotonically increase with experimental time - It might be pointed out that more dissolution of alloying elements into water took place in 316NG 


\section{Possible effect of nitrogen in steel on carbon and hydrogen generation and consequential oxidation kinetics}

nuclear transformation of nitrogen :

$$
\mathrm{n}+{ }_{7}^{14} \mathrm{~N} \rightarrow{ }_{6}^{14} \mathrm{C}+{ }^{1} \mathrm{H}
$$

Carbon \& hydrogen formed during the irradiation test

Role of Hydrogen in oxidation and SCC 
>Quantum Chemical Molecular Dynamics and Atomic Scale Modeling of Metal Oxidation with Water

$>$ Electron State of Interstitial Hydrogen in Metal - Negatively Charged Hydrogen

$>$ Vacancy - Hydrogen Interaction (Superabundant Vacancies) and promotion of Metal diffusivity

$>$ Hydrogen Enhanced Oxidation 


\section{Issue concern 2}

Fundamental Mechanistic Study of Stress Corrosion Cracking -Quantum Chemical Molecular Dynamics Approach 


\section{Introduction}

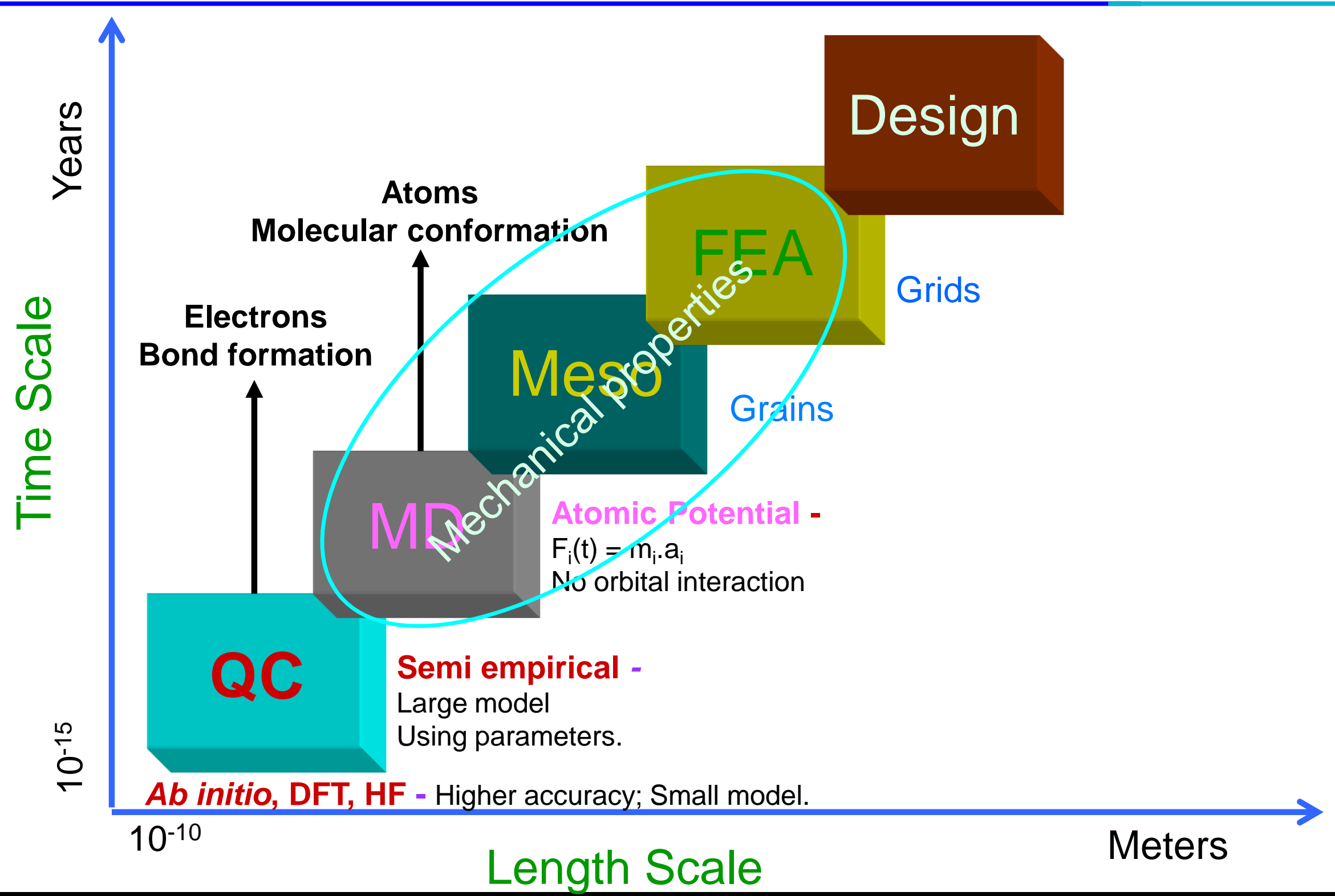




\section{Underlying Theory}

Extended Hückel approximation

$$
\begin{aligned}
& \mathrm{HC}=\mathrm{SC} \varepsilon \quad \text { Where } \mathrm{H} \text { : Hamiltonian matrix, } \\
& \mathrm{C}^{\top} \mathrm{SC}=\mathrm{I} \\
& S \text { : Overlap matrix, } \\
& C \text { : Eigen vector, } \\
& \varepsilon \text { : Eigen value and } \\
& \mathrm{C}^{\mathrm{T}} \text { : Transposed matrix of } \mathrm{C} \text {. }
\end{aligned}
$$

Total Energy: $E=\sum_{A=1}^{M} \frac{1}{2} m_{A} v_{A}^{2}+\sum_{i=1}^{O C C} n_{i} \varepsilon_{i}+\sum_{A=1}^{M} \sum_{A<B}^{M} \frac{Z_{A} Z_{B} e^{2}}{r_{A B}}+\sum_{A=1}^{M} \sum_{A<B}^{M} E_{\text {repuls }}\left(r_{A B}\right)$

Repulsion term: $E_{\text {repuls }}\left(r_{A B}\right)=b_{A B} \exp \left(\frac{a_{A B}-r_{A B}}{b_{A B}}\right)$

Force for each atom:

$$
F_{A}=\sum_{A \neq B}^{M} \sum_{i=1}^{O C C} C_{i}^{T} \frac{\partial H}{\partial r_{A B}} C_{i}+\sum_{A \neq B}^{M} \sum_{i=1}^{O C C} \varepsilon_{i} C_{i}^{T} \frac{\partial S}{\partial r_{A B}} C_{i}-\sum_{A \neq B}^{M} \frac{Z_{A} Z_{B} e^{2}}{r_{\mathbf{A} B}^{2}}+\sum_{A \neq B i}^{M} \frac{\partial E_{\text {repuls }}\left(r_{A B}\right)}{\partial r_{A B}}
$$




\section{Optimization of parameters}

$$
\begin{gathered}
\text { Atomic pairs } \\
\mathrm{O}-\mathrm{O} \mathrm{O}-\mathrm{H} \mathrm{H}-\mathrm{H} \\
\mathrm{Fe}-\mathrm{Fe} \mathrm{Fe}-\mathrm{O} \mathrm{Fe}-\mathrm{H} \mathrm{Fe}-\mathrm{Cr} \mathrm{Fe}-\mathrm{Ni} \\
\mathrm{Cr}-\mathrm{Cr} \mathrm{Cr}-\mathrm{O} \mathrm{Cr}-\mathrm{H} \mathrm{Cr}-\mathrm{Ni} \\
\mathrm{Ni}-\mathrm{Ni} \mathrm{Ni}-\mathrm{ONi}-\mathrm{H}
\end{gathered}
$$

Diatomic bond energy, equilibrium distance, and charges etc.

Bulk model cohesive energy, charges, lattice constant, and mean square displacement. 


\section{Tight-binding QCMD}

Fe, Fe-Cr and Fe-Cr-Ni matrix water interaction at high temperature

-To study the solid state oxidation mechanism by considering hydrogen and oxygen diffusion in perfect crystal matrixes

Defect and strained matrix water interaction at high temperature

- To study the surface defect and strain effect on oxygen and hydrogen diffusivity into matrixes 


\section{Models}

The Fe, Fe-Cr and Fe-Cr-Ni (111) surface of face-centered cubic structure is used as slab model. The $\mathrm{Fe}, \mathrm{Fe}-\mathrm{Cr}$ and $\mathrm{Fe}-\mathrm{Cr}-\mathrm{Ni} / \mathrm{H}_{2} \mathrm{O}$ interface is modeled by the placement of monolayer six molecules of $\mathrm{H}_{2} \mathrm{O}$ on the (111) surfaces. Ensembles NVT.

(111)

Z

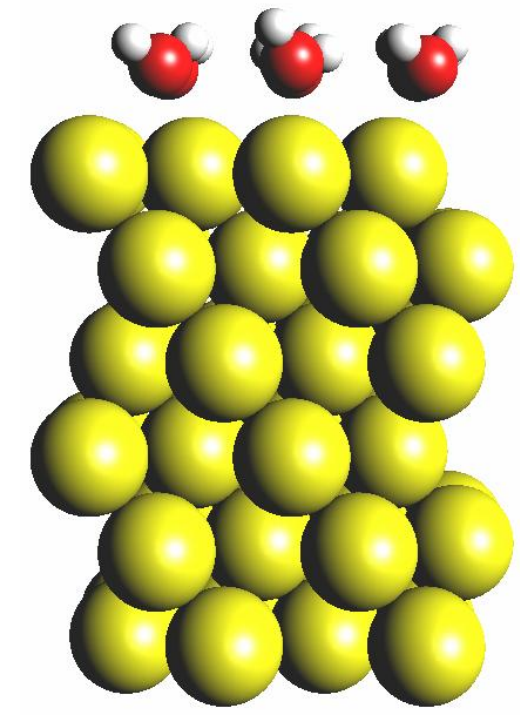

$\mathrm{Fe}$

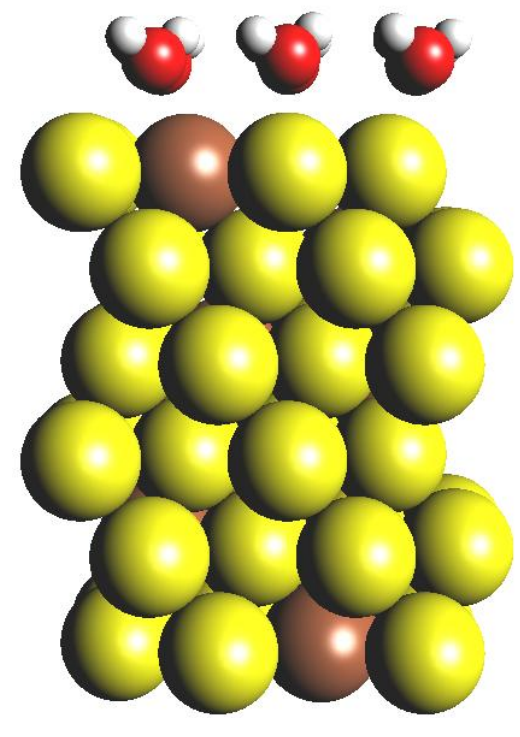

$\mathrm{Fe}-\mathrm{Cr}$

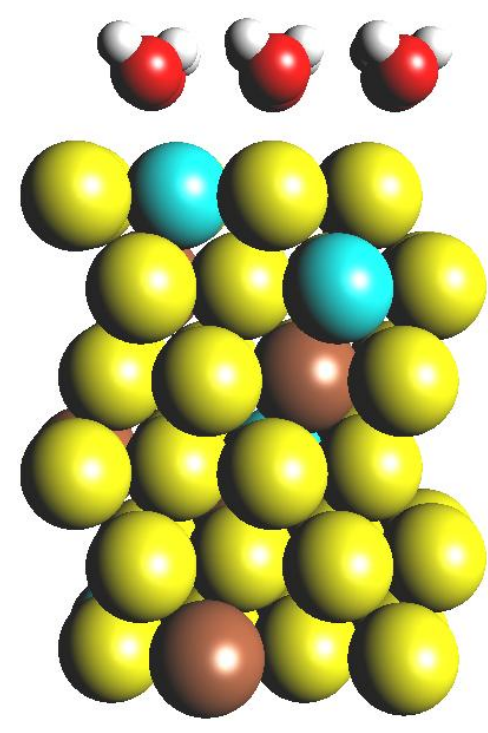

$\mathrm{Fe}-\mathrm{Cr}-\mathrm{Ni}$

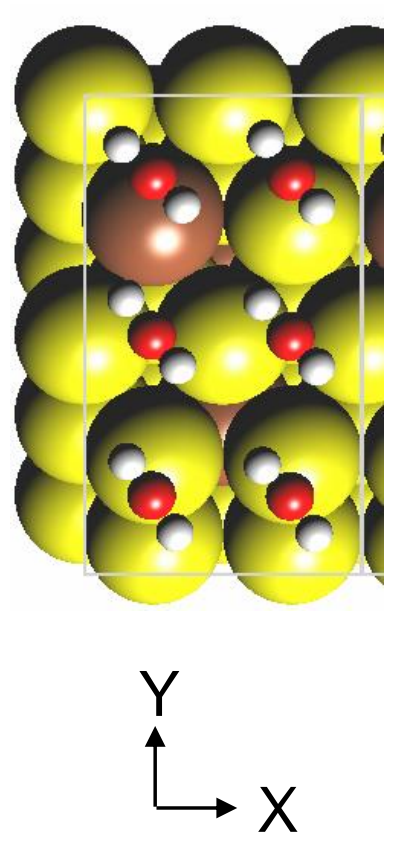




\section{Regular matrix morphologies}

Metal atom dissolution and passive film formation

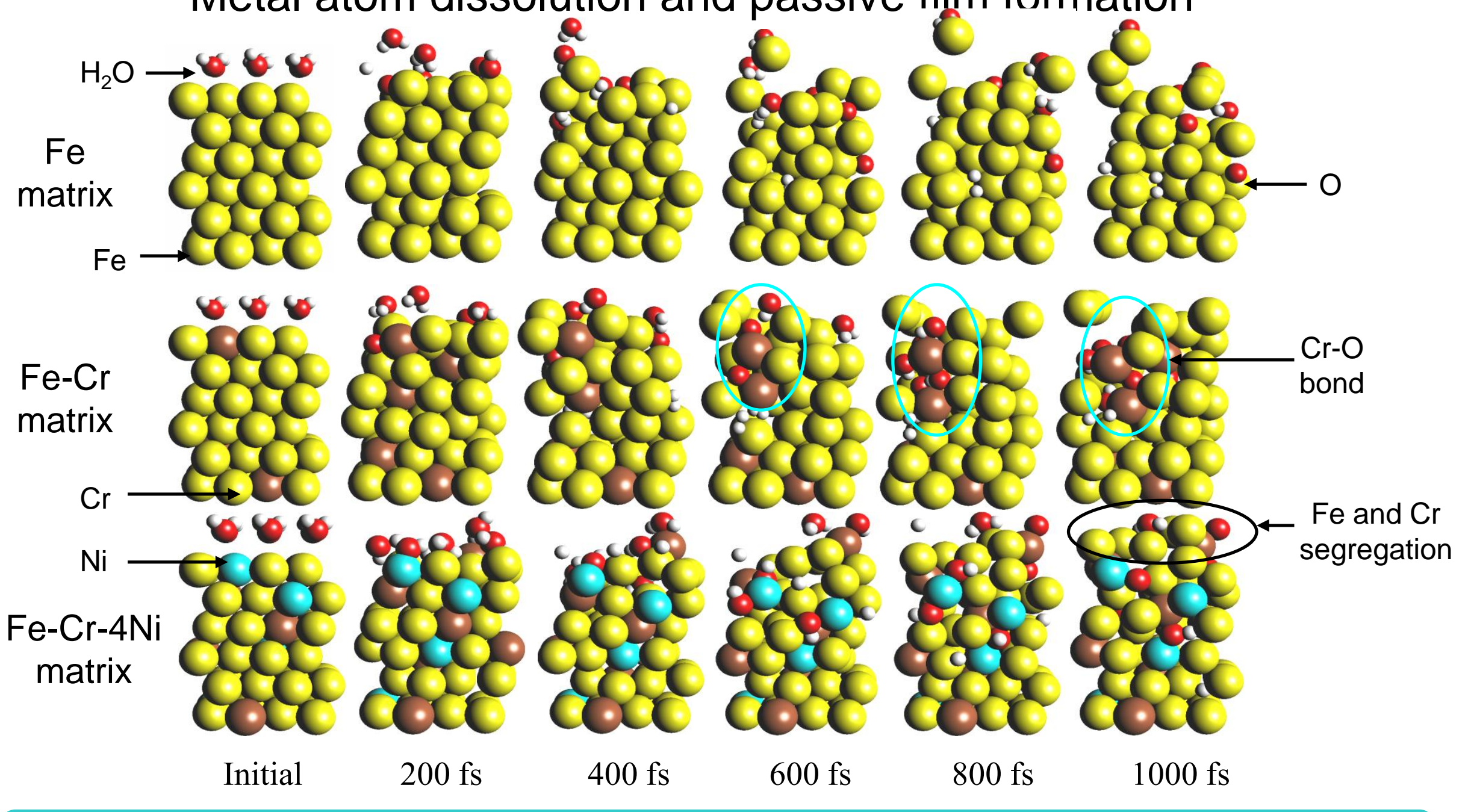

$\mathrm{Fe}$ and $\mathrm{Cr}$ are segregating from the surface and $\mathrm{Ni}$ is not moving upward. 


\section{Atomic charge change with diffusion}

Atomic charge change indicates the oxidation

Metal
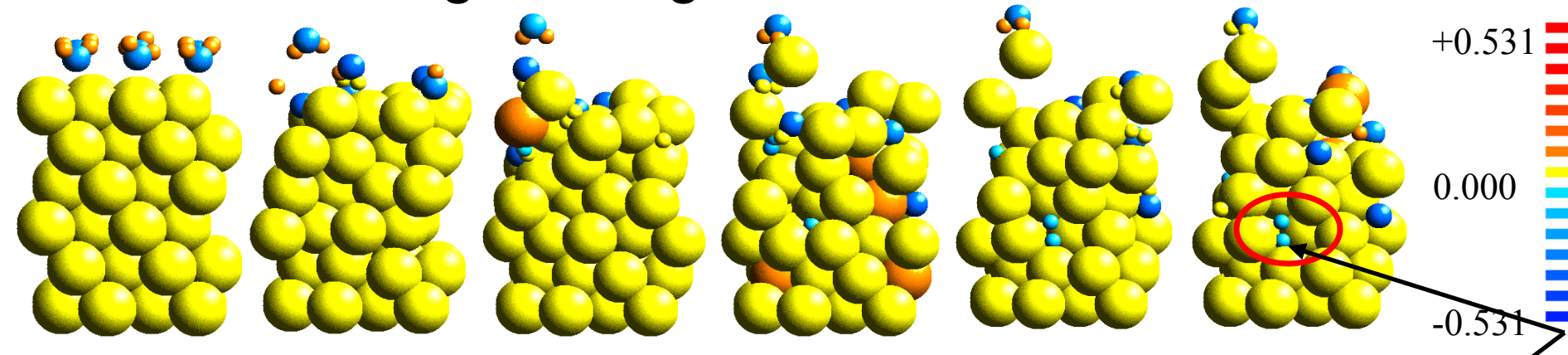

Negative $\mathrm{H}$

Metal

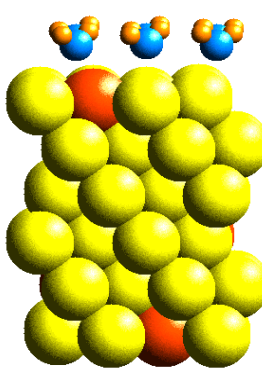

Initial

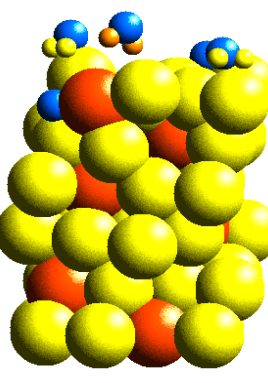

200 fs

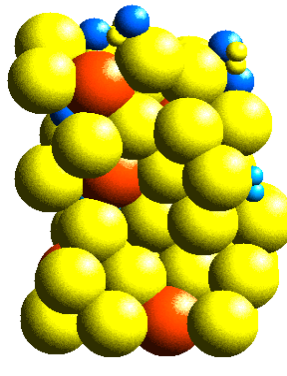

$400 \mathrm{fs}$

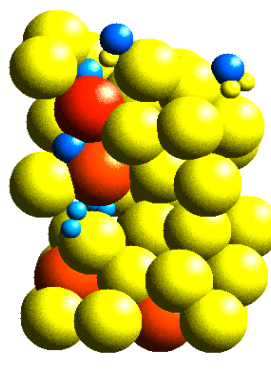

600 fs

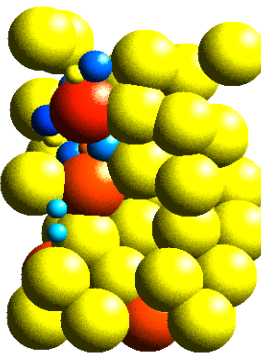

$800 \mathrm{fs}$

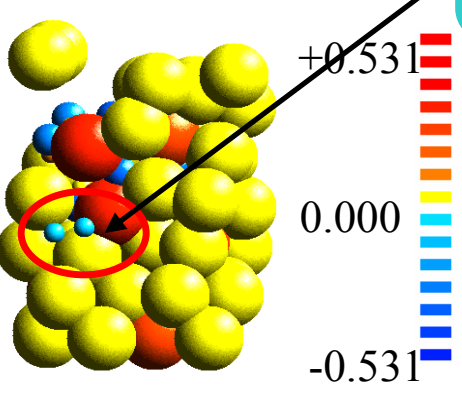

1000 fs

Early dissociated diffused $\mathrm{H}$ have negative charge into the matrixes.

Itsumi \& Ellis (1996) and H. Adachi \& S. Imoto (1979) study have shown the well consistency with the present study that electron transferred from metal to hydrogen. 


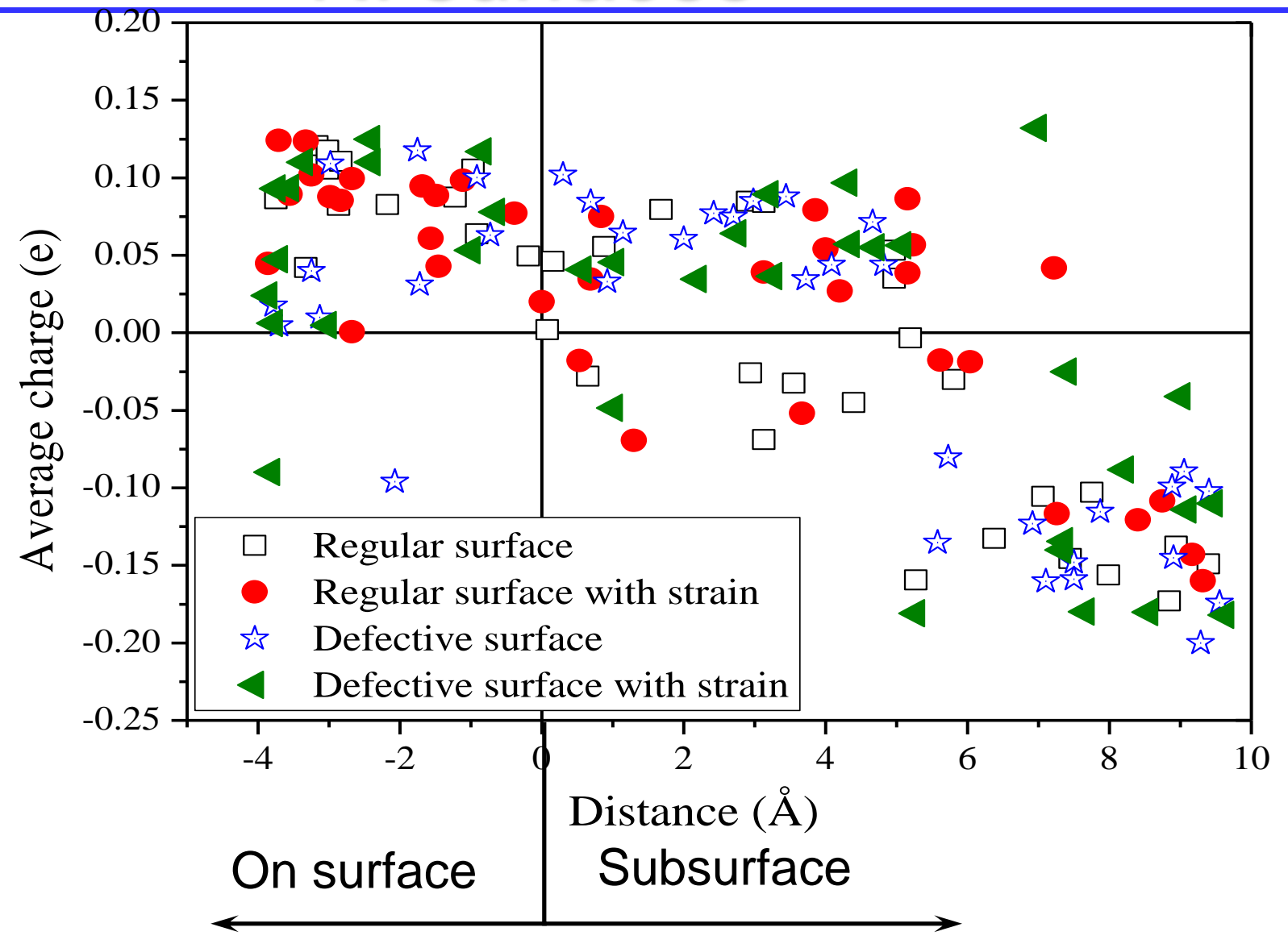

Deeply diffused hydrogen atom receives electron from metallic atom leads to weaken the bond strength in order to generate coulombic repulsion consequently the process initiates surface oxidation. 


\section{$\mathrm{H}$ atomic av. charges in Oxides}

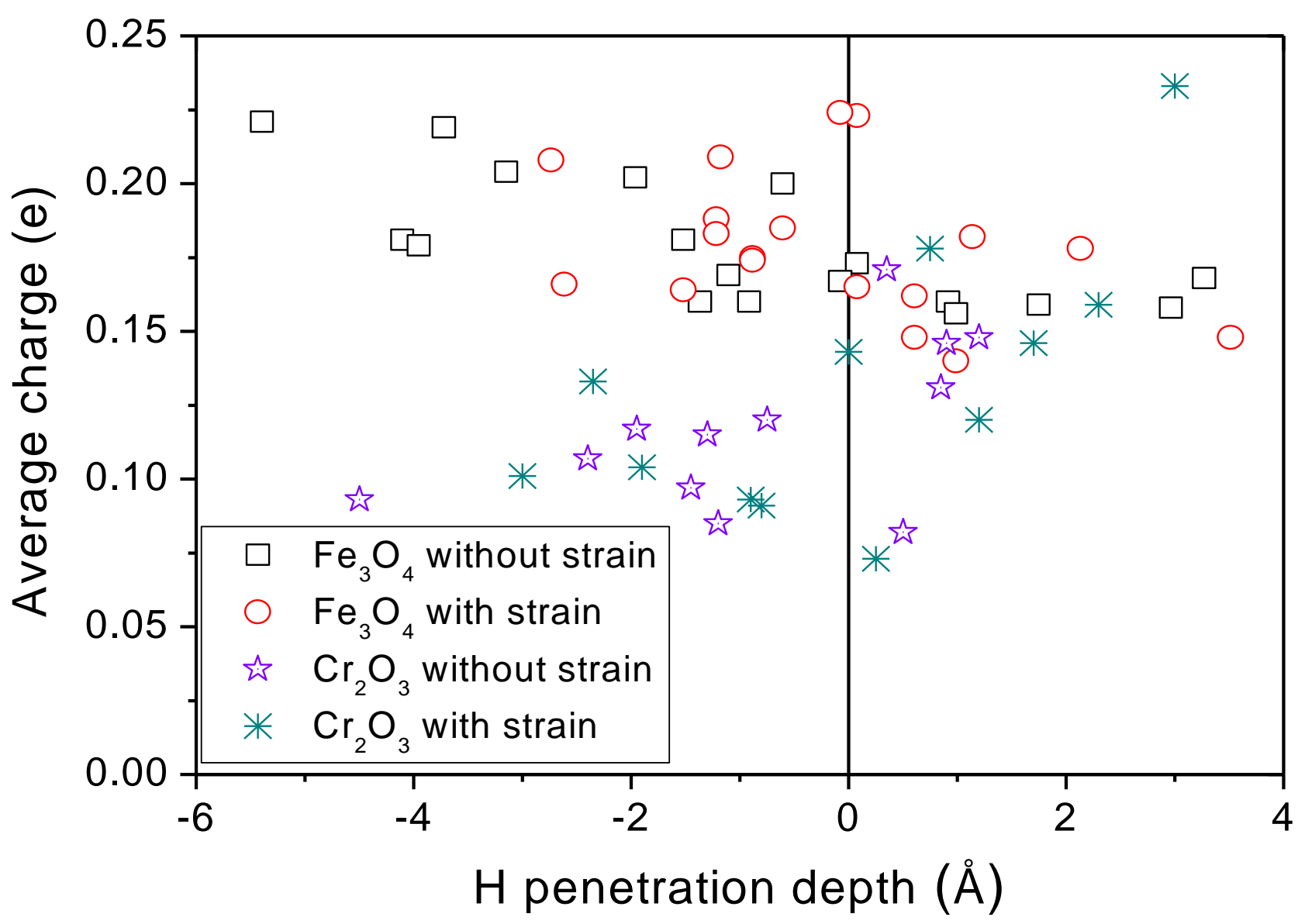

Hydrogen atoms remain positively charge in the oxide film whereas it shows negatively charged into the metal surfaces. 


\section{Discussion}

Hydrogen is a major reactants with solids as a result of its strong chemical activity, high mobility, and wide occurrence as $\mathrm{H}_{2}$. The consequences for Materials Science and Technology are widespread and growing.

There are three different models proposed for interstitial Hydrogen in metal (Fiks, Sov. Phys. Solid State, 1959). Which is:

'Protonic model' - Hydrogen is positively charged and it receives electron from metals. Well known.

'Anionic model' - Hydrogen is negatively charged and it receives electron from metal atoms.

'Hydrogenic model' - third model assumed that the metal and hydrogen atoms are covalently bonded.

For hydrogen in transition metals, XPS analysis demonstrated that hydrogen prefers to act as an electron acceptor rather than an electron accepter. 


\section{Discussion}

Fe-H system study have shown that the $0.20 \sim 0.30$ e charge transferred from iron atom to hydrogen.

(A. Juan et al., Surf. Sci., 1999; P Cremaschi et al., Surf. Sci., 1995; Y. Itsumi et al., J. Mater. Res., 1996, and H. Adachi et al., J. Phys. Soc. Japan, 1979).

QCMD study also have shown the similar results.

Several experimental studies have concluded as follows:

The high-temperature oxidation study of Fe-Cr alloy $\left(800-1100{ }^{\circ} \mathrm{C}\right)$ and Fe-Al alloy $\left(450-900{ }^{\circ} \mathrm{C}\right)$ have shown, "Hydrogen works as an

oxygen carrier".

(C. T. Fujii et al., J. Electrochem. Soc., 1964; W. E. Boggs, J. Electrochem. Soc., 1971).

The oxidation analysis of Stainless steel and Fe-Cr demonstrated, "the

oxidation rate is higher when hydrogen is present in the metal".

(D. Wallinder et al., J. Electrochem. Soc., 2002; E. Essuman et al., Oxid. Met., 2008).

'Hydrogen Anionic model' should necessary to consider for SCC initiation process. 


\section{initiation process}

Water dissociate on metal surface

$\mathrm{H}$ diffused faster than $\mathrm{O}$ into matrix

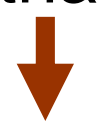

Deeply diffused $\mathrm{H}$ oxidize metal surface

by taking electron from metal atom

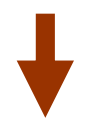

This process weaken metal atomic bond strength

Metal atom become positively charged

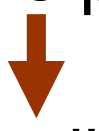

These may help to diffuse oxygen into

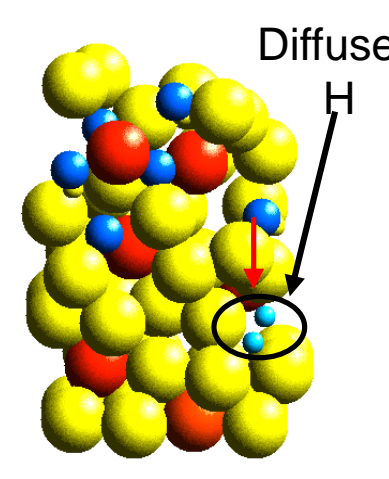

800 fs

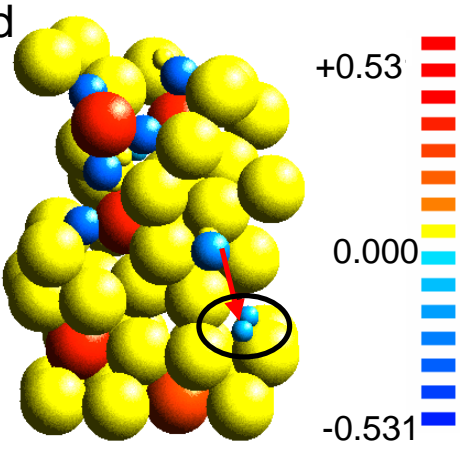

1000 fs

QCMD analysis metal

$\mathrm{H}$ can accelerate oxidation which may enhance the SCC initiation. 


\section{Conclusions}

Defect and strain enhance the diffusion of $\mathrm{H}$ and $\mathrm{O}$ into matrixes.

The initially dissociated $\mathrm{H}$ atoms interstitially trapped into matrix and receive electron from metallic atoms which weaken metal atomic bond strength.

Several experimental study recommend that ' $\mathrm{H}$ work as $\mathrm{O}$ carrier' or 'H in metal increased the O diffusivity' (1964, 1971, 2002 and 2008).

Diffused negative ' $\mathrm{H}$ ' atoms can enhance the oxidation process into metal.

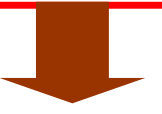

This process may accelerate early stage SCC initiation process. 


\section{Issue concern 3}

\section{A strange phenomenon was observed;}

\section{A gradual lattice contraction took place at high $p_{\mathrm{H}}, T \mathrm{~s}$}

First observation; Fukai, Okuma, 1992

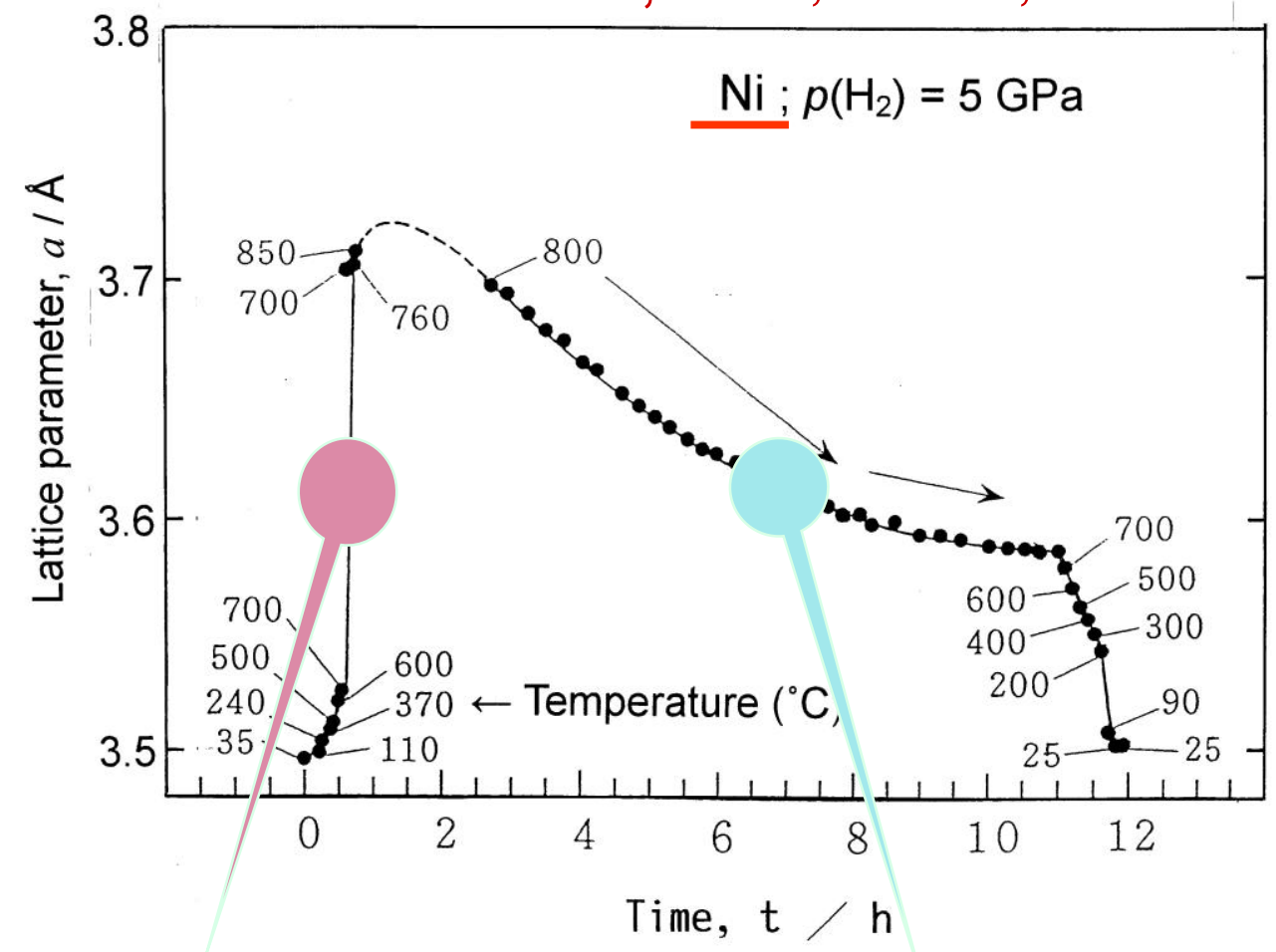

Remember:

Formation of vacancies results in

volume expansion \& lattice contraction.

Hydrogenation

Vacancy formation

Vacancy conc. may be estimated from the observed lattice contraction. 
Mechanism of SAV formation (by Fukai, Quantitative Micro-Nano Approach to Predicting SCC of Fe-Cr-Ni Alloys, June 13 - 18, 2010, Sun Valley, Idaho, USA)

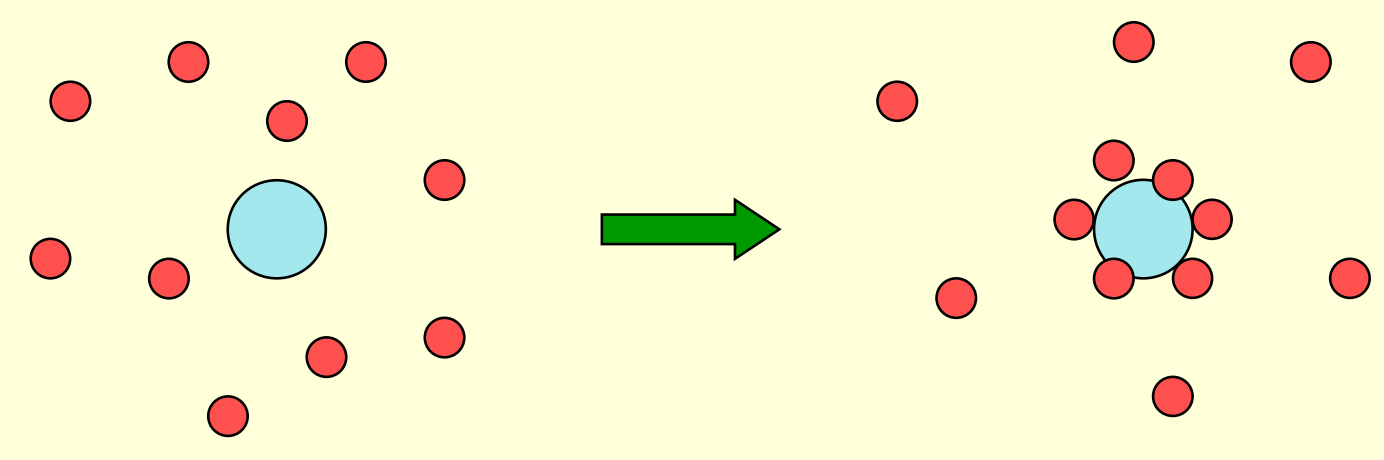

Formation energy of a vacancy is lowered by trapping $\mathrm{H}$ atoms.

$$
\begin{aligned}
\mathrm{Vac}+r \mathrm{H} & \rightarrow \mathrm{VacH}_{r} \\
e_{\mathrm{f}}^{\mathrm{v}}+r e_{\mathrm{s}} & \rightarrow\left(e_{\mathrm{f}}^{\mathrm{v}}-r e_{\mathrm{b}}\right)+r e_{\mathrm{s}} \quad(r \leq 6)
\end{aligned}
$$

Form. en. of a vacancy Heat of solution $e_{f}^{c l}$ : Form. energy of a Vac-H cluster

\begin{tabular}{cccc} 
& $e_{\mathrm{f}}^{\mathrm{V}}$ & $e_{\mathrm{b}}$ & $e_{\mathrm{f}}^{\mathrm{cl}}(\mathrm{eV})$ \\
\hline $\mathrm{Ni}$ & 1.78 & 0.28 & 0.10 \\
$\mathrm{Pd}$ & 1.70 & 0.15 & 0.80 \\
$\mathrm{Nb}$ & 3.0 & 0.45 & 0.30 \\
\hline
\end{tabular}

Big reduction of $e_{f}$ !

Reduction of the formation energy results in enhancements of thermal-equilibrium concs. of vacancies. 


\section{$\mathrm{H}$-induced enhancement of $\mathrm{M}$-atom diffusion}

$\because: \because$

Diffusion of $\mathrm{M}$ atoms proceeds via vacancy mechanism.

In the presence of $\mathrm{H}$, however, diffusion of $\mathrm{M}$ atoms should be mediated by Vac-H clusters.

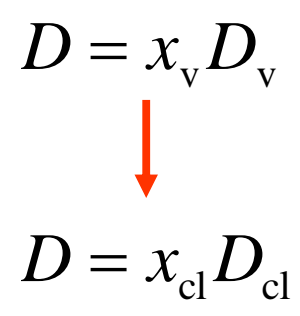

$D_{\mathrm{cl}}$ : slightly smaller than $D_{\mathrm{v}}$

$x_{\mathrm{cl}}$ : much larger than $x_{\mathrm{v}}$

Drastic enhancement of $D$ is expected.

Enhancements have indeed been observed for interdiffusion in $\mathrm{Pd}-\mathrm{Rh}, \mathrm{Cu}-\mathrm{Ni}, \mathrm{Au}-\mathrm{Fe}$, and self diffusion in $\mathrm{Nb}$. 


\section{Summary of Superabundant Vacancy by Fukai}

1. A vacancy can trap a multiple number of interstitial $\mathrm{H}$ atoms, to form a Vac-H cluster $\mathrm{VacH}_{r}(r \leq 6)$.

2. The formation energy of a vacancy is lowered by trapping $\mathrm{H}$ atoms. Thus, the equilibrium concentration of Vac-H clusters becomes much higher than that of vacancies in pure metals.

3. The formation of $\mathrm{H}$-induced superabundant vacancies (SAVs) leads to enhancements of M-atom diffusion.

4. These SAVs may be an important source of voids observed in the stress-concentrated region in the $\mathrm{HE}$ and SCC of steels. 


\section{H-Vacancy Interaction energy}

$7 \mathrm{H} \quad 8 \mathrm{H}$

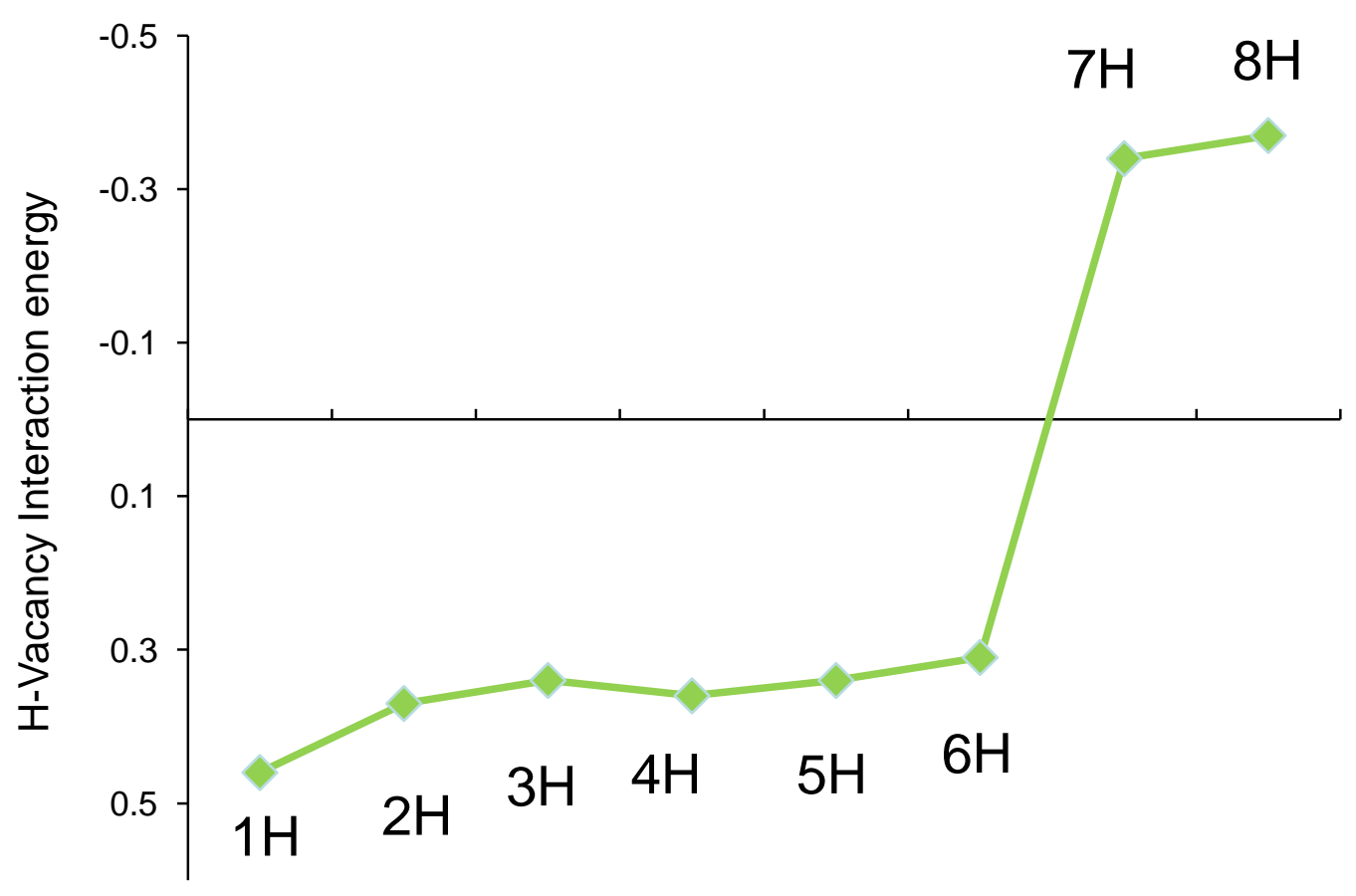

The calculated energy shows that a single nickel vacancy can trap six hydrogen atoms.

$\mathrm{H}_{2}$ bubble did not formed at the vacancy center. 


\section{Effects of Hydrogen in metal on oxidation of 316 L SS in HT water at $288 \mathrm{C}$ for 887 hours}

Without Hydrogen charging

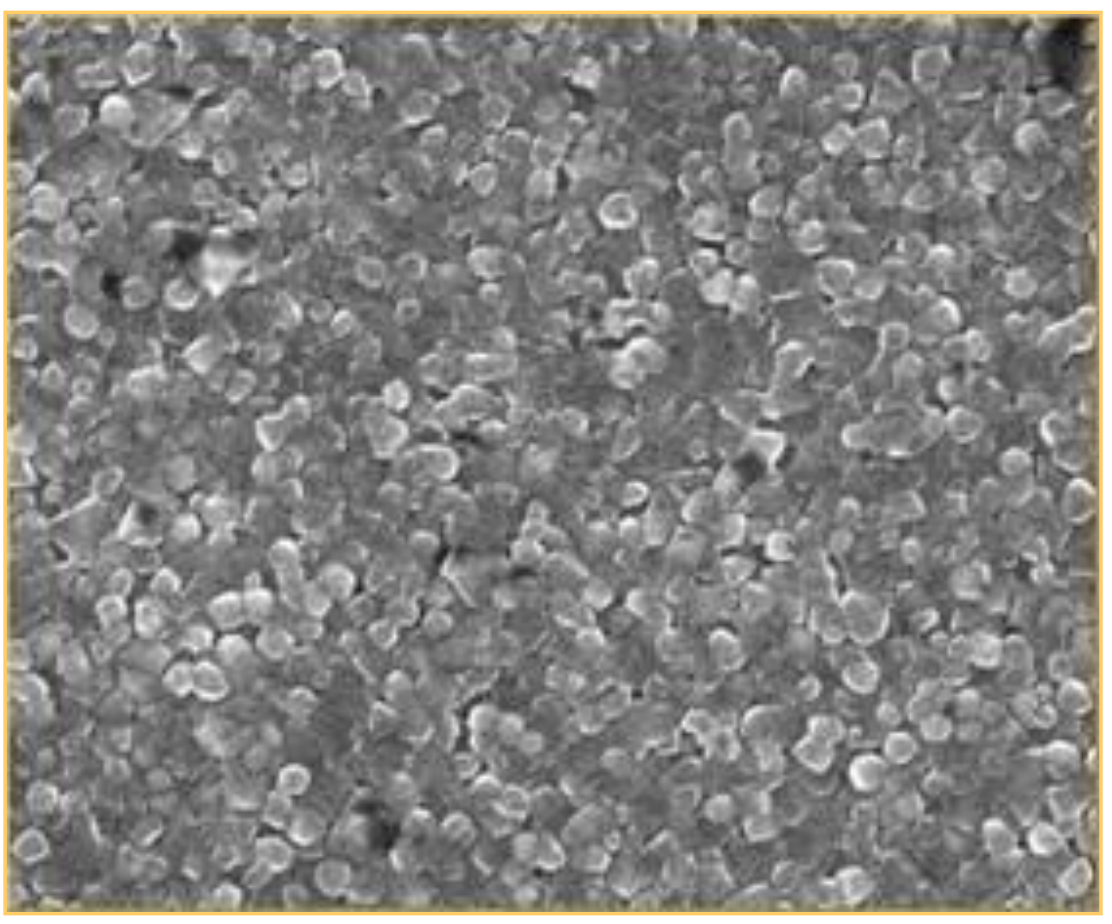

With Hydrogen charging(35 mass ppm)

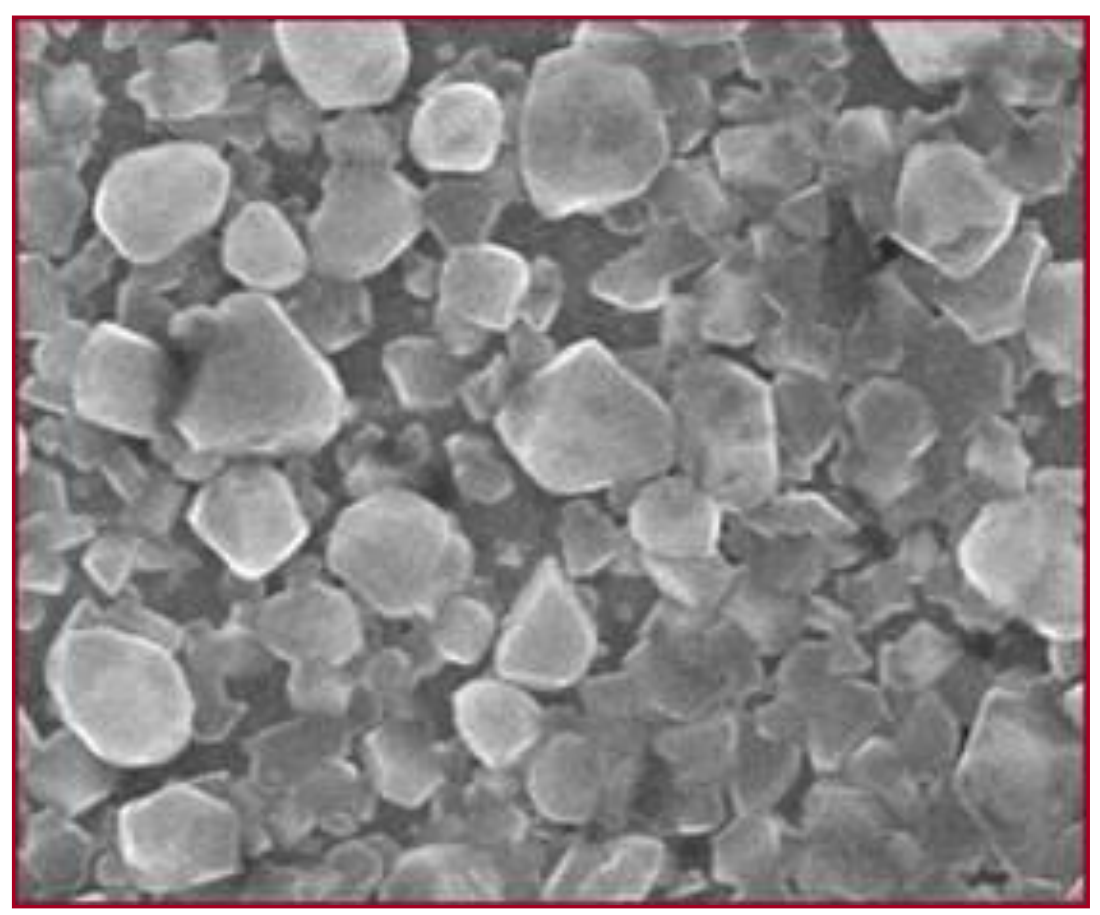

Also concerns to DH effects in PWR 


\section{Effect of hydrogen on oxidation of $316 \mathrm{NG}$ stainless steel}

Experimental conditions

口Materials: $316 \mathrm{NG}$

口Corrosion Condition

$\square 290{ }^{\circ} \mathrm{C}$ water with dissolved hydrogen (DH) of

$30 \mathrm{cc} / \mathrm{kg} \mathrm{H} \mathrm{H}_{2} \mathrm{O}$

口Tube specimens with \& without internally pressurized

hydrogen

口Measurements

口Oxidation and hydrogen distribution analyzed by glowdischarged

口Glow Discharge Optical Emission Spectroscopy (GDOES)

June Kameda et al., Unpublished work 


\section{Experimental setup}

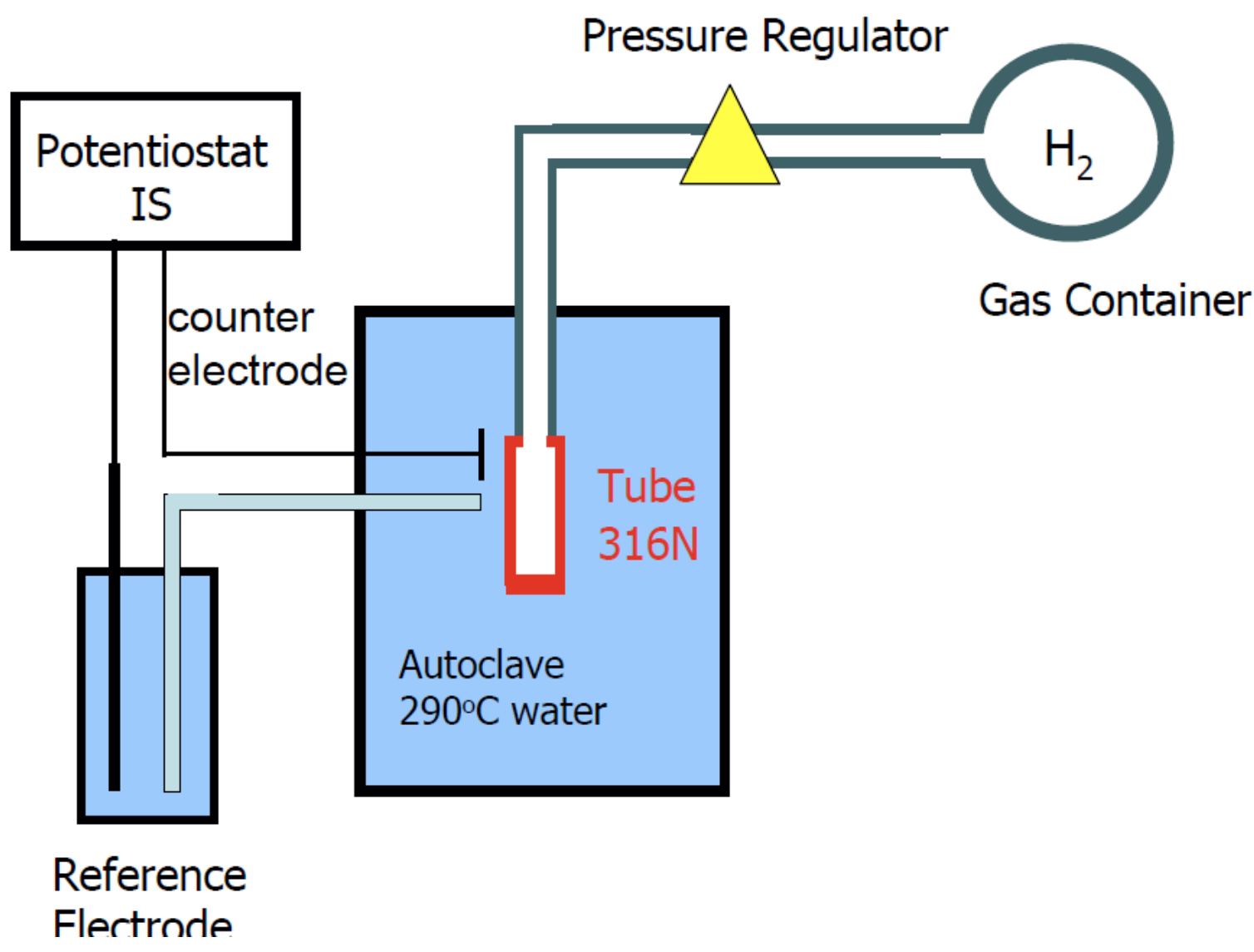

-Testing condition

- Dissolved $\mathrm{H}$ in water; $30 \mathrm{cc} / \mathrm{kg}$ (3.74 atm)

Two tube samples exposed under the same water condition

- Internal H: $4.2 \mathrm{~atm}$

- Vacuum: <-1 atm 


\section{Oxide film analysis by GD-OES}
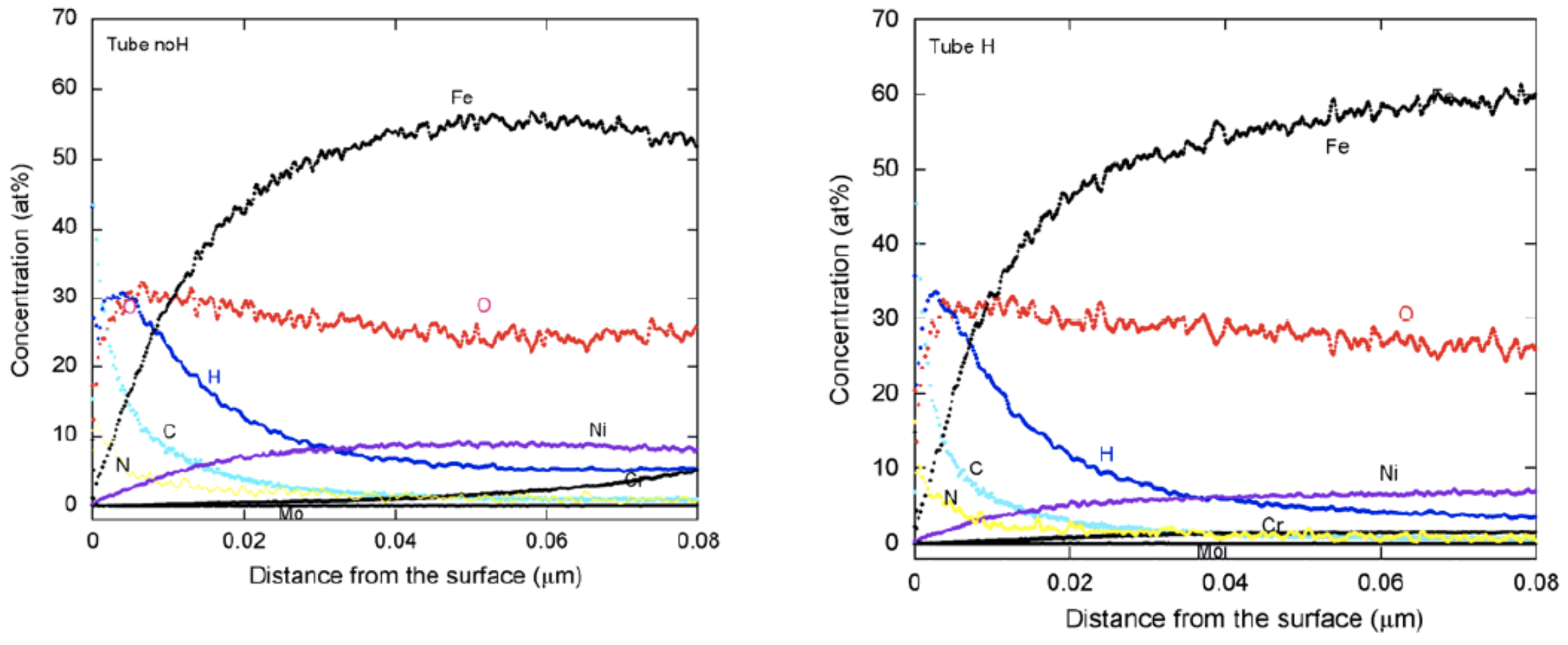

- No difference in elemental concentration in outermost layer of the oxide 


\section{Elemental distribution near oxide / metal interface}
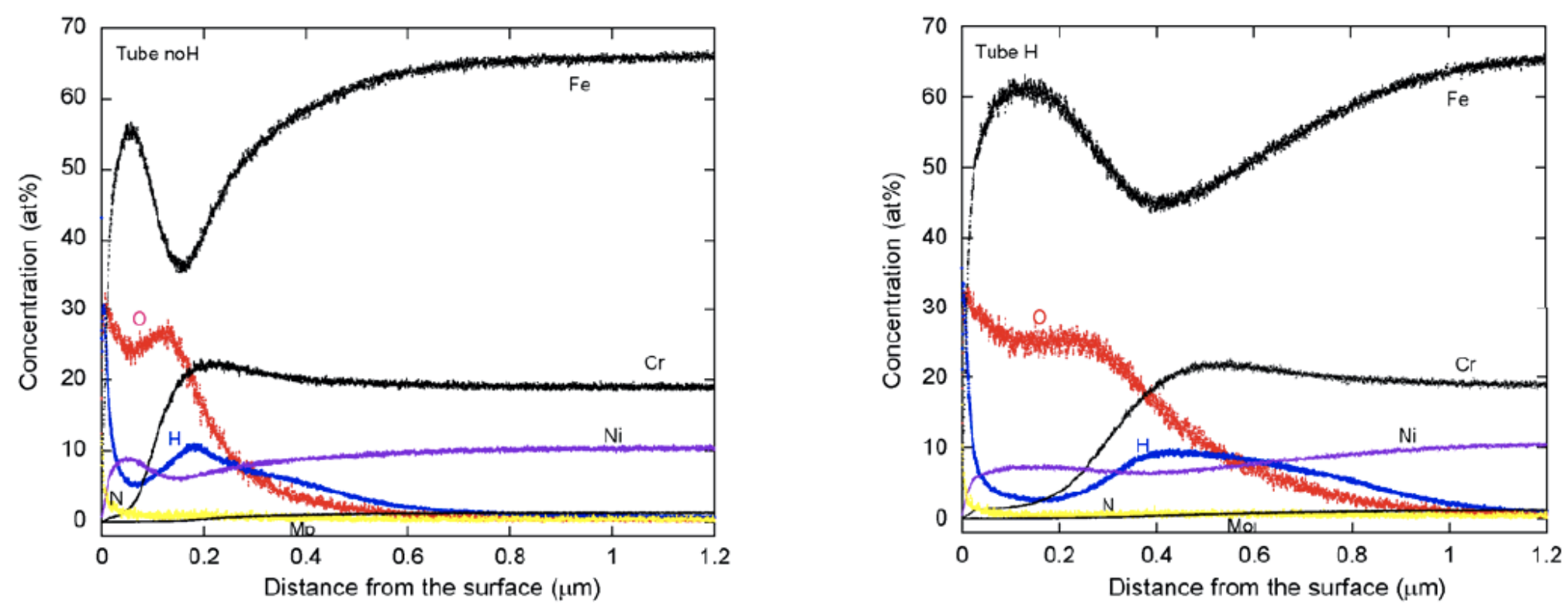

- The GDOES analysis has shown the deeper oxidation behavior under the internally pressurized hydrogen associated with more extensively hydrogenated zone. 


\section{Possible impact of hydrogen in metals}

- Hydrogen embrittlement

- Hydrogen enhanced oxidation and SCC

- Acceleration of microstructure evolution

- Abnormal microstructure evolution

- Enhanced plasticity

- Enhanced creep

- Irradiation microstructure

- Cavity formation

- Etc

\section{To be proactive!!}




\section{Content}

- Introduction and background

- Technical Evaluation of Aging Management

- Degradation, Materials, Systems, PDCA

- Proactive Materials Aging Degradation Management

- Annual Experts' Panel Meeting

- Proactive Issues raised and summarized by the Experts'

Panel

- Proactive Issues raised by FRI from the outcomes of NISA, NRA projects

- Fukushima Daiichi Accident

- Sequence, Actions taken or being taken for future and lesson learn

- Long-and Mid term road map for decommissioning

- Summary 


\section{Sequence, Actions taken or being taken for future and lessons learned}

\section{From}

the presentation by Shun-ichi Suzuki at NISA aging management program, PMDM Experts' meeting at Mt. Zao, October 2011 


\section{Tsunami Height @1F v.s. 2F}

- The new design basis Tsunami height for $1 \mathrm{~F} \& 2 \mathrm{~F}$ were evaluated based on the JSCE Tsunami assessment methodology. (1F: O.P.+5.7m, 2 F: O.P.+5.2m)

- The countermeasures were implemented at both NPSs, such as pump motor elevation raised @1F and openings sealed @2F, that were all equivalent from the viewpoint of resistance against Tsunami hazard.

- The $15 \mathrm{~m}$ class Tsunami caused by M9.0 class earthquake that accidentally attacked $1 \mathrm{~F}$ was far beyond design basis and whatever evaluation and whatever countermeasures did not matter at this time.

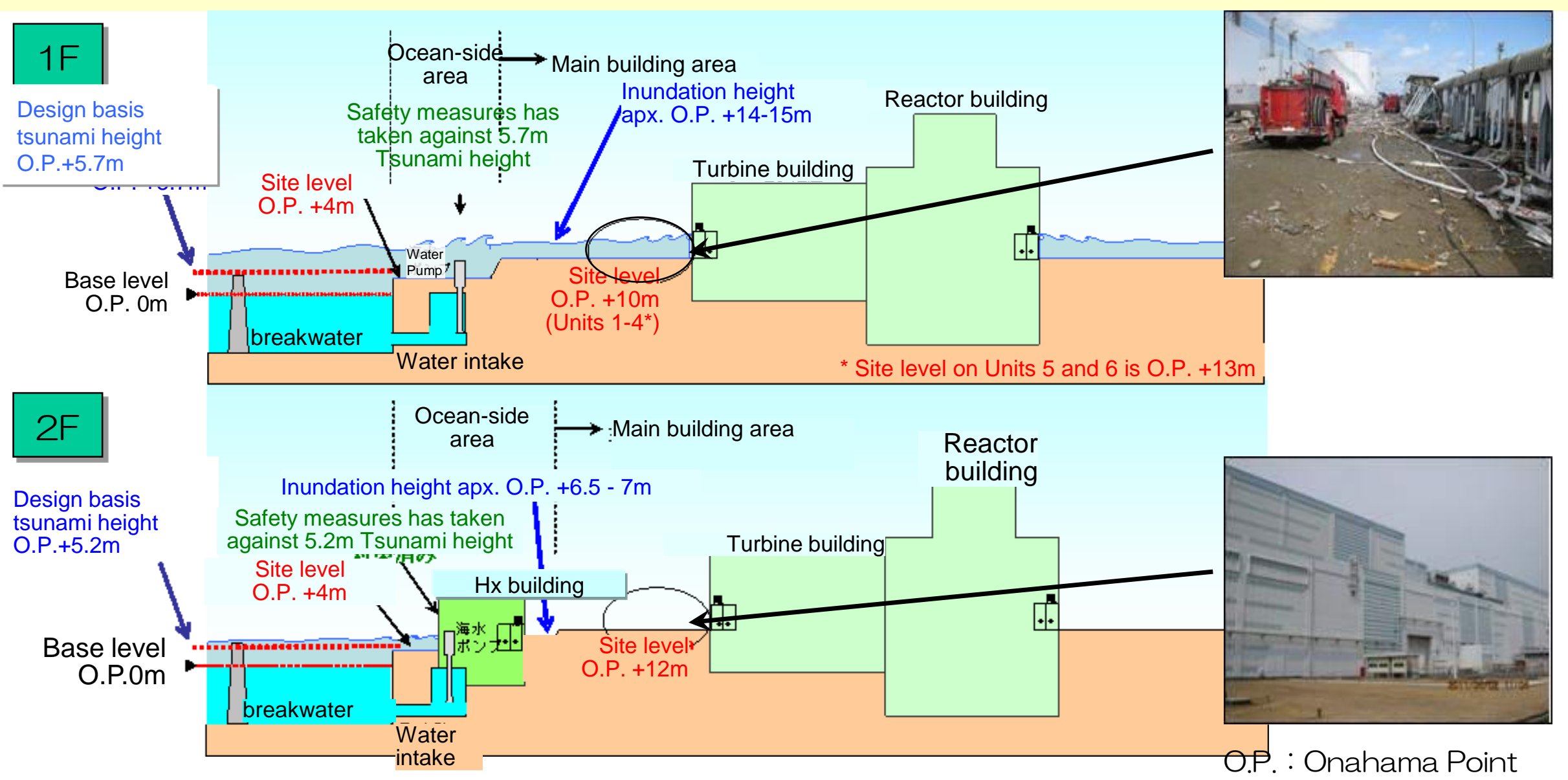




\section{Differences in Tsunami that hit Fukushima Daiichi and Daini NPSs}

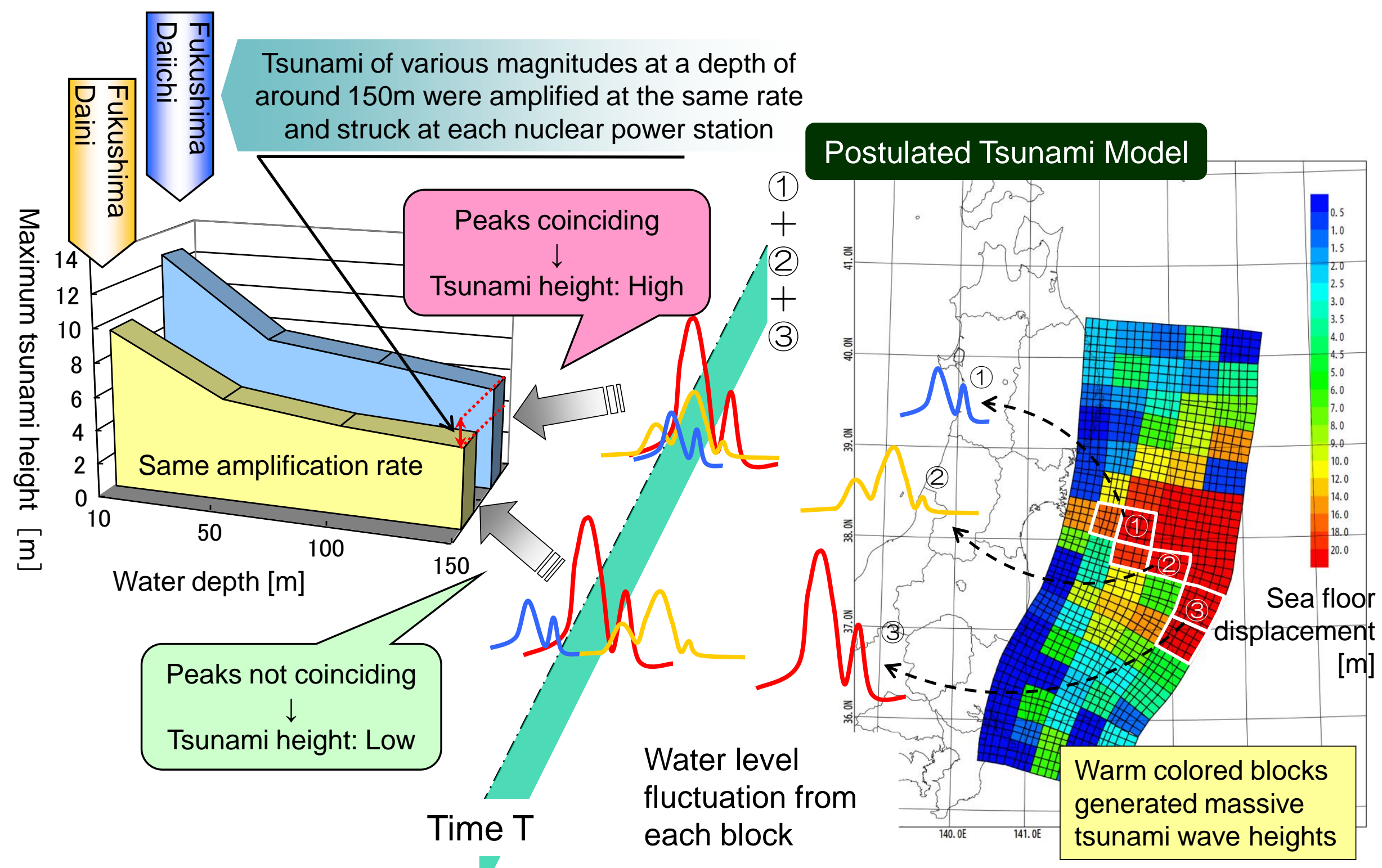




\section{Summary of Lessons Learned}

TEPCO delivers the message as follows, "If we express the lessons learned from our accident in one sentence"

"Carefully consider the robustness of current design of nuclear power plants and emergency preparedness against beyond design basis events that could lead to common cause failures regardless of their assumed probability demonstrating a continuous learning organization." 


\section{Lesson 1: Design Consideration}

The accident at Fukushima Daiichi and Daini was caused by Tsunami far beyond the design basis. (No significant damage by earthquake)

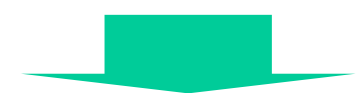

The current design of external barriers were not enough to cope with hydrodynamic forces of flooding and large debris impact.

- The current design of safety-related electric and I\&C equipment might not be robust enough to prevent common cause failure by severe external flooding and their layout, diversity and internal barriers for separation need to be reviewed.

$\star$ Other design features to be considered:

- Hydrogen detonation/deflagration outside of PCV

- Operability of venting system

- Accident instrumentation

- Internal barriers for separation of important equipments, such as RCIC, DDFP, MUWC, FPC, M/C, P/C, battery etc. 


\section{Lesson 2: Procedures and equipments to be prepared}

Several implementable countermeasures/modifications that could have lessened the damage at the unforeseeable accident have been identified.

- Mobile power vehicles could be considered as redundant measures against extended SBO situation from the defense in depth viewpoint.

- Emergency water injection and cooling capability, against extended SBO situation, such as fire engines, air cylinders and batteries, should be considered.

- Better preplanning, staging and logistics of emergency and spare equipment would make a quicker recovery possible.

- Greater consideration should be given to redundant communication measures for organized actions.

$\star$ Procedures not robust enough against beyond design basis events:

- EOP - SAMG - EDMG (not thoroughly prepared yet in Japan)

- internal events - external events 


\section{Lesson 3: Emergency Preparedness}

Without newly built Emergency Response Center, the post-accident activities could not have been carried out.
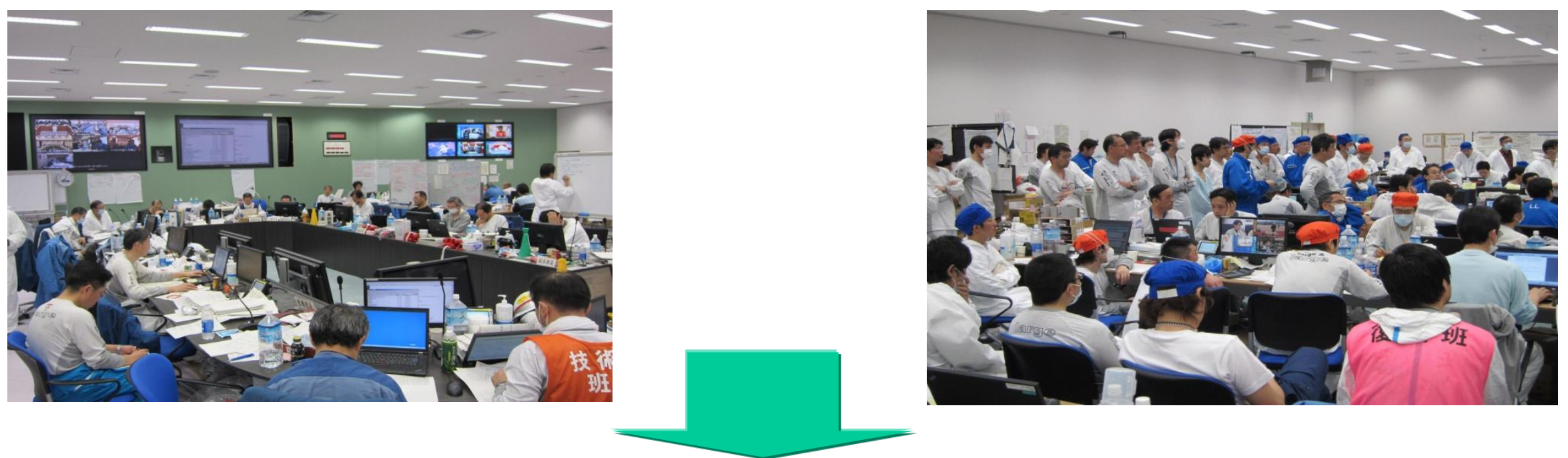

Measures taken after Niigata Chuetsu Oki Earthquake were effective:

- Emergency response center in robust building (Seismic isolation, Shielding, Communication, etc.)

- Underground water tank (16 units/site $\times 40$ m3/site) and Fire Engines (3/site)

- Emergency Response Drills 


\section{Long-and Mid term road map for decommissioning}

From

Government - TEPCO Mid-and-long Term Response Council As of October 22, 2012 
1. "Cold Shutdown Condition" is maintained at Unit 1-3. Measures to complement status monitoring are being implemented.

- The RPV bottom temperature and the PCV gaseous phase temperatures at Units 1-3 were approx $30-50^{\circ} \mathrm{C}$ (35 of October 19) and futlll the requirement (100'C or less).

- The steam generation in the PCV is suppressed by controlling the water injection amounts, which contributes to sumclently low levels of ceslum released from Unit 1-3 Reactor Buldings.

- Adequate backup equipment is secured. (Water injection pumps: 3 systems: water sources: 2 ,

power supply secured by multiple generating lines, fire engines etc.)

Even If multiple simultaneous falures of water injection equipment should occur, water injection can be restarted within about 3 hours.

[Overview of the circulating injection cooling system for cooling the reactor]

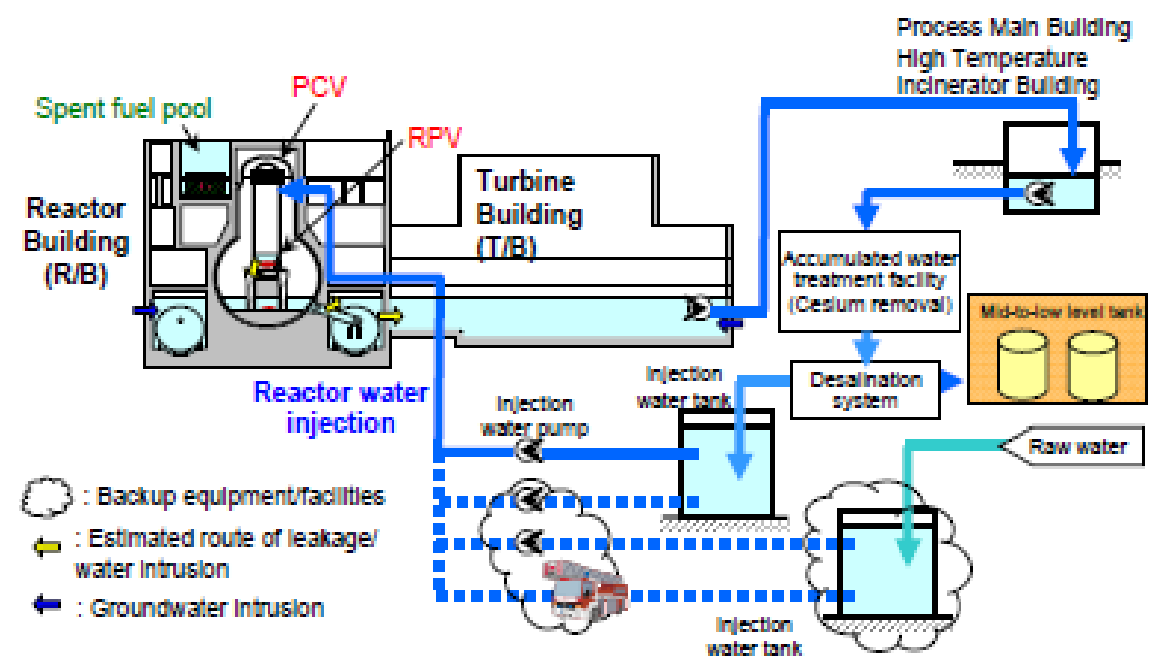

\section{7 important tasks}

Investigation of the inside of Unit 1 PCV and installation of PCV thermometer and water gauge

- The inside of Unit 1 PCV was Investlgated with a camera, and the radlation dose and water level were measured (October 9-13).

- The maximum radlation dose was approx. $11.15 \mathrm{~s} / \mathrm{h}$ and the water level was approx. $+2.8 \mathrm{~m}$ from the bottom of the PCV.

- A thermometer and water gauge will be installed. The thermometer will be monitored for a month to determine whether or not it can be used for monitoring the cooling condilion of the PCV.

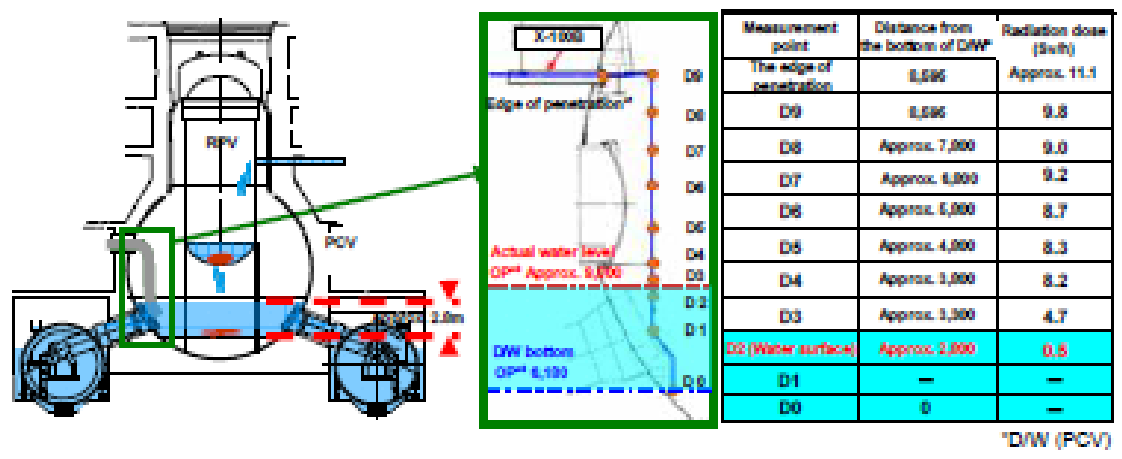

Installation of Unit 2 RPV alternative thermometer

- An altemative thermometer has been Installed to replace the broken thermometer in addition to the exsting monitoring thermometer ( $\mathrm{TE}-2-3-69 \mathrm{H} 3)$ (October 3 )

- The newly Installed thermometer is confirmed to be functioning property as the temperature

Indlcated by the new thermometer is about the same as that of the existing monitoring thermometer (TE-2-3-69H3) (approx. $43-46^{\circ} \mathrm{C}$ ).

- The temperature behavior of the thermometer will be monitored for a month to determine whether or not it can be used as a monitoring themometer.

- In the case that this thermometer is broken, it can be removed for repair or replacement.

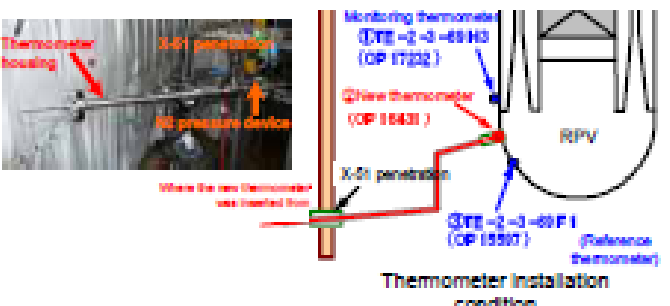

Themometer inats:

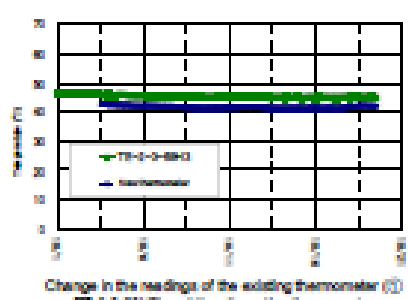

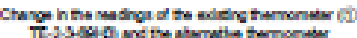


The highly radloactive water accumulated in the bulding basement is treated to be used for reactor cooling. The contaminated water generated in this process treated and stored. a. Prevent groundwater flow into the bulling $\rightarrow$ Develop a groundwater bypass

b. Remove the radloactive materials in the contaminated water $\rightarrow$ Install mult-nuclide remova) equipment

c. Storage of contaminated water/treated water $\rightarrow$ Bulld addilional storage tanks in the power station site.

\section{[Accumulated water treatment]}

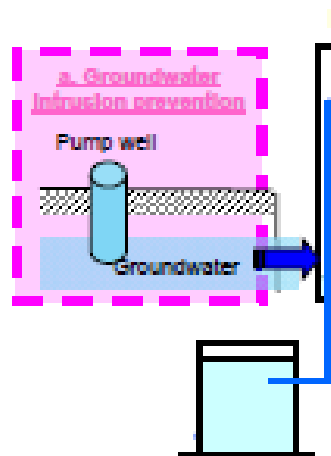

Reactor Bullding
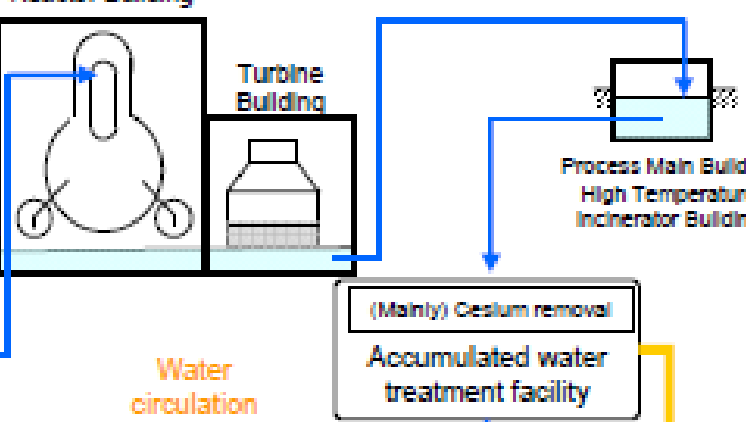

Process Main Eulding High Temperahure incinerator Bulding

Injection
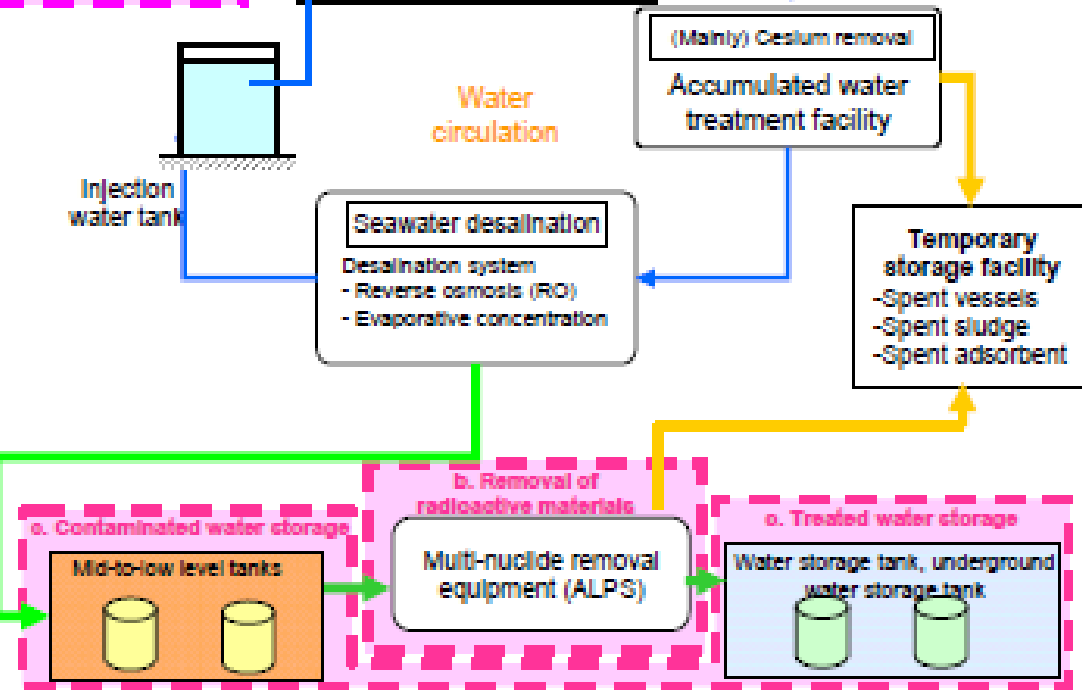

\section{Groundwater intrusion prevention (Groundwater bypass)}

- The groundwater towing from the mountain side is pumped up in the upstream side of the bulding at the pump well in order to prevent it from fowing into the bulloing (Groundwater bypass).

- Measurement is in progress for the pump well Installation which is planned to start in November. After a verification testing using the pllot pump wel, the pump well will be in operation.

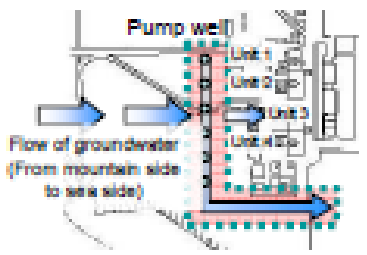

Top view

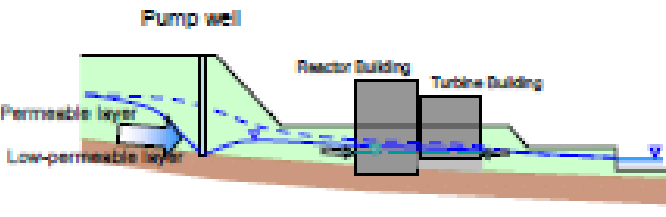

SIde vlew
Removal of radioactive materials (Multi-nuclide removal equipment installation)

- Multi-nuclide removal equipment was installed to further reduce the densitles of the radloactive materials Included in the accumulated water in the power station site.

- Equipment Installation, leakage test using non-radloactive water and a system test have been completed (August 24 - October 1 ).

- After implementing additional measures to ensure further safety (installation of ralnwater protection cover, system separation dam, etc.), leakage test using radloactive water will be performed before the equipment starts operation.

\section{Storage of contaminated water/treated water (Additional tanks)}

- A tank operation plan was developed for enabiling the storage of treated water, etc. The total capacity of existing storage tanks is approx. $241,00 \mathrm{Cm}^{3}$, and approx. $26,000 \mathrm{~m}^{3}$ Is avallable for use (as of October 16).

- Additional tanks are currently being bult, and the total capacity will increase to approx. $320,000 \mathrm{~m}^{3}$ by the end of this November.

- Capacity of approx. $80,000 \mathrm{~m}^{3}$ will be added by the end of the first half of FY2013, and approx. $300,000 \mathrm{~m}^{3}$ is planned to be added within the next 3 years (the estimated maximum capacity:

$\left.700,000 \mathrm{~m}^{2}\right)$.

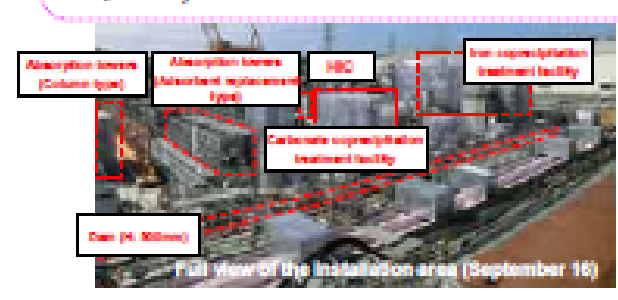

Multi-nuclide removal equipment instalaton

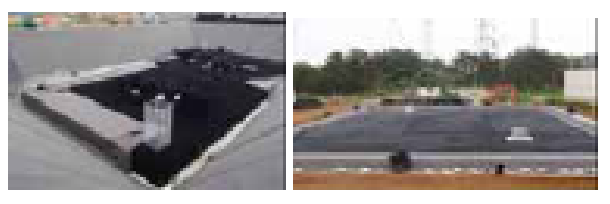

Underground water storage tank instalation 
3. Continue implementation of measures to minimize the impact of radiation on the

area outside the power station

- The maximum total release rate of ceslum (Units 1-3) is approx. 0.01 billon Bqh with fuctuation factors taken Into account, which is about $1 / 80,000,000$ of that of right after the accident. The release rate has been below this value since February.

- The radiation exposure dose at slte boundarles is 0.03 mSviyear (excluding the effects of the radloactive materials so far released), which is about 1/100 of the annual natural radiation exposure (world average: approx. 2.4mSwyear)

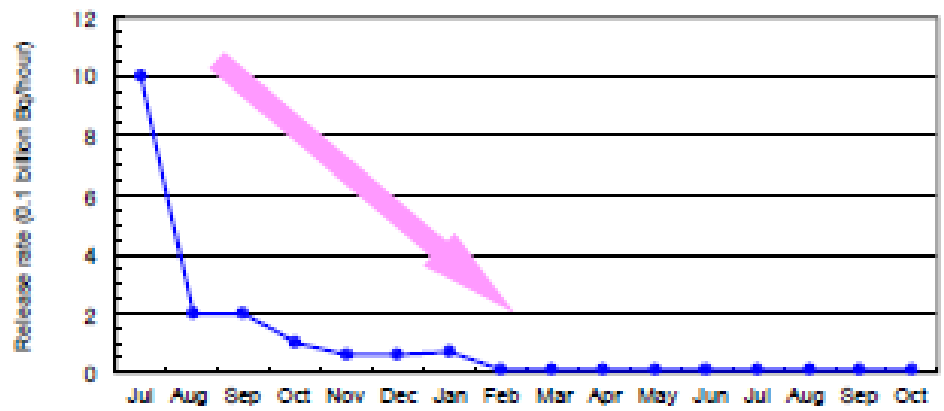

[Release rate of radioactive material (cesium) at Units 1-3 Reactor Buildings per hour]

- The debrls, etc. gathered during restoration work is stored in the temporary storage area atter being sorted by radlation dose rate and composition (trimmed trees are separated Into trunk and

branches/leaves). (Concrete/metal: $54,000 \mathrm{~m}^{3}$, trimmed trees: $68,000 \mathrm{~m}^{3}$ (as of September 28))

- A temporary storage faclity shieided by soll and sandbags was bullt to reduce radlation doses at site boundarles. We plan to move the more highly contaminated debris currently stored near the site boundarles further away from the site boundarles.

\section{Measures to reduce radiation dose at site boundaries}

Debris and trimmed trees

- Highly contaminated debris stored near the slte boundarles will be moved further away fom the boundarles.

- Highly contaminated debris wil be stored In the temporary storage faclity covered with soll.

- The trimmed trees which may affect the radiation dose at the site boundarles wil be covered with soll for radiation dose reduction.

Tanks and equipment

- Equipment layout to mitigate the radlation dose at the slite boundarles - Additional shlelding

Mitigation of radioactive materials emission

- Covering up buldings

- Protection cover Instalation on the openings of bulldings

\section{Effective radiation dose reduction at the site boundaries}

- The most recent radloactlve materials emission and radioactlve waste storage condition were evaluated in September to achleve the target effective radlation dose (1mSw/year or less) at the site boundarles. As a resuit, It was found that the maximum radlaton dose was approx.

$.7 \mathrm{mSv}$ year at the site boundary in the north area. Installation of a sol-covered-type temporan storage facility is under consideration considering that its impact will be signifcant (aporox.

9.6mSviyear)

- Preparation for 2 facilltes has been completed and debris transfer was started (September 5 ).

- The target radlation dose ( $1 \mathrm{mSw} / \mathrm{year}$ or less) will be achleved for the year starting from the end of March, 2013 by Implementing further radiation dose reduction measures (covering the debris and trimmed trees with sol, shlelding the mult-nuclide removal equipment, moving the storage faclittes further away from the slite boundarles, etc.) currently belng planned.

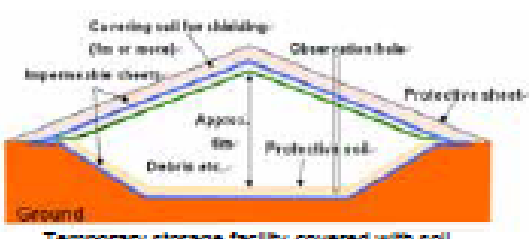

Temporary storage facility covered wth soll

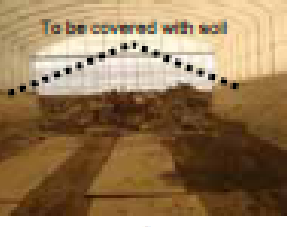

Debria storage (September 12 )

\section{Reduction of densities of radioactive materials included in the seawater in the port}

In order to reduce the radloactlvity density (ceslum) of the seawater in the port to the density Ilmit specited by the reactor reguiation (outside the surrounding monitored areas) by the end of September, the marine soll was covered and the seawater circulating purfication system was put in operation. As a result, the ceslum densittes measured at 8 locatons where seawater flow is comparatvely large were below the density limit. On the contrary, the radioactivity densitles of seawater in 5 locations where seawater fow is smaler were stil above the density IImit. Density reduction measures such as continuous filtration and replacement of the silt fence (assumed to be the source of contamination) will be implemented whlle discussing addtional measures in

collaboration with external research institutions.

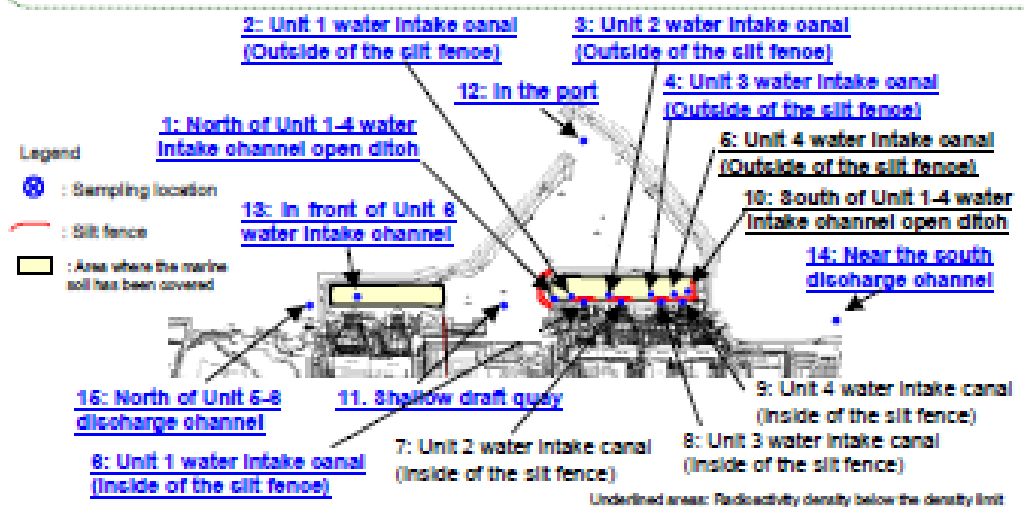

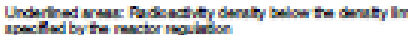




\section{Preparation for fuel removal from the spent fuel pool is in progress}

Fuel removal from Unit 4 spent fuel pool (planned to start in 2013)

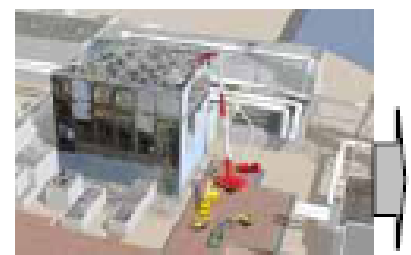

Debris remova from the upper part of the Resctor Bulding

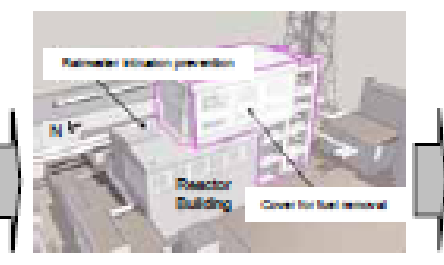

Cover inztalation for tuel removal

\section{Started in Aorll 2012}

nned compietion: Mid FY 2013

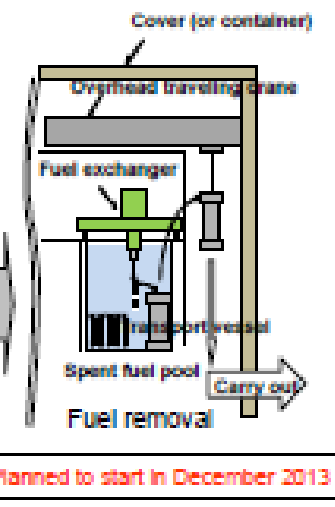

Flsnned completion: Md FY 2012

Ater securng spoce avalsbie for use in
common pool, the fuel will be removed
transported to be stored.

[Cask Inatallation procedure]

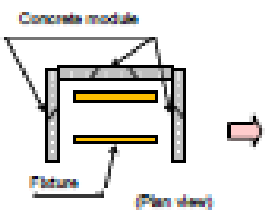

Wall inatalation on 3 urrtact

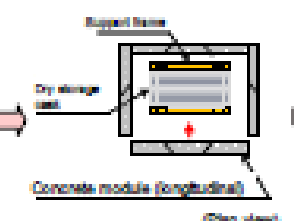

c. Wal hitalusioe
$\Rightarrow$

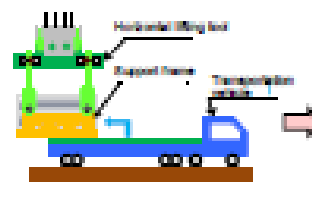

2. Cank tmapertason

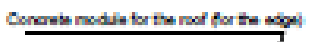

$\Rightarrow$

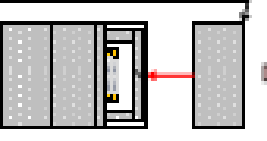

prenvivers,

6. Roof in atialusion
Dry cask temporary storage facility

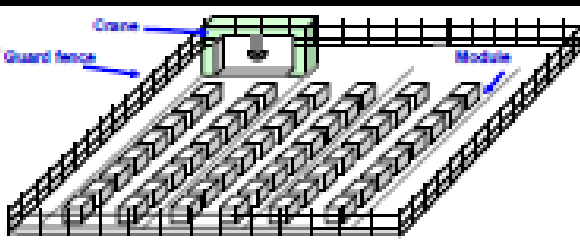

Spent fuel tranaportation from the common poo

Current status: Installation (Includes preparation) has been ongoing from June 2012
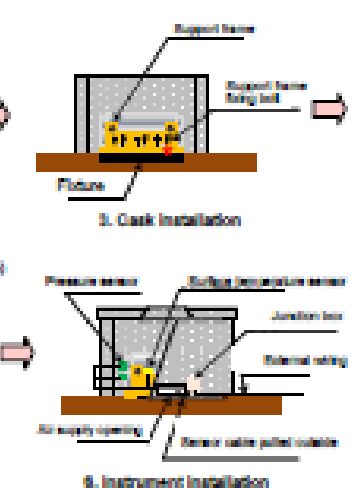

Debris removal from the upper part of Units 3-4 Reactor Building and cover installation for fuel remoyal at. Unit. 4.

- Debris removal from the upper part of Units 3-4 Reactor Bullding is in progress to prepare for fuel removal from the spent fuel pool.

- At Unit 3, a steel beam which had been unstable during debris removal fell into the spent fuel pool. A report Including the cause and recurrence prevention measures was submitted to the Nuclear Regulation Authority (October 3,19 ). With the lessons leamed from the Incident, further safety will be ensured during debris removal.

- At Unit 4, large equipment has been removed (July 24-October 2) and cover Installation for fuel removal is on going (to be completed in mid FY 2013).

[Debris removal from the upper part of the Reactor Bulling]
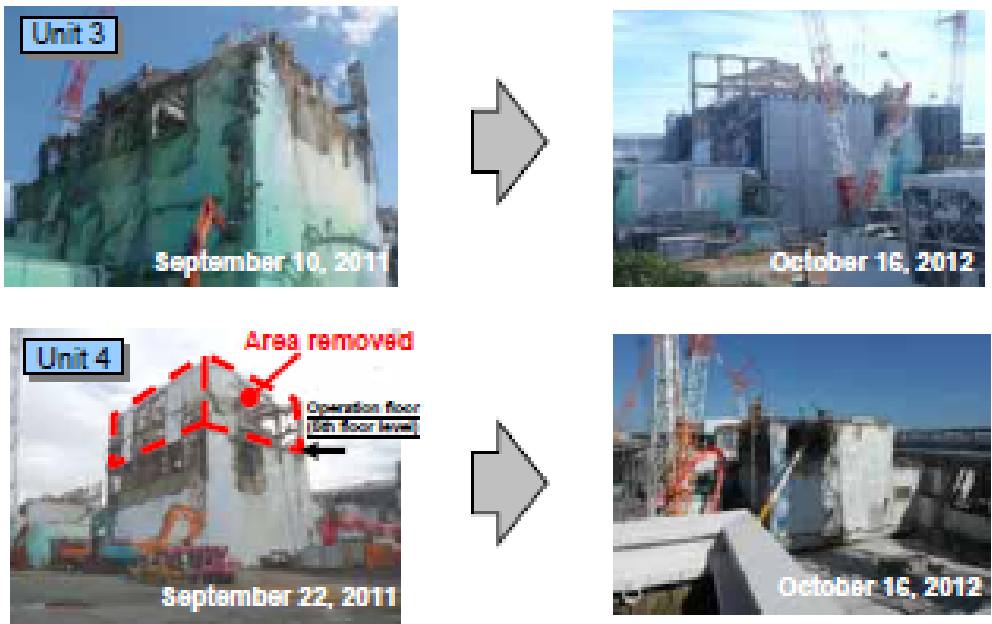

Soundness investioation of the unused (unirradiatedh fuel in Unit 4 snent fuel nool?

Two unused fuel rods were taken out trom the pool for a soundness Investigation to check for corrosion (August 27-29). Since no deformation, damage or comosion was found with the fuel rods and their structural materials, it was conciuded that spent fuel removal will not be affected significantly by material corrosion.

[Removal and soundness Investigation of unused fuel]

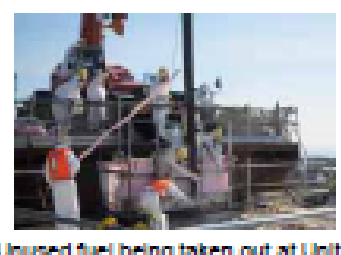

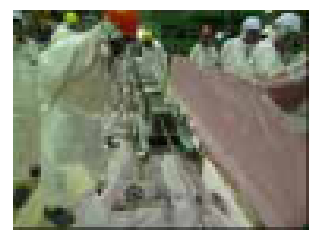

Fuel goundness investigation

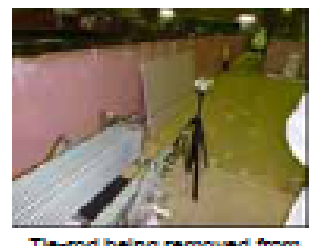

Tle-rod being removed from tuel assembly 


\section{Securing a sufficient number of workers and work safety}

\section{Ensuring the APD usaage and collaboration with cooperative companies}

- Recurrence prevention measures are implemented in response to the Inappropriate APD usage 1: TEPCO supervisors or main contractor employees check for APD usage when they visit the work site without prior notice.

2: Wear protective clothing with its chest area transparent to faclltate checking

3: Identify employees who must have an APD (target of checking)

- Reduce burden on workers by Implementing work environment improvements such as the non-requirement of face masks and breathable tyveks.

- A survey on working conditions was performed to understand the actual conditions of the working environment, working conditions and employment conditions. (The questionnalres were sent out on September 20, and the results will be summarized in late November.)

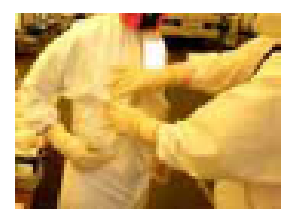

1. Checking for APO without prior notce

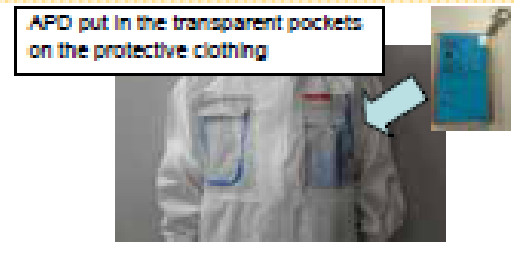

2. Protective dothing wen its chest ares transparent (From October 15)

\section{Heat stroke prevention}

As a result of Implementing the following heat stroke prevention measures, the number of heat strokes has significantly reduced compared to FY 2011. (FY 2012: $7 /$ FY 2011: 23)

"The number of emergency medlcal transports in July and August increased compared to 2011 throughout Japan (announced by the Fire and Disaster Management Agency)

- Earty Implementation of heat stroke measures (trom May) in order to be well prepared for the extremely hot season.

- Installation of an electronic display panel indlcating WBGT valuevits. Working hours, frequency and

length of breaks and work load are adjusted according to the WBGT value.

- Prohibition of work during the period from 2:00 PM to 5:D0 PM under blazing sun.

- Encourage wearing the cool vest.
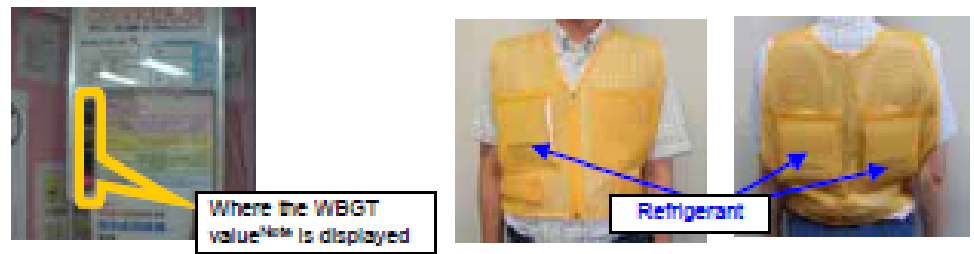

Nots WaGT value: An index of humldty, radiant heat and air tempersture which has a slgincant impact on the hest balance of a human bodt.

\section{Research and development for fuel debris removal and radioactive waste}

processing and disposal

Decontamination of the inside of buildinos and development of the comprehensive radiation dose reduction plar

- In order to reduce the radlation exposure among workers in the buldings, effective decontamination methods and target locations are being considered.

- Effective contamination methods are being studled based on the JAEA analysis results of wallinoor samples collected from the buldings.

- The locations targeted for decontamination are considered based on the contamination conditions of the work area.

Investigation and repair of the leakage on the bottom of the PCV

- The basic technology development WG for the suppression chamber (S/C) water level measurement robot and the basic technology development WG for an underwater swimming robot were establlshed under the remote technology task force.

- Robot development is in progress for operation in high radlation dose areas. In order to determine the specincations of the robot, the inside of PCV and the trlangle corner and the torus room in the Reactor Bullding are Investigated and the radlation dose, accumulated water level and amblent temperature are obtained.

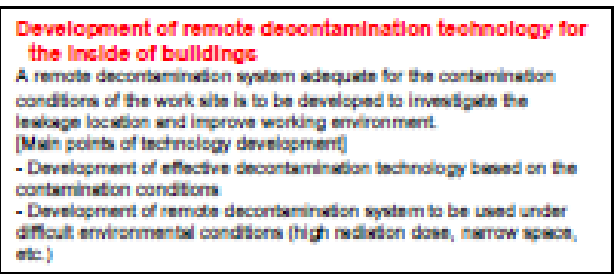

Devolopment of teohnology cpeolallzed in Identifying the leakage loostion of the PCV

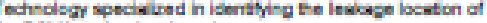
The Rev is to be developed

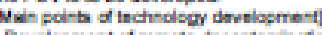
disen syoments be uned

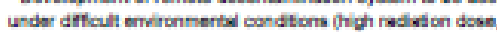
nerrove speces otei

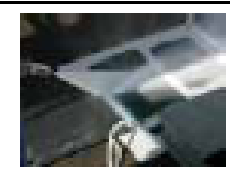

Hils-prosiure wate cleansery

Sell-proseliot Decortamingtion technologiea (Examples)

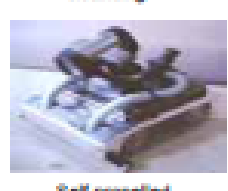

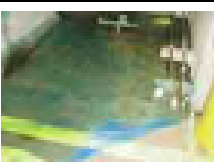

Shoppeselo peits

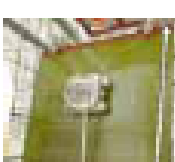

sufwos dipping

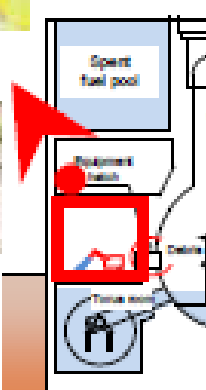

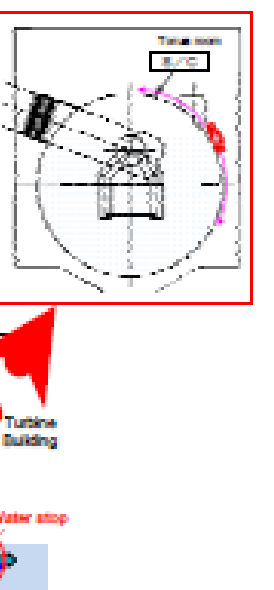




\section{Understanding and analyzing the condition of the inside of the reactor}

\section{- Enhancement of the analysis code used to simulate the condton of the Inside of the reactor} - Internatonal benchmark Fukushima nuclear accident analysis project was establlshed in collaboration with OECDINEA, and the first meeting and workshop will be held on November 6-9, 2012 in Tokyo.

\section{Characterization of fuel debris and preparation for fuel debris processing}

- The physica propertes of fuel debris which affect the development of equipments used for fuel debris removal wil be identfed and an organized chart of fuel debris physical properties will be created.

- Mockup debris will be manifactured to obtain basic data on high temperature resction to the sea salt.

- A drat scenario of fuel debris handing process (storage, processing and dlaposal) will be created and trade-off evaluason regarding a part of the process (debris storsge) will be done.
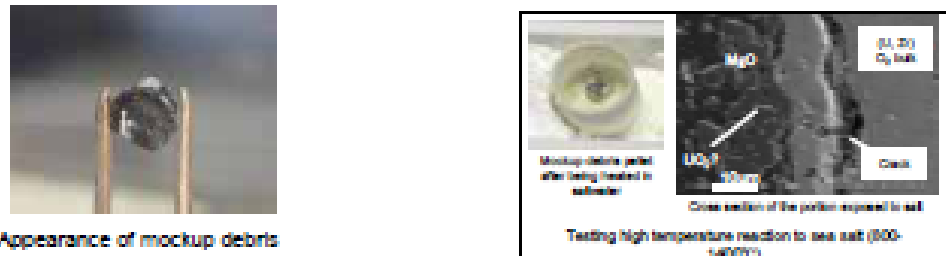

Radioactive waste processing and disposal.

\section{- In order to examine the characteristics of the secondary waste generated by water treatment,} samples of accumulated water and treatment water were analyzed. Based on the results, the densittes of the radloactive materials Included in the secondary waste are being analyzed.

- Sample collection and analysls are in progress to examine the characteristics of debris and trimmed trees in the power station slte.

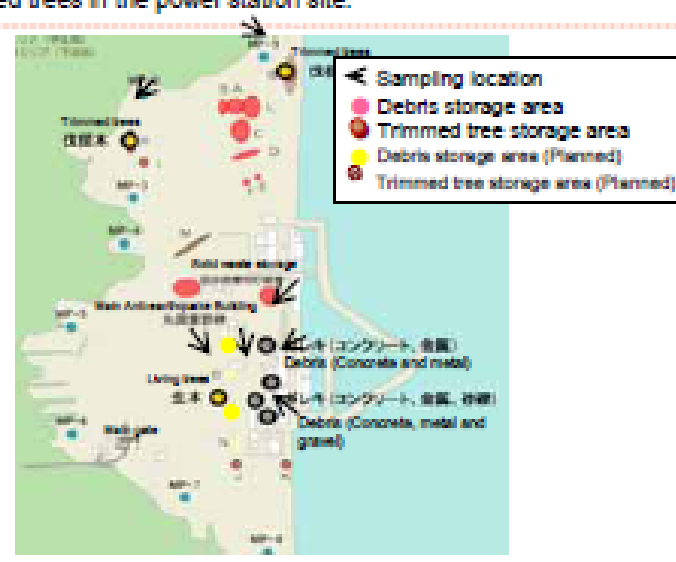

Debratorimmed trees rampling locatons

Sampie erample (Concrete)

\section{Strengthening of Research and Development management}

\section{Future plan for research centers}

- Conceptual design and basic design for the "Radloactlve material analysis" and Tacilty for remote control equipment development and demonstration" necessary for advancing the long-and-mid term roadmap are ongoing.

- In accordance with the Basic Pollcy for Recovery and Reconstruction of Fukushima, the research centers are almed to be international Institutions in the future contributing to the local employment and economic growth.

\section{Research and Development Management Headquarters}

- Based on the "Results of consideration on the long-and-mid term measure Implementation at TEPCO Fukushima Dalichl Nuclear Power Station" developed by a special committee of the Japan Atomic Energy Commission last December, the Research and Development Management Headquarters was recommended to be operated as a special organlzation in order to efficlently advance research and development over a long period of time.

- The best possible organization will be developed to achleve the stated goals (effectively and efliclently advancing research and development projects, International collaboration with overseas research institurions, etc.) which have been clarifled.

\section{Securing and fostering human resources from a long- and-mid term perspective}

The manpower necessary for fleld work and research and development to achleve reactor decommissioning in 10 to 20 -year time frame will be secured and fostered In collaboraton with unlvergitles and research instlutions.

\section{[Terms]}

- Peneiration: Penetration area in the PCV, etc.

- Cask: Transportation vessel for spent tuel.

- Nonrequirement of face mask: Setting areas where face mask is not required.

- Breathable tyveks: Protection clothing which lets more air through compared to the regular type (for more comfort)

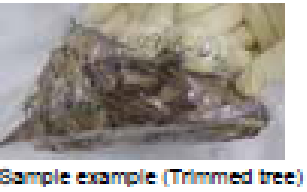

- Suppresslon Chamber (S/C): Stores cooling water in the lower part of the PCV. When the pressure Inside the PCV Increases due to the reactor water and steam released, the suppression chamber reduces the pressure by directing reactor water and steam through the vent plpe. Also used as Water source, etc. for the emergency reactor core cooling system.

- Triangle comer. Sta rcase to go through to get to the Torus Room.

- Torus Room: Room where SiC is stored In.

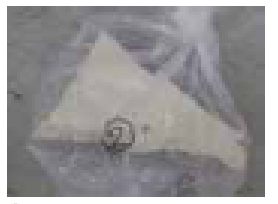

- OECD/NEA: Organisation for Economic Co-operation and Development/Nuclear Energy Agency 


\section{Acknowledgements}

The author would like to express his sincere gratitude to Dr. Jiro Kuniya, Associate Professor Yoichi Takeda and Dr. June Kameda of Tohoku University, Dr. Shun-ichi Suzuki, TEPCO and Dr. Masayuki Takizawa, MRI., Inc. for their support to prepare this presentation. 
口Remark : No direct evidence that Plant Materials Aging triggered or promoted the progress of F1 accident was pointed out by the final reports either by the Investigation committee on the accident at the Fukushima NPP by the government and by the parliament. TEPCO final accident investigation report was also issued on June $20^{\text {th }}, 2012$ and showed the same conclusive remark. 


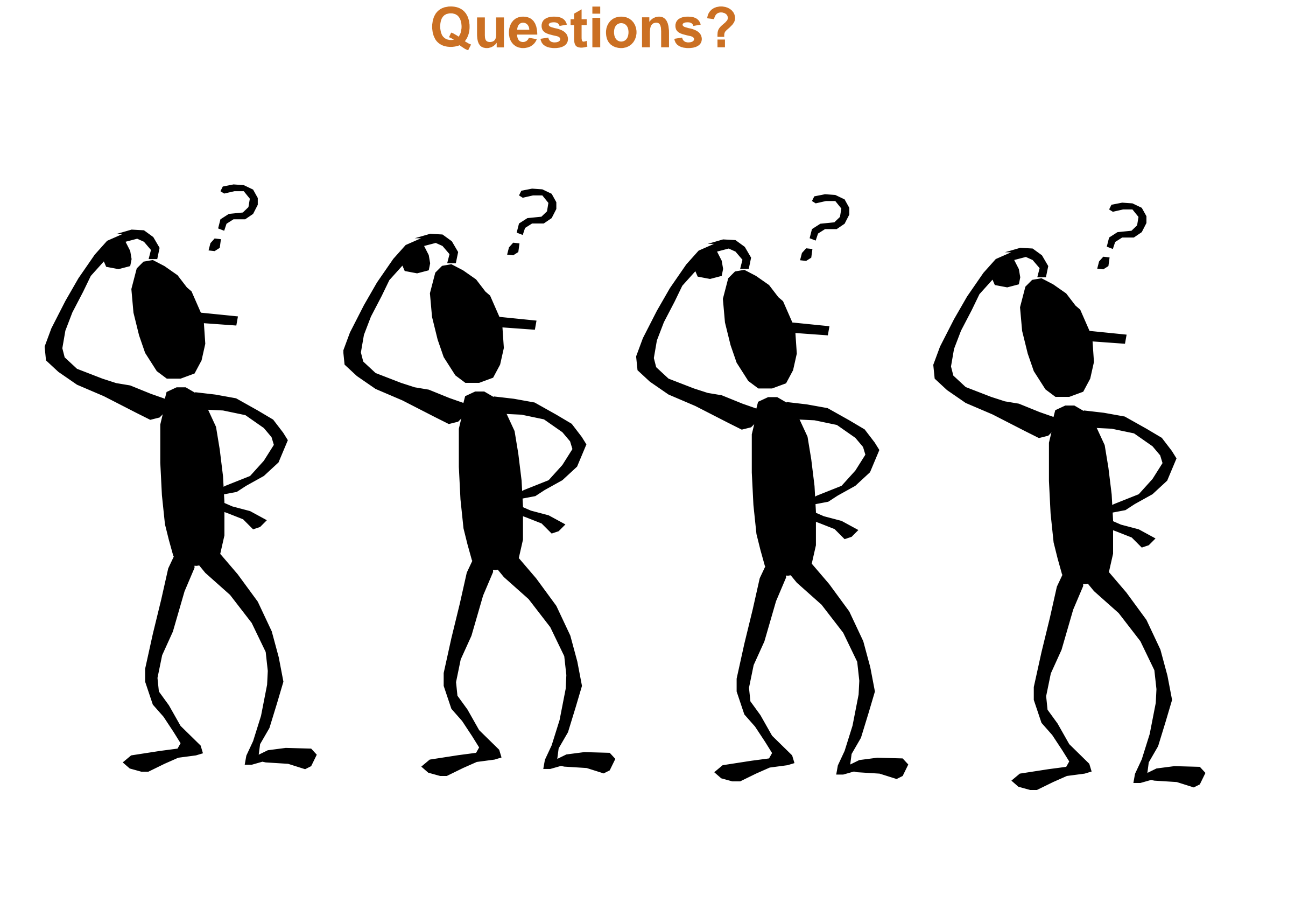

